\title{
Norbert Kiss
}

Improving network performance in the health care system: a network-based analysis of the Hungarian health care services 
Institute of Management

Department of Management Control

Thesis Supervisor:

Viktória Bodnár, Ph.D

(C) 2014 Norbert Kiss 


\section{Corvinus University of Budapest}

Ph.D. Programme in Business Administration

\section{Improving network performance in the health care system: a network-based analysis of the Hungarian health care services}

Ph.D dissertation

\section{Norbert Tamás Kiss}





\section{Contents}

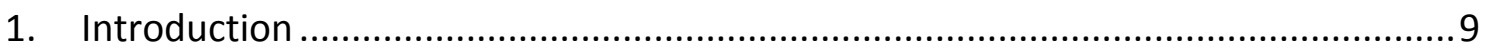

2. A performance model for public services......................................................... 14

2.1. An emerging need for creating performance-orientation in public

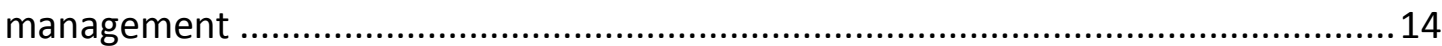

2.2. Defining performance in the public sector ................................................15

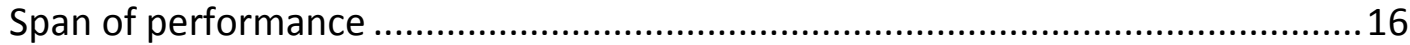

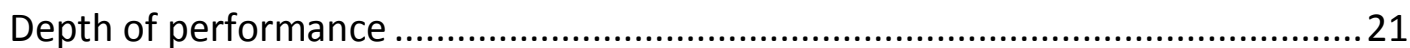

2.3. Defining performance measurement and management in the public sector. 25

2.4. Performance in the health care system .........................................................29

3. Network theory and performance improvement of public services......................32

3.1. Fragmentation and the need for greater coordination ................................32

New Public Management and the Whole of Government approach.....................32

Rationale for a network based research approach .............................................. 34

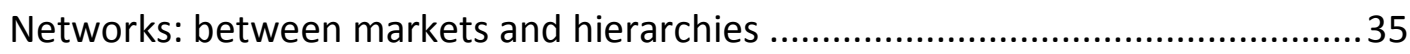

Present research interest of the scientific community .......................................37

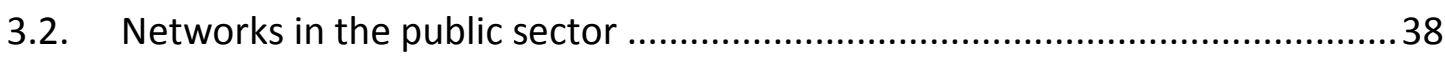

Research streams and traditions in public network research ..............................38

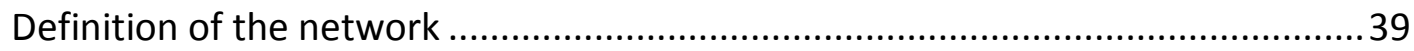

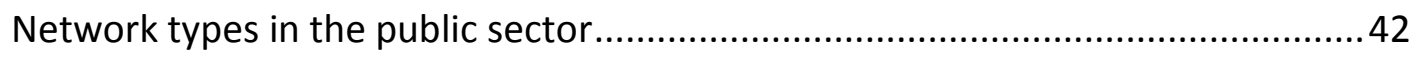

The connection between policy networks and service provision networks ...........46

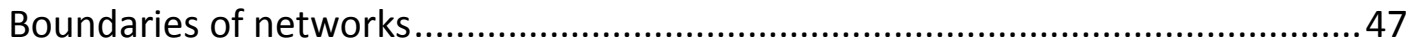

3.3. The performance of public service provision networks ................................49

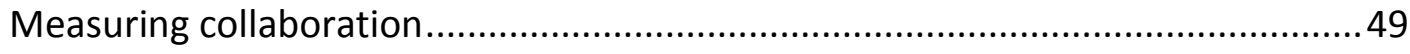

Network performance vs. network effectiveness ..............................................50

Accountability and performance measurement in public networks.......................54

Connecting the performance of service provision and policy networks.................55

3.4. Network management and network governance models ............................60

Managerial skills and competencies for effective network management .............64

Network management processes and strategies ..................................................66

3.5. Managing network performance at multiple levels.................................... 70 


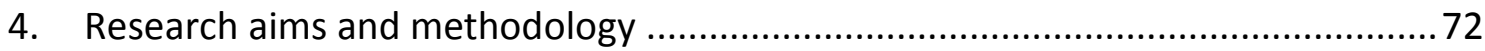

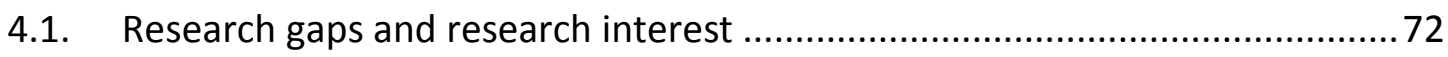

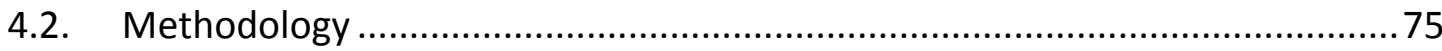

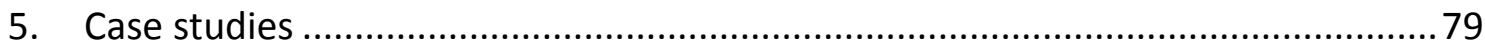

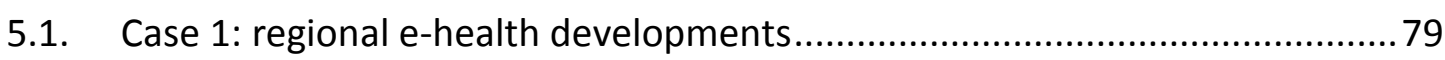

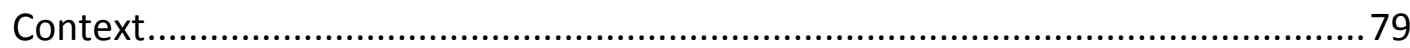

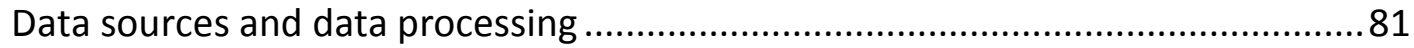

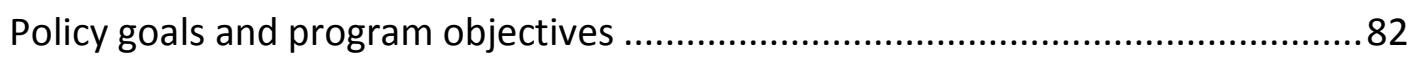

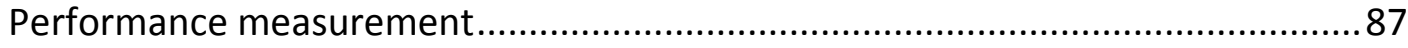

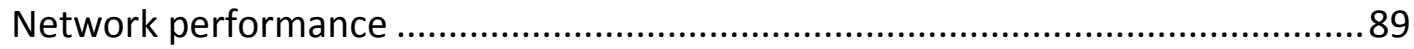

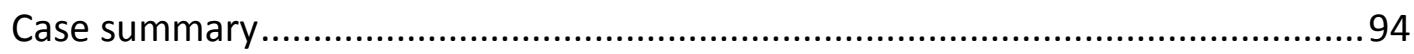

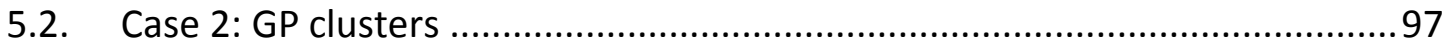

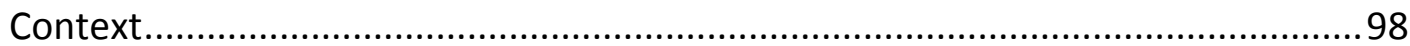

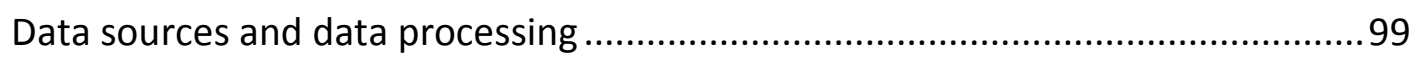

Policy goals and program objectives ................................................................. 103

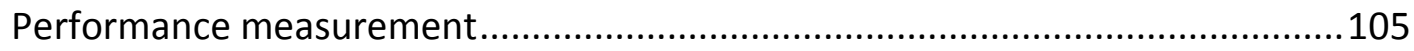

Network performance ............................................................................... 111

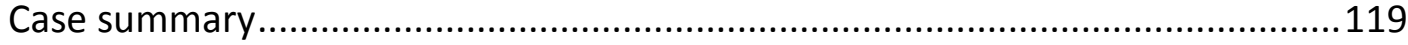

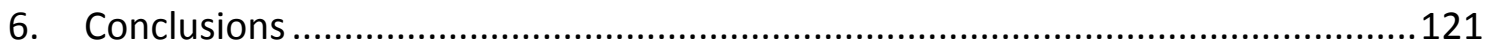

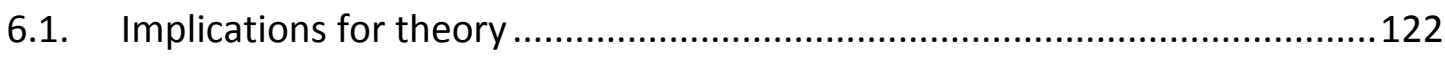

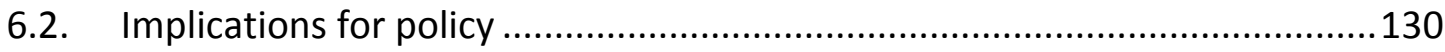

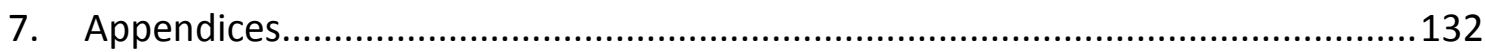

7.1. Determinants of network effectiveness......................................................132

7.2. E-health developments: a network-performance based approach ...............135

7.3. Performance measurement of the GP cluster project ...............................138

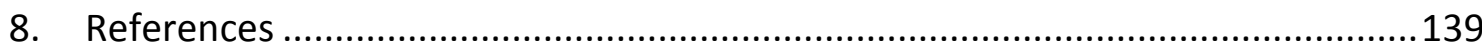




\section{List of figures}

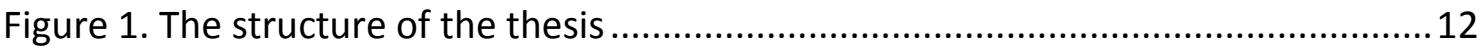

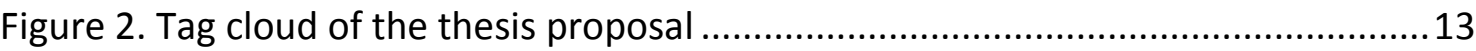

Figure 3. Performance in the public sector: The concept of 4E.................................. 16

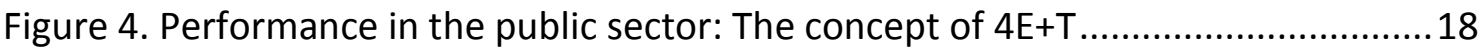

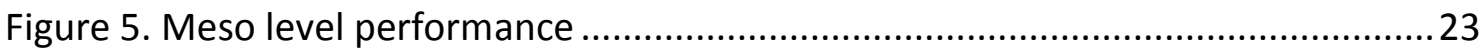

Figure 6. Network types in various models and their connections ..............................45

Figure 7. The connection between public policy making and service provision ............47

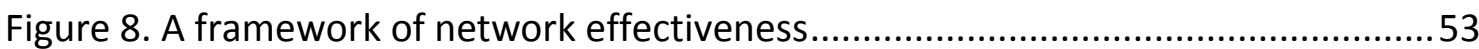

Figure 9. Performance dimensions of service provision and policy networks ...............57

Figure 10. The adaptation of the primary care monitoring system (PCMonitor) to GP

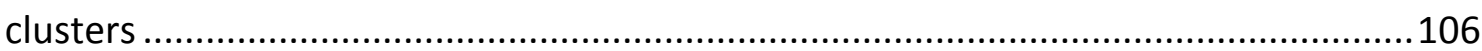

Figure 11. Service provision networks in the $4 \mathrm{E}(+\mathrm{T})$ performance model ..................123 


\section{List of tables}

Table 1. Constructs/propositions used for the case studies

Table 2. Policy goals and programme objectives of the regional e-health developments

Table 3. Indicators used for planning and monitoring the regional e-health developments.

Table 4. Regional e-health development indicators, according to depth and span of performance.

Table 5. Network characteristics of the e-health developments

Table 6. Interviews with GP cluster members

Table 7. Policy goals and programme objectives related to the GP cluster pilot project

Table 8. Indicators used for monitoring the GPs nationally and the GP cluster pilot project

Table 9. GP cluster pilot project indicators, according to depth and span of performance. 108

Table 10. Network characteristics of the GP cluster pilot project 


\section{Introduction}

Health service is one of the most complex public services. There is a large number of public, private and not-for-profit actors involved. The demand of customers for health is almost unlimited, and the industry is characterised by rapid change of technology. The regulatory role of the state is inevitable, and in most countries the government is also considered as the largest service purchaser. Constantly growing costs have been an issue for more than a decade, and the outcomes of the services are not easy to measure. The sector is in the centre of political and ethical debates, with each country struggling with constant need for health care reforms. The model how health care services are organized, provided and financed are varying from country to country, making crosscountry comparisons a challenging task and mutual learning and knowledge transfer more difficult. Still, it is a central question of interest in all the countries how this sector can provide better value for the money spent on it, or how the performance of the health care sector can be improved.

The performance of the health care sector is not only dependent on the performance of the individual actors (e.g. general practitioners, outpatient care facilities, and hospitals) - it does also matter how these actors coordinate their activities. Patients have various pathways in this system, and improving their health status requires efforts from every actor (e.g. there are referrals among physicians). The use of modern technology and the higher specialization of providers lead to a growing need for coordination among the actors. How health care services are organised will have an impact on how the actors coordinate their activities, and thus how the health care system as a whole may perform. Beyond the basic models of organising health care services (e.g. private health insurance, social health insurance, or state-centred models), there are lots of lower level elements effecting the performance of the health care system: for example, who and how decides about the capacities of providers, what communication standards there are for providers to follow, how patients are referred and corresponding information about their health status is forwarded among health care providers and physicians. 
There are inevitably linkages among the actors in the health care system and there is inevitably a common goal for all of them: improving the health status of patients. It is done not by just performing one's own task well but also by coordinating one's activities with the activities of all the other parties involved in the treatment process. Thus, the health care system can be considered as a networked one. Unlike in 'classical' examples of the networked industries of telecommunication or railways where there are physical infrastructural connections, in the health care sector it is the flow of patients and their health-related information which connects the actors. The organisation of health care services will have an impact on how these connections among the actors work and thus how the system as a whole performs.

For the last two decades, performance measurement and performance management as well as network theories and practical applications of networks as a means of coordination have gained popularity in the public administration and public management literature. While research was made into some of the complex ("wicked") problems, studying networks and network-type coordination in the health care sector has remained rare. Meanwhile, it is also recognised that the way how health service provision is organised has an effect on performance. In this context, performance is mainly described by efficiency ("do we get the most for the money we spend on health care") and effectiveness ("is the quality of services adequate"). Performance management in the health care sector focused on either financing techniques and their consequences on the behaviour of health care providers (for example, how doctors behave when they are paid on a fee-for-service basis), or on the measurement of service quality and mechanisms that improve quality of care (for example, whether publication of hospital quality data has a positive effect on quality). Although research has been made into collaboration of physicians (for example, for promoting team-based approaches in oncology care, or the work of clinical networks), scholars of health policy and health care management have rarely looked into how the theory of organisational networks from the public management field can shape our understanding about the organisation of the health care sector. Since health care is a sector where policy interventions are continuously implemented, the relationship between policy performance and health care performance is also an interesting area for research. 
The theoretical background of the thesis is twofold. First, it builds on the literature of public sector performance measurement and management by summarizing recent knowledge about how the term of performance can be defined and broken down to lower-level elements in public services and, especially, in the health care sector. Second, the thesis uses a public network management approach to conceptualize the relations among health care providers and to analyse the management factors that improve performance. The thesis also builds on the basic concepts and the main elements of organising health care services, by using literature from the fields of health policy and health care management, and provides several examples from the health care sector to illustrate the models of the two other areas.

My research interest lays in the intersection of these fields of study. The empirical work is partly descriptive, partly exploratory in its approach. After the literature review it was concluded that currently available theories do not adequately address how networks fit into the performance model of public services, how health care policy relates to organisational networks in the health care sector, how networks can be "better used" to improve performance, and how the performance of these networks could be measured, or at least how a framework could be set up to better understand what elements of performance measurement should there be. My research ambition is to contribute to the research field of public sector performance management and service provision network theory. Thus, my central research question is a broad one:

\section{How can we better understand what role networks play in the organisation of health care services, and how networks contribute to better performance of health care?}

As regards to the scope of the thesis, the main focus is on public networks, their performance, the relationship between service provision networks and public policy and the applicability of the findings of these fields to the health care sector. Illustrations and examples from the health care sector are given during the literature review, and the empirical research uses two cases from the Hungarian health care sector. The first case 
is about the regional e-health development projects, and the second case describes a recent pilot project about forming general practitioner clusters.

The structure of the thesis is as follows (see Figure 1). After this first introductory part, Chapter 2 defines performance and performance management in the public sector as well as for the case of health care services. Chapter 3 describes how networks appear in the public sector and how they shape public service provision. Illustrations are also given for the health care sector. Having reviewed the literature, Chapter 4 summarises current research gaps, defines the research aim, and describes what methodology was used in the empirical research. Chapter 5 contains the empirical work: two cases from the Hungarian health care sector are described, using the constructs of the public services performance management and network management theories. The thesis concludes with Chapter 6: it focuses on contributing to a better understanding of the constructs used in the research, leading to potential implications for theory and policy. The content of the thesis is visualised by a tag cloud, see Figure 2 .

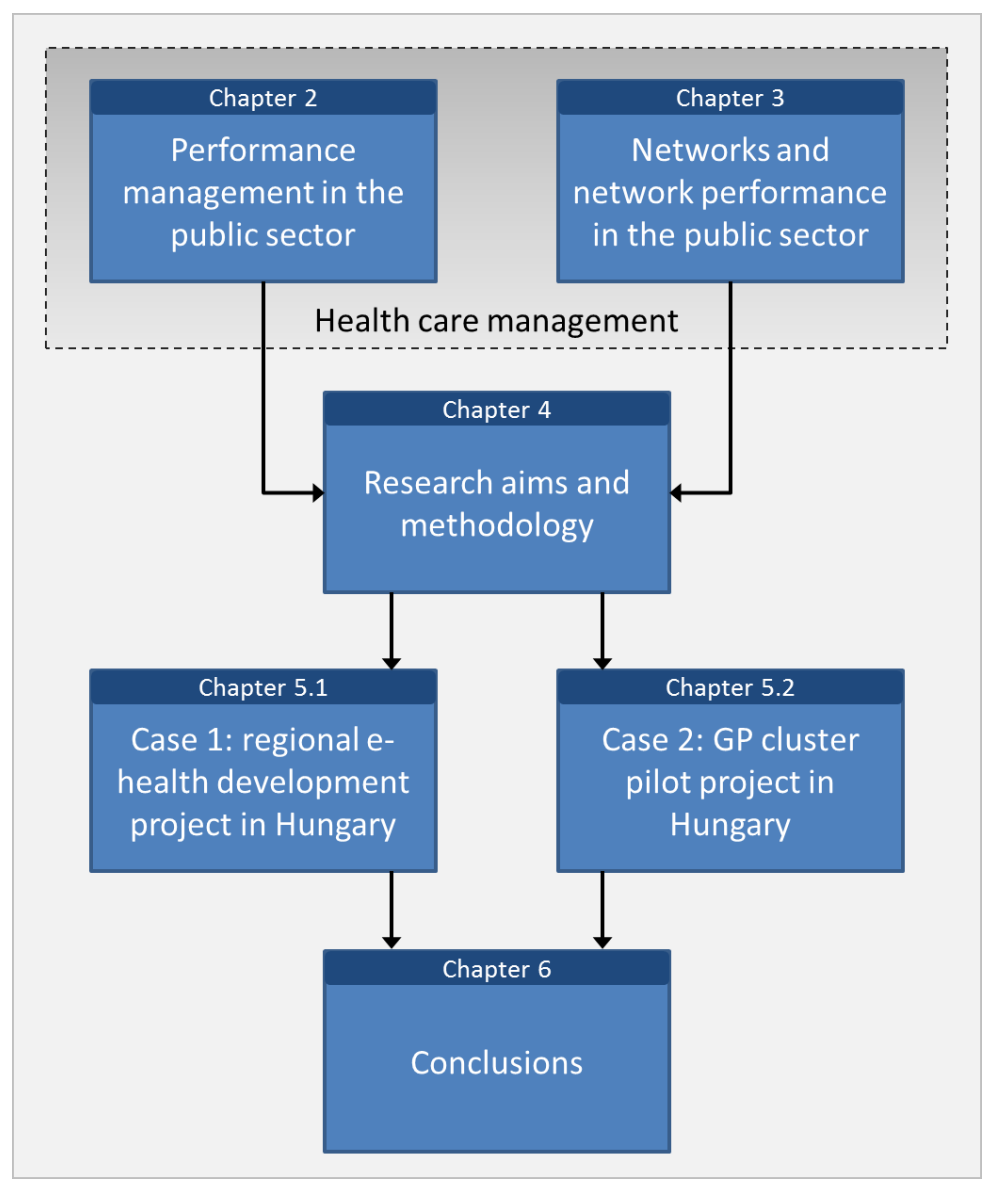

Figure 1. The structure of the thesis 


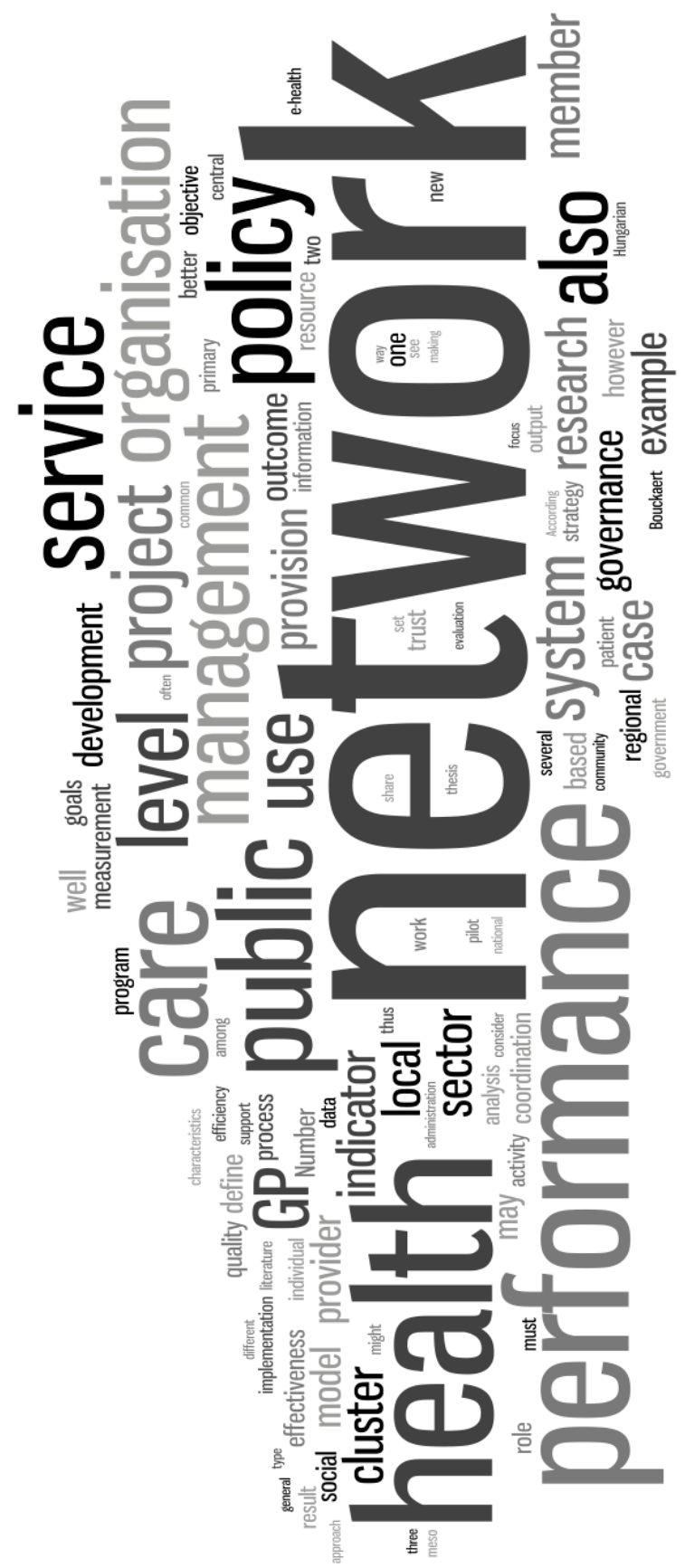

Figure 2. Tag cloud of the thesis proposal

Created with Wordle (http://www.wordle.net/create) 


\section{A performance model for public services}

\subsection{An emerging need for creating performance-orientation in public management}

During the last two decades performance and performance-orientation have become key concepts in the private sector (see, for example Simons, 1999; or Neely et al., 2002) as well as in public administration and public service management (see, for example, Bouckaert-Van Dooren, 2003; OECD, 2004; or Bouckaert-Halligan, 2008). Citizens demand better public services at lower costs (or better "value for money"), which moves the focus of planning and reporting systems towards performance- or result-orientation. (OECD, 2004) Beyond the need for managing for results, performance management in the public sector also serves as a tool for mapping various stakeholders' expectations and enhancing accountability of public managers and politicians. (Flynn, 2002, pp.206209)

The movement of "New Public Management" (NPM) strongly propagates the use of performance management and measurement tools, claiming that they contribute to better value services. As Bouckaert and Halligan (2008, p.27.) note, "installing performance measurement systems, integrating these in documents and procedures, institutionalising this activity through performance audit institutions, and using it for decisions, allocations and accountability purposes, assumes a »positive"r effect on performance itself."

NPM also adapts a wide range of concepts from the experience of the private sector. This effect can even be recognised in how the language is used: for example, in the US the "[GPRA legislation] draws on (indeed, transplants) concepts from the private sector management models and establishes a system in which market-like discipline could be used to improve federal government management." (Radin, 1998, p.308) The term of performance is quite easily defined for private companies, operating under market conditions. Most of the times, good performance is an equivalent for long-term profitability or sufficient rate of return on investment, and good performance of 
specialised organisational units is derived from this top-level performance definition with the help of integrated performance management frameworks. However, several methodological challenges arise in the public sector. The measurability of the goals is less clear, and, in fact, the goals are themselves more blurred and complex. Defining objectives of "lower level units" is also more problematic: it is highly dependent on the bureaucratic operation of the government, while also prone to be influenced by political processes.

In Hungary the field of performance measurement and management has been recently studied both in the private (see, for example, Wimmer, 2000; Lázár, 2002; Bodnár, 2005) and public sectors (Hajnal, 1999; Király, 1999; Kiss-Révész, 2007; Révész, 2010), with the latter primarily building on an NPM tradition (Hajnal, 2004; Révész, 2010; Rosta, 2011). It seems that the idea of performance measurement is being (somewhat slowly) adapted in the Hungarian public sector, mainly driven by a few organisational champions (Bodnár et al., 2004) but also "making appearance" in government programs. The growing role of EU structural funds in development policy tends to strengthen performance orientation in public administration by requiring a wider use of performance indicators. Indicators are present in operational programmes (development plans of certain sectors), action plans as well as application calls. Still, the adaptation is slow in Hungary, with many barriers (Dan-Pollit, 2014), with incoherence in government development plans and proposed applications (Rosta, 2012).

\subsection{Defining performance in the public sector}

There is no one and clear definition for "performance". As Bouckaert and Halligan (2008, p.14) states, "[t]here are different performances according to the range of disciplines". In the private sector, authors often do not even define what performance means for them, assuming that there is a "general" meaning of the word (Wimmer, 2000). Even one of the seminal management textbooks in this field, Simon's (1999) "Performance Measurement and Control Systems for Implementing Strategy" skips this step. Most often, the (good) performance of a business organisation is simply associated with 
fulfilling strategic goals and being profitable: delivering results, expected by the management and the shareholders.

Regarding the public sector, Bouckaert and Halligan (2008) also use the term of performance as "the generic key concept to define results and bottom lines". According to Van Dooren (2007), the concept of performance can be interpreted either as value or as intended behaviour. Based on Dubnick (2005), the intended action can be described among two dimensions: the quality of the performed action, and the quality of the results achieved (for details, see Révész, 2010). In this thesis, performance is interpreted as intended actions where "good performance" is a set of actions, leading to the desired results.

\section{Span of performance}

There is a span and depth of performance defined in the public sector. The span of performance has long been described among the "classical" 4E model, depicted on Figure 3. (Bouckaert-Van Dooren, 2003)

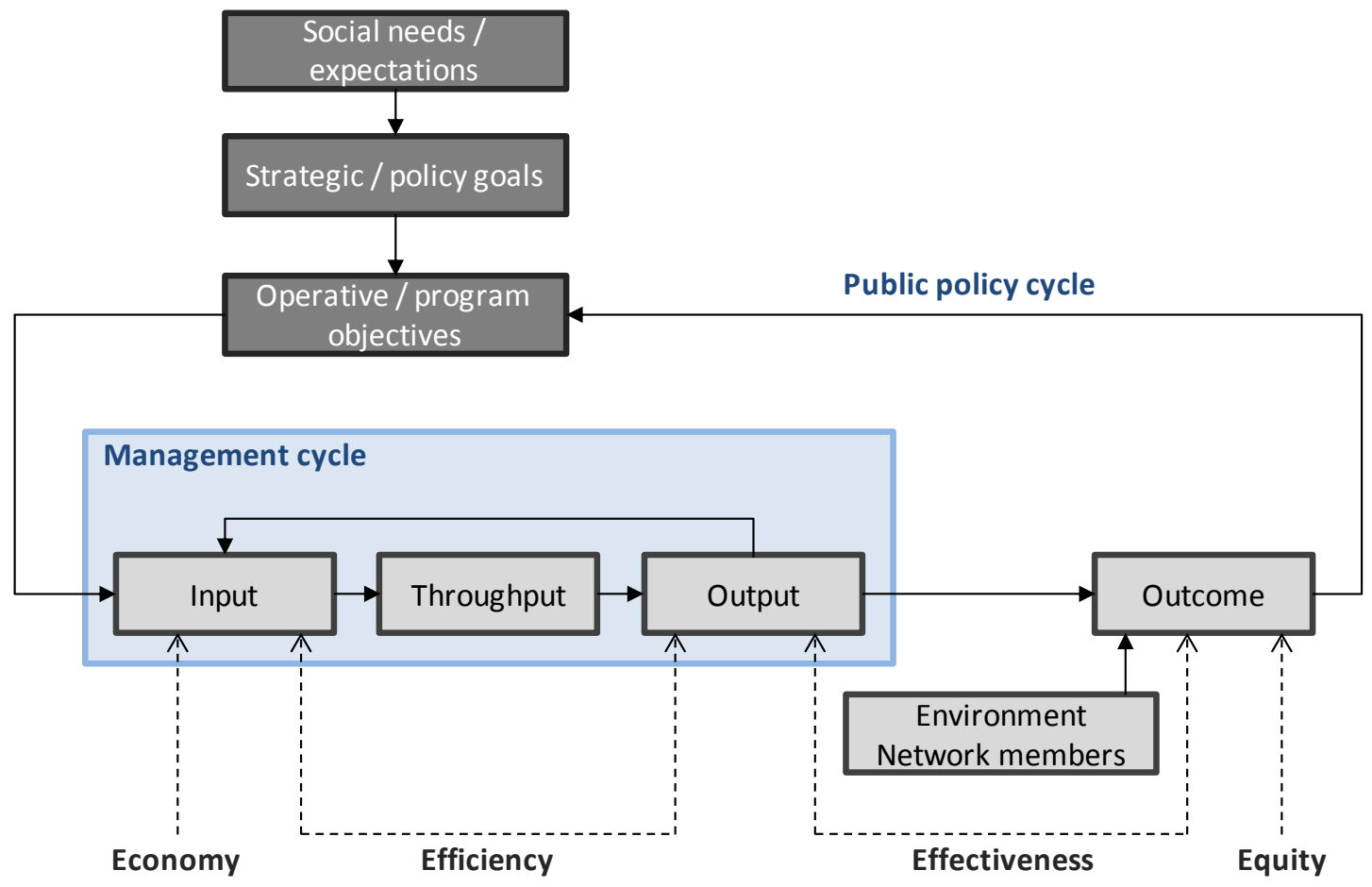

Figure 3. Performance in the public sector: The concept of $4 E$ (based on: Bouckaert-Van Dooren, 2003) 
Based on social needs, public policy decisions lead to defining various program objectives and also inflict changes in the legal framework and financial rules of public service providers. These changes are aimed at influencing their behaviour in a way that drives them towards the fulfilment of program objectives. Public service providers use the inputs available for their organisations for producing outputs (either goods or services). Outputs are, however, "not an end in themselves if subsequent intermediate and ultimate effects or outcomes are a central focus" (Bouckaert-Halligan, 2008, p.16), which is definitely the case with public services. How outcomes may be produced is also affected by the changing environment. The public policy cycle then evaluates whether outcomes are adequate for the objectives set up earlier - if not, corrective actions will be needed in the legal or financial framework. While the public policy cycle focuses on public policy making and evaluation, the management cycle concentrates on how a public provider organisation is run (it involves issues that can be effected by the manager of a single organisation).

The span of performance will be determined how wide inputs, outputs and outcomes are related to each other: the $4 \mathrm{E}$ stands for economy, efficiency, effectiveness, and equity. The performance is quantified by using measures (or, in an other word, indicators).

In their book, Bouckaert and Halligan $(2008$, p.17) also incorporate trust into this framework, claiming that "outcomes [...] are not an and in itself in the public sector. The ultimate ambition is to guarantee a functional level of trust by the citizens in all its institutions and organisations, but especially in its public organisations and institutions." Figure 4 illustrates how trust is incorporated in the model. Policy and management cycles have been added to the original model of Bouckaert and Halligan (2008), and only the "outcome/trust" performance dimension was kept. Trust is also an important element because it effects how outcomes can be produced (for example, trust in the education system influences education outcomes, see Bouckaert, 2011), and also determines how willing people will be to finance public services. This way, trust level influences inputs in a cyclic way. (Bouckaert, 2011) 


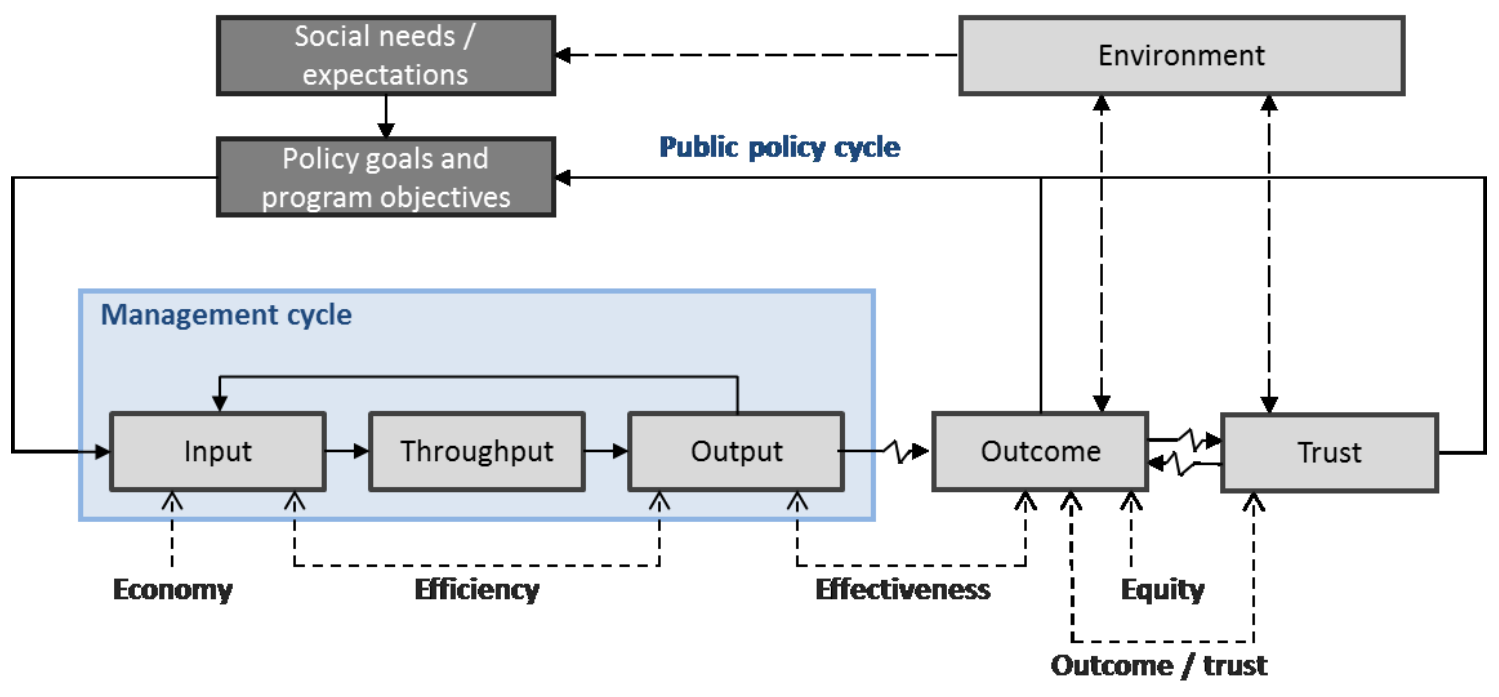

Figure 4. Performance in the public sector: The concept of $4 E+T$

(based on: Bouckaert-Halligan, 2008)

Economy measures refer to the volume of inputs (or the ratio between inputs) used by the organisation. Performance indicators based on economy are commonly used in the public sector: for example, the size of budget, the number of employees, cost per number of employees or cost per one hospital bed are popular measures in spite of their apparent shortcomings. Economy measures can only be used for benchmarking purposes when outputs of the organizations are homogeneous enough (for example, two agencies with almost exactly the same profile, or two hospitals with a very similar service mix)-which is rarely the case for public sector organizations.

Efficiency measures are intended to compare input-output ratios. Resources (inputs) are used in order to produce public services (outputs), consistent with organizational mission and objectives. For example, treatments provided for patients are outputs of hospitals (measured usually by hospital admittances). An organisation producing the same volume of output from less inputs, or producing more outputs from the same volume of inputs is considered as more efficient than an other one. Sometimes, the term of productivity is used instead of efficiency (see the NHS productivity review in, for example, Micheli et al., 2005). Technical or production efficiency can also be considered as synonyms, however, some authors claim that inputs are measured in natural units in the case of technical and in monetary terms in the case of production efficiency (see, for 
example, Evetovits-Gaál, 2005). The term of allocation efficiency is also used but it refers to whether outputs are produced and allocated in accordance with social needs and expectations and thus rather covered by the effectiveness dimension of the $4 \mathrm{E}$ model.

Efficiency measures are becoming especially important for the management when a public organization is financed based on its output performance (for example, DRGbased financing of health care providers). Comparing efficiency measures among organisations presumes that all the inputs and outputs can be evaluated by using "a common platform". It usually means that they can be 'translated' to terms of money, or defined by using a standard classification (e.g. a DRG system). In spite of the fact that carrying out these "translations" can sometimes be difficult in the public sector, resource allocation decisions utilise this kind of performance measurement to a great extent. Efficiency improvement is often defined as a policy goal in various areas in public sector reform initiatives.

Effectiveness indicators cover outcomes as well. The operation of public organisations is effective if organizational outputs are produced in appropriate quantities and qualities so that the "service mix", which is produced, suits social needs well. In the private sector effectiveness refers to whether the organisational goals are reached (see, for example, Dobák, 1996). These organisational goals are largely decided by the organisational actors (the management and the shareholders). In the public sector, however, what outputs public service provider organisations produce will be heavily dependent on what outputs the public policy "orders" from them.

Most of the times, the requirement of being efficient is also added: services should be provided by using input resources efficiently. For example, health provision is considered to be more effective if health outcomes (measured with the overall health status of a citizen or a covered population) improve. The importance of taking both efficiency and effectiveness into consideration regarding health care financing decisions was first propagated by Cochrane (1972). In the field of medicine, the term of efficacy is also used (Evetovits-Gaál, 2005). It refers to potential effects of health technologies (e.g. 
pharmaceuticals) under ideal clinical circumstances (e.g. in a clinical trial) while effectiveness describes what can actually be expected from use in "real life" (Drummond et al., 2005).

As it has already been stated, outcomes can rarely be attributed to a single organization in the public sector: other organizations do also affect outcomes. (In a contingency view each external organisation is part of the environment; in a network view, however, other network members also contribute to the desired outcomes.) For example, health status is affected by such factors as prevention in schools, the system of social benefits, education, employment as well as a wide range of health care services (e.g. general practitioners, outpatient care facilities, acute and long-stay hospitals etc.). The WHO (2011) refers to these factors as determinants of health, of which the performance of health services is only one. While social needs and expectations are mainly formulated in terms of outcomes, it is not easy to assess effectiveness due to the ambiguity of relations between outputs and outcomes. For example, it cannot be precisely calculated what level of prevention activities should be sponsored to improve health status in the long run.

As regards to health care services, there is also an "extension" of effectiveness which is commonly used: the cost-effectiveness ratio. When decision makers prioritise what should and should not be included in the coverage of a (private or social) health insurance plan, the "ultimate" indicator they (try to) use is QALY (or quality-adjusted life years). The cost of saving a quality-adjusted life year is calculated in health technology assessments (HTA). Those health technologies that save one QALY at a lower cost are considered as more desirable (or more cost-effective). (NICE, 2010)

Equity measures refer to whether citizens or various groups of citizens have equal opportunities to access public services in the same quantity and quality, resulting in a more equal distribution of the benefits of public services. For example, getting health care services should be based on medical needs and not on socio-economical status (this principle is a central one in social health insurance systems). Equity can be controlled to 
some extent at organizational level if, for example, anti-discrimination rules are present but this problem should mainly be addressed "systematically" from policy level.

Trust and its relation to inputs, outputs, and outcomes have not been used widespread as an element of performance measurement for public services, and the ratio of "outcome/trust" has not been named yet. Trust level and its effect on outcomes or satisfaction has already been studied in a few cases (see for example, Bouckaert, 2012), but there is not much evidence of that outcomes positively influence trust (BouckaertHalligan, 2008). It is not yet understood in details how desirable outcomes of public services contribute to trust building.

From an aspect of public management, the question of how the performance of public services can be improved is central. While economy and efficiency can be basically managed at organizational level in the management cycle, effectiveness, equity and trust building is to be mainly influenced by the public policy cycle.

In the classical $4 \mathrm{E}$ model, supplemented by trust (“4E+T"), managing (or governing) the population of public service providers (or a network or networks of providers) is a policy issue. It must be noted, however, that this approach assumes that there is a clear role of a network manager, and this role belongs to the policy maker. This is not certainly the case. Sometimes the relationship of policy makers and service providers is more interrelated (especially, for example, in the case of monopoly providers). There may also be additional middle levels present (e.g. regions below national public policy), and single public organisations themselves can also initiate network partnerships. Thus, in reality the boundary between policy and organisations (or between the policy cycle and the management cycle) is rarely clear cut.

\section{Depth of performance}

While the $4 \mathrm{E}+\mathrm{T}$ model covers the horizontal span of performance, there is also a vertical dimension, or depth, including micro, meso and macro layers. (Bouckaert, 2006; Bouckaert-Halligan, 2008) "Micro performance is at the level of an individual public 
organisation and its interface with citizens or other organisations. Meso performance is at the level of a consistent policy (this also may include public enterprises in specific policy fields [...] or the European level of government [...]). Finally, macro performance is government wide, or even governance wide." (Bouckaert-Halligan, 2008, p.18) It must be noted that in addition to these levels (inside the organisational micro level) performance can also be defined at organisational unit and individual levels, however, these levels are not part of the analysis here.

Micro level performance refers to the case of individual public sector organisations: a given range of outputs are produced by using inputs. As customer-orientation is spreading across the public sector, not just the quantity but also the quality of outputs is more and more monitored, with using adequate performance management frameworks. (Bouckaert-Halligan, 2008) Since it is the management cycle (see above) which is focused on individual public organisations, micro level performance measures mainly cover economy and efficiency measures. In some areas, however, the effects/outcomes of services provided are also measured: for example, monitoring the career of university graduates provides feedback about how successful the education program has been in terms of meeting labour market needs. One may argue that there are still a lot of other external factors that influence the outcomes but in cases where the connection between the output and the outcome is tighter (e.g. in the case above), good outcomes may reflect good quality of the output. Equity indicators are also becoming more and more important at organisational level, especially in programs financed by the European Union where even single projects must demonstrate their contribution to such horizontal policy aims as improving equal access to services (among, for example, women or minority people).

Meso level performance can be interpreted at the level of a policy field (e.g. health or any of its subsets, for example, hospitals, or public education), a product/service chain (e.g. the boundary of public and higher education) (Bouckaert-Halligan, 2008, p.21) or in spatial/geographic terms (e.g. a regional health system) (Révész, 2010, p.14). Networks are usually also tied to the meso level. At this level, all the four E's can be easily interpreted: effectiveness and equity mainly refer to the appropriateness and 
expected distribution of system- or network level outcomes while economy and efficiency indicators reflect average values of individual public organisations (where, of course, the distribution of data values describing each participating organisation may be a valuable source of information for the policy level, too). Trust is mainly measured at the level of public service sectors (e.g. trust in education, trust in physicians), and rarely studied at lower levels (for example, regions or localities). In the case of a policy program, the meso performance model can be depicted as shown in Figure 5.

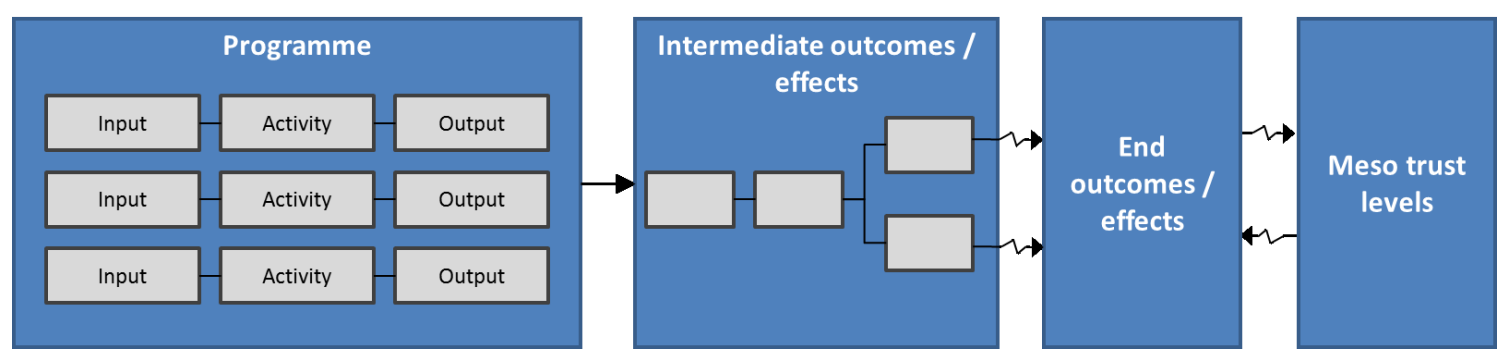

Figure 5. Meso level performance

(source: Bouckaert-Halligan, 2008, p.22)

Macro level performance refers to country-level or government-wide performance. (Bouckaert-Halligan, 2008, p.25) Due to its high level, it uses economy and efficiency measures to a less extent and focuses rather on outcomes, effectiveness, and equity measurement. Public reforms essentially build on the assumption of a positive relation between outcomes ("what good did the government do") and trust ("people will trust in those who performed well"). Regarding outcomes, two basic types of indicators can be identified:

- Economic indicators: among the economic indicators, the GDP (PPP) per capita and the GDP growth rate are the most often used ones to measure the success (the performance) of a country.

- Non-economic indicators: the development, the sustainability, or life satisfaction of people in a country can be measured with other than economic indicators as well. This is what the so-called "happiness economics" is about. Indices include, for example, the Human Development Index, the Happy Planet Index, or the elements of the OECD's Your Better Life Index. 
There are two main and in international comparisons widely used concepts that contribute to either the economic or non-economic success of a country: the quality of government (or public governance) and the competitiveness of the economy. Both these two concepts have internationally used indicator sets:

- Competitiveness: IMD World Competitiveness Yearbook and World Economic Forum Global Competitiveness Index are more general frameworks, including some aspects of the quality of public services and government while the Doing Business ranking focuses on business regulations.

- Quality of government: most frequently used indicator sets involve OECD's Government at a Glance reports, Bertelsmann Foundation's Sustainable Governance Indicators, or World Bank's World Wide Governance Indicators. "Democracy rankings" can be identified as a subset of this type: for example, Economist Intelligence Unit Democracy Index or Freedom House's Freedom in the World ranking.

However, the vertical dimension (or depth) of performance might refer to more than three levels. For example:

- Macro level performance may refer to country-level or government-wide performance where the main question is how health care services contribute to overall wellbeing.

- Policy level performance (or health care performance or superstructure performance), as a subset of meso level performance as defined above, may refer to high performance of the health care system (sector performance, policy performance).

- Network (or regional/local) level performance, as other subsets of meso level performance as defined above, may refer to the performance of a part of the (for example, regional or local health system). Where the boundaries of a regional and local health system lay, of course, can be discussed and debated.

- Micro level performance may refer to individual organisations providing any service relevant for the health system.

It should be noted however, that the distinction made between the levels might not be always unambiguous, and may also be dependent on the unit of analysis. It seems that 
networks lay somewhere in the middle, at meso level. (In principle, it is also possible to treat networks as the unit of analysis in the $4 \mathrm{E}+\mathrm{T}$ model, so that networks are the micro level actors, and performance measurement refers to inputs, outputs, outcomes, and trust used and generated by the networks. But then organisations which act as network members would be missing from the picture.)

\subsection{Defining performance measurement and management in the public sector}

Having defined how the term of performance is used in this thesis, it must be put into the context of measurement and management. Bouckaert and Halligan (2008, pp.3032.) and, in recent Hungarian literature, Révész (2010) overviewed the concept of performance management in the public sector in great details, therefore the thesis proposal will restrict itself to define how this term is used in this research.

Performance measurement is a part of performance management activities. In a narrow technical interpretation, "measurement is the projection of a certain empirical structure into a numeric structure" (Lázár, 2002, p.29). Beyond mere calculations, in a wider sense measurement serves an aim, too, and can be characterised as a repetitive action: "[m]easuring performance is to systematically collect data by observing and registering performance related issues for some performance related purpose." (BouckaertHalligan, 2008, p.26.) This purpose can be defined in various ways, in relation to the horizontal and vertical dimensions of performance: "[t]here seems to be a need for different performances for different purposes, which has an impact on measurement. Performance as an object with a specific span and depth requires measurement which is matching a specifically or broadly defined performance." (Bouckaert-Halligan, 2008, pp. 26-27.) How the purpose of measuring network performance can be defined will be reviewed in details later. In an even wider sense, performance measurement involves evaluation as well, having "two main elements: the use of performance indicators to signal whether performance is on target, and programme evaluation involving an indepth assessment of performance." (OECD, 2005, p.34) With this addition, a general purpose of measurement is addressed: to be able to assess current position against 
plans. What we do with this information, leads us to the term of performance management.

Performance was considered as a generic term, with various meanings for a wide range of disciplines, and the same applies to the case of performance management. As Révész $(2010$, p.5.) notes, "[...] performance management is a buzzword both in business and public sector, and there are no common (and exact) definition in the literature [...]. The main reason of conceptual uncertainty is that performance management is a multidisciplinary research field, it can be interpreted based on many scientific fields." In a technical sense, performance management is a series of activities of measurement, evaluation, and feedback. Figure 3 already depicted two cycles: the policy cycle (at higher level) and the management cycle (at organisational level), each involving these activities in a repetitive (cyclical) manner. It resembles the PDCA (plan-do-check-act) cycle (see, for example, Bodnár, 1999), serving also as a general systems theory and cybernetic model for controlling (Horváth and Partner, 1999) or management control (Anthony-Govindarajan, 2006; Anthony-Young, 2002). It is the feedback which turns the cycle into a control cycle; the role of control is highlighted by Simons (1999), having "performance measurement and control systems" in the title of his seminal book about performance management.

Performance management serves the same purpose both in business and public organisations: using managerial tools in order to enhance the performance of an organisation or a wider network of organisations. "A broad and generic definition of performance-based public management is taking/allocating responsibility for the performance of a system and being accountable for its results." (Pollitt-Bouckaert, 2004; cited by Bouckaert-Halligan, 2008, p.2.) When the managerial tools with this purpose are put together, performance management systems are created.

Simons (1999, pp.4-5.) emphasises four aspects of performance measurement and control (or performance management) systems:

- focus on conveying information for managerial decision making;

- having formal routines and procedures; 
- it is designed to be used by managers;

- it is used to maintain or alter organisational patterns.

While Simons' definition was primarily targeted at individual (and private sector) organisations, based on OECD (1995), as cited by Pollitt (2001, pp.10-11.), "a performance management system [in the public sector] is defined via a series of processes related to:

- setting performance objectives and targets for programmes (and in many cases made public);

- giving managers responsible for each programme the freedom to implement processes to achieve these objectives and targets;

- measuring and reporting the actual level of performance against these objectives and targets;

- feeding information about performance level into decisions about future programme funding, changes to programme content or design and the provision or the provision of organisational or individual rewards or penalties;

- providing information ex post review bodies such as legislative committees and the external auditor (depending on the latter's performance audit mandate), whose views may also feed into the decisions referred to above."

There are public sector organisations which design programmes (the policy makers), and there are those that actually carry out these programmes (the providers). In this sense, the organisational strategy of a single public provider can also be considered as a programme: it aims to meet the local needs of the local public. The thesis uses the term of performance management in a wide policy context, similar to the definition given by OECD.

From an economic point of view, the use of performance measurement and management systems cannot be easily justified (somewhat similar to most managerial tools): as Bouckaert and Halligan note (2008, p. 27.), "[a] problematic issue is the asymmetrical cost benefit analysis of a performance measurement system. [...] Benefits are [...] conditional (depending on using information), intangible (how do you value 
knowledge on improvement, better decisions, better accountability?) and scheduled for the future (going through learning cycles takes time). Costs on the other hand are unconditional (one has to pay for collection, storage, processing of data, diffusion of information, evaluating and auditing), tangible (measurable) and immediate (almost real time)." Performance measurement and management systems in the public sector, however, cannot be judged solely based on a cost-benefit analysis. Creating responsibility for results and enhancing accountability of politicians, public servants, and managers of public service providers is popular argument, too (for example, Flynn, 2002; OECD, 2004). The thesis primarily looks at performance measurement and managements systems in a technocratic way, considering them as managerial tools, aimed at improving the performance of the various policy sectors (e.g. health care). It must be underlined, however, that a cost/benefit approach to performance management systems does not contradict with the issue of transparency and accountability. If there is a (social) need for transparent performance management, the question is still there: how these performance management systems should be constructed so that they have as positive as possible impact on performance.

Bouckaert and Halligan (2008), based on Osborne (2006), use the concept of performance governance as a (potential) successor to performance management, describing its ideal type in their book. Governance is based on two concepts: (1) governmental processes and formal government structures, (2) networks of public and private interactions. Performance, according to this approach, extends to meso level, includes several levels of government as well as several sectors and stakeholders. The incorporation of networks into the meso level measurement is one of the issues to be solved.

The book also describes four stages of managing performance, with "performance governance" being at the highest and historically most developed level. These are ideal types, meaning that actual practical implementation may not be perfect. "Performance Administration" mostly focuses on input and process indicators, registers administrative data, and has limited reporting capabilities. The "Managements of Performances" type has specialised performance measurement systems, including 
outputs and outcomes, but different performances are used for different purposes, lacking a government-wide coherence. "Performance Management" integrates measurement systems used all over the public sector but may not offer as deep societal coverage as the fourth type, the "Performance Governance".

\subsection{Performance in the health care system}

Performance measurement has been present in health services since the uprise of the performance-orientation in the public sector. The availability of performance information (even in an international context) is considered to be high (Van DoorenLonti, 2011). This way the health care sector is a popular target of international comparisons, even despite the structural differences among countries. Medical procedures have also been scrutinised according to scientific standards for several decades, contributing to the creation of a performance culture at "product level" as well. The latter is defined as evidence-based medicine or EBM (Cochrane, 1972).

A distinction should be made between the terms of health and health care systems. WHO (2000, p.5) defines a health system "to include all the activities whose primary purpose is to promote, restore or maintain health." This includes those activities "whose primary purpose is something other than health - education, for example - even if these activities have a secondary, health-enhancing benefit." (ibid, p.5) Based on the WHO's definition, Nolte et al. (2009), citing Arah et al. (2006), define health care system as "the combined functioning of public health and personal health-care services that are under the direct control of identifiable agents, especially ministries of health." These include "preventive, curative and palliative interventions, whether directed to individuals or to populations" (WHO, 2000, p.6).

This thesis restricts analysis to the performance of the health care system. According to Arah et al. (2006, p.7), "[h]ealth care performance refers to the maintenance of an efficient and equitable system of health care without emphasizing an assessment of the non-health care determinants. [...] [T] he direct functioning of the delivery system of 
health care is evaluated vis-à-vis its established public goals for the level and distribution of the benefits and costs of personal and public health care." A summary book about health system performance improvement, edited by Smith et al. (2009), refers to the dimensions of performance in the health sector. The span of public sector performance $(4 \mathrm{E}+\mathrm{T})$ can be identified in the case of health services, too:

- economy, productivity, and efficiency are becoming more important in the era of spiralling health care costs;

- outcomes and effectiveness can be interpreted in clinical terms (quality of care) and based on health status (population health), from the point of view of both professionals (clinical outcomes) and patients (patient-reported outcomes and responsiveness to individual needs and expectations);

- equity in access to care and, due to the high costs, the role of financial protection;

- trust in physicians, the health care system as a whole, or in parts of the health care system (for example, in the national health service vs. private providers).

In their paper, prepared for the OECD, Hurst and Jee-Hughes (2001) use key indicators of performance in categories such as health outcomes, responsiveness, equity, and efficiency.

As regards to the depth of performance, macro, meso (policy and regional) and micro levels can be identified in the health (care) system as well. As the levels have been defined for the research, macro level performance mainly deals with population health status, taking other than the health care sector into consideration, too. Due to the predominance of (social) health insurance schemes in developed countries, the performance of the (social) health insurance systems can also be defined "inside" the performance of the health care sector. Still at meso level, regional (or local) entities (like statistical regions or counties) can also be used as units for performance measurement - and are often used when geographical inequities are analysed. The health care system consists of a lot of service providers at the micro level. 
The issue of centralisation and decentralisation is also a focal point of how the health care system is organised (Saltman et al., 2007), and contributes to where and how the meso level is created. In the case of federal states (e.g. USA, Germany, Austria) it is natural that states play a role in organising health care services, even if some of them is also characterised by competing health insurance funds (or companies). However, to some extent, these competing funds can also be considered as a meso level. Regions can also play an important role (like it is the case in Denmark or Italy). The most typical model of state-run and tax-funded health care systems, the Beveridge model in England also uses a decentralised model by creating strategic health authorities (NHS, 2011). One of their primary responsibilities is "making sure local health services are of a high quality and are performing well" (ibid). Except for the case of the smallest countries, some form of decentralisation is always present in planning, managing, and/or financing health care services. This meso level increases the complexity of performance management in the health care sector to a great extent. 


\section{Network theory and performance improvement of public services}

\subsection{Fragmentation and the need for greater coordination}

\section{New Public Management and the Whole of Government approach}

Performance-orientation, especially in countries where the New Public Management movement had a significant effect, included heavy decentralisation of responsibilities among public sector organisations, including separating the role of policy making and implementation (or execution). The need for separation led to creating a high number of executive agencies in NPM-countries (for an overview about the performance management of agency-type organisations, see Révész, 2010). Among other doctrinal components of NPM, Hood (1991) identified hands-on professional management, with "active, visible discretionary control of organizations from named persons at the top, free to manage", leading to "clear assignment of responsibility for action" (p.4) as well as a shift to disaggregation of units in the public sector, with "break up of formerly 'monolithic' units, unbundling of U-form management systems into corporatized units around products, operating on decentralized 'one-line' budgets and dealing with one another on an 'arms-length' basis", leading to separation of "provision and production interests" (p.5). Consequently, "[a] central feature of NPM was the unbundling of the public sector into corporative units with clear responsibility specified in contracts, quasimarkets with private sector management style, output controls, and hands-on management." (Hood, 1995; cited by Aristigueta - van Dooren, 2007, p.466)

The specialisation and decentralisation led to fragmentation and lack of coordination and cooperation inside the public sector, resulting in lower overall efficiency and effectiveness: "NPM changes seem to have increased the capacity of individual programmes and organisations to resist coordination efforts, and thus have strengthened the tendency for fragmented government" (Jann et al., 2010, p.294.). While agencies, focusing on narrow fields of service provision, could improve efficiency regarding their areas of responsibility, fulfilment of overall government objectives became more difficult. It was the most transparent in fields which needed a contribution from several policy areas (the so-called "wicked problems"). An example cited by Allen 
(2000) refers to the closure of a pregnancy advice clinic, showing good performance by saving some costs for the health authority. Consequences of this cost reduction would, however, fall to social services in forms of unwanted pregnancies and more social problems.

Sometimes, critics even refer to the issue of democratic deficit: longer-term task assignments and stable rules of financing are prerequisites for efficient agency performance, however, this kind of long term commitment limits government actions in case of a changing environment and changing needs. The "real" control over public sector spending is being transferred from democratically elected members of legislation to state bureaucracies and experts. (Robinson, 2002)

In response to the fragmentation described above, the Whole-of-Government (or joined-up-government or holistic government) approach emerged during the 2000s in the countries greatly affected by NPM earlier (see, for example, Christensen-Lægreid, 2007 or Bouckaert et al., 2010). Christensen and Lægreid (2007) cite the Australian Management Advisory Committee's definition for Whole-of-Government: "[it] denotes public services agencies working across portfolio boundaries to achieve a shared goal and an integrated government response to particular issues. Approaches can be formal or informal. They can focus on policy development, program management, and service delivery." (p.1060) Similar to NPM, it cannot be considered as a coherent tool set but rather an approach, with focus on setting shared objectives for public sector organisations at all levels, including policy making and service delivery.

Above all, the Whole-of-Government approach has implications for the meso-level performance. As Bouckaert and Halligan (2008) noted, "there is a need for new coordinating mechanisms between projects of major policy programs, between organisations in a policy field, and between stages of a service chain, especially after the disastrous organisational fragmentation driven by the new public management ideology[.]" (p.24.) As Jann et al. (2010, p.294) described, "[r]ecently, governments in many NPM frontrunner countries [...] put a renewed emphasis on coordination of policy 
and management. But also in more NPM-resistant countries governments invest in better coordination and collaboration. "Whole of government» initiatives focus on horizontal collaboration and integrated service delivery between public organisations and governmental levels."

There is a series of countries, including Hungary, where the NPM ideology did not play a significant role in public sector reforms. While Hungary was more like an "NPMresistant country", better coordination and collaboration in the public sector are still to be achieved. Hungarian reform initiatives primarily focused (and currently focus) on how the public sector is organised in terms of centralisation / decentralisation. This is also true for the case of health services where individual hospitals are being centralised (by transferring ownership from local governments to the state) and health system management is decentralised (by creating regional health management units - it must be noted that their role is somewhat unclear in the current system). Based on the international experience with NPM and Whole of government approaches, it is essential that reform attempts take a wide range of performance improvement and coordination tools into consideration.

\section{Rationale for a network based research approach}

As a response to the problem of coordination, described above, networks emerged as an alternative coordination mechanism. According to Aristigueta and van Dooren (2007, p.466),

"[t]he split of government into smaller decentralized subunits has led not only to clear lines of responsibility, but also to conflicts among these subunits, and the devolution of government initiated new coordination problems. These coordination problems in the market-style public sector reinforced the interest in networks as an alternative coordination mechanism."

Given the need for improving or reinforcing coordination among various units in the public sector, scientific research more and more focuses on connections among these organisation. This research is directed at various forms of networked entities as well as 
at how these entities perform in solving public sector problems. As Agranoff (2008, p.315) notes:

"The operational shift from government to governance transforms managerial focus from the internal workings of public organizations to the connections among those networks of actors-intergovernmental and nongovernmental-upon whom governments now collaborate. Today's governmental units vertically (federal, state, and local) and horizontally (interlocal/public and nonpublic organizations) manage by engaging a host of linkages with other entities. The result is a myriad of cross-agency networks, partnerships, consortia, alliances, joint ventures, contracts, and other collaborative ventures. Such collaborative management is understood as sthe process of facilitating and operating in multi-organizational arrangements to solve problems that cannot be solved, or solved easily by single organizations" (Agranoff \& McGuire, 2003, p.4). As a result, attention needs to be paid to how these entities perform, particularly the question as to the degree(s) to which they might add public value (Berry \& Brower, 2005)."

In accordance with the trend of bureaucracy deconstruction, networked approaches of public service provision are gaining popularity: increasing flexibility, and decreasing bureaucratic transaction costs (Williamson, 1985) are making the rationale for networked governance: "networks are an alternative when markets and bureaucracies fail." (Isett et al., 2011, p.i159) However, critical opinions hold that using networks serves as a means to distance the state from the problem by using local agencies and not-for-profits in a large number: "networks can be a symbolic-political choice when there is a pressure for state action yet disincentives for the state to definitively address policy problems." (O'Toole-Meier, 2004:683) In other words, "[c]ollaborative structures may be needed in problem areas in which the public simultaneously prefers more government action and less government involvement" (McGuire, 2006, p.34), or "more governance but less government" (Osborne-Gaebler, 1992).

\section{Networks: between markets and hierarchies}

The relevant literature defines three governance styles as ideal types of public administration: hierarchical, market, and network governance. Hierarchies, markets and 
networks are well-established "models of coordination", initially referenced via chronological paradigm shifts in Western Europe (Meuleman, 2008; Exworthy et al., 1999) :

- From the 1950s hierarchical style of governing was the major organizational logic, based on high degrees of centralization of policy making and resource allocation, suggesting central direction with limited autonomy for the periphery.

- The hierarchical style has been gradually replaced by market mechanisms from the 1980s, closely related to the progress of New Public Management. Market based governance styles are usually defined by parameters within the neoclassical model, or the transaction cost concept of Williamson (1985).

- In the 1990s a new style of governing has emerged based on networks, further widening the range of possible steering and coordination mechanisms. Networks have often been associated with the critiques of markets and hierarchies, and characterized as extended chains of connections and linkages, informal organizational forms, or trust relationships.

Since the 1950s the evolution of styles of governing, however, has not led to one new common style but rather to dynamic mixtures of styles. Therefore, these "ideal-type" styles may best be used as theoretical constructs. In reality, mixed forms of organisations tend to appear, and contemporary public administration is best characterized by complex and dynamic combinations. Since about the 2000s an important strain of the literature focuses on the challenge, formulated for example by Davis and Rhodes (2000, p. 25.), that "the trick will not be to manage contracts or steer networks but to mix the three systems effectively when they conflict with and undermine one another."

When positioning the relevance of the network-based coordination in the field of governance mechanisms, a common explanation to the emergence of the new networkbased governance is the need to effectively addressing complex social issues, that cannot be tackled by single public sector organisations working on their own. Huxham and Vangen $(2005$, p.3.) use the "collaborative alliances" to define the inter- 
organizational partnerships that able to tackle these issues, primarily "through collaboration [...] you are not limited by your own resources and expertise".

Scholars, however, also warn against considering networks as an all-encompassing solution for complex problems (Lecy at al., 2014), and focus on identifying the types of problems that networks are appropriate to address. The same dilemmas may also be raised regarding markets and hierarchies as well, and have to be considered when deciding about the use of a specific organizational form. Review of the literature suggests that inter-organizational networks should only be applied as coordination mechanisms when there is a potential for real collaborative advantage, and this situation primarily occurs when more traditional organizational logic cannot adequately address the issue in question. (Hoberecht et al., 2011; Huxham-Vangen, 2005; Isett et al., 2011) Some would even formulate the need for network coordination explicitly in terms of failure, for example "because traditional methods, including cooperation and coordination, have not been sufficient, in fact, network structures are established when all other options have failed." (Keast et al, 2004, p.365) This approach, however, disregards the possibility that network organisations might come together not just as a result of previously failing governance systems, but rather as a result of careful planning and previous anticipation of potential obstacles and shortcomings of more traditional styles. Holley (2012), for example, suggests that networks are best used when changes in existing systems, or innovation and flexibility are desirable.

\section{Present research interest of the scientific community}

Public sector networks and their performance have recently been becoming an emerging field of investigation in the international research community as well, proven by the presence of the topic on the most significant scientific conferences. The Public Management Research Association (PMRA) hosted a panel about network performance and a panel about network management on its biannual research symposium in 2011. (PMRA, 2011) The main research questions covered how to measure network performance, how networks evolve, and what role network management plays in formulating network structure and improving network performance. 
The International Research Society for Public Management (IRSPM) started a panel on its annual conference in 2011, too, titled "Predicting the performance of public networks". The main research questions of the panel are as follows: "Do public networks really work? What are the predictors of successful and unsuccessful networks? [This] panel track aims at empirically exploring the "visible» and »invisible» predictors of successful and unsuccessful networks, by considering and testing their simultaneous effect on the network performance." (IRSPM, 2011) Research questions that are considered important for scientific advancement in this field include ones as follows:

- "What do we mean by public network performance?

- How did the idea of network performance evolve over time, in different Countries and in different sectors?

- How can we measure the public network performance?

- What are the "visible" predictors of public network performance? What is the role of network structure, network functioning and network management in affecting the network performance?

- What are the "invisible" predictors of public network performance? What are the relationships among the aforementioned categories of network performance predictors?

- What is the interplay between visible and invisible predictors of public network performance?" (IRSPM, 2011)

This thesis joins this relatively new stream of research by primarily focusing on how networks are defined and managed in the health care sector.

\subsection{Networks in the public sector}

\section{Research streams and traditions in public network research}

Berry et al. (2004) separate three major traditions of network research: the sociological, the political science, and the public management traditions. They also discuss how the concepts of social networks and policy networks can contribute to the further development of the public management networks research agenda. The starting point of the social network analysis stream is that "structure matters" (ibid, p.545): network 
structure affects micro-level, individual characteristics (such as attitudes, satisfaction, power, and other behavioural issues), and vice versa, as well as macro-level antecedents and outcomes (where the research is focused on, for example, board interlocks, joint ventures, alliances, and shared knowledge). The principal questions of the policy network stream are "how policy actors achieve the policies they desire", and "how actors' roles and the network structures themselves influence policy outcomes" (ibid, p.546). The public management network stream focuses on two questions: "How do networks-especially network structure-influence effectiveness in public service delivery? And, how managers' actions affect networks and their performance?" (ibid., p.546)

While the latter two streams are directly connected to public sector analysis, social networks influence public sector research to the extent as human behaviour affects all kind of networks and other institutions. The role of network analysis in understanding the specific working mechanisms of the public sector can be found in two areas: in policy networks, and in service provision networks. Being engaged in working out policy programs and setting policy objectives at policy level, the "frontline" where public services are actually provided for citizens (where citizens "meet" policy objectives, and get high or low satisfaction with them) can be found across a wide range of organizations: these are the members of the service provision network.

\section{Definition of the network}

Isett et al. (2011) note that there is a lack of clarity how the term of 'network' is used by public administration scholars. They claim that there are three general ways to look at networks, mainly based on the methodological approach used by scholars:

- network as a metaphor or an organizing concept to be able to describe a social phenomenon;

- network as a method to describe structure and measure structural dynamics;

- network as a utilitarian approach to understand public service provision where "networks are used to get something done" (ibid., p.i161). 
O'Toole (1997, p.45) defines networks as "structures of interdependence involving multiple organizations or parts thereof, where one unit is not merely the formal subordinate of the others in some larger hierarchical arrangement" and adds that "networks exhibit some structural stability but extend beyond formally established linkages and policy legitimated ties." In their literature overview, Turrini et al. (2010, p.528) add that this organisational approach of networks "typically assume a set of organizations (and not individuals or parts of organizations) that coordinate their joint activities through different types of peer-to-peer relations."

Isett et al. (2011, p.i161) define network as "a group of goal-oriented interdependent but autonomous actors that come together to produce a collective output (tangible or intangible) that no one actor could produce on its own". As it was described in the previous chapter, it is often the case with public services that the desired outcomes are dependent on having each public service provider produce the "right" output. In this aspect the term of "collective output" can be identified as the term of "outcome" of the general performance management model.

How much interdependence and coordination is needed among actors to be able to label an object as a network is not straightforward. The terms of "collaboration" or "collaborative arrangements" are also often used in connection with (or sometimes as a synonym of) networks. (Provan-Lemair, 2012) Collaboration occurs "when a group of autonomous stakeholders of a problem domain engage in an interactive process, using shared rules, norms, and structures, to act or decide on issues related to that domain". (Wood-Grey, 1996, p.146) Mandell and Steelman (2003) described five "steps" of interorganisational collaborative arrangements:

- intermittent coordination: policies and procedures of organisations are adjusted;

- temporary task force: working for a specific purpose;

- permanent or regular coordination: a formal arrangement drives coordination towards specific goals;

- coalition: narrower scope with a specific purpose and actions happen inside organisations; 
- network structure: broader tasks and simultaneous actions.

It might not be useful to see the network as a final step in strengthening collaboration. The exact form of the cooperation might not be as important as the presence of interdependence and thus the need for the joint production of outcomes.

Networks are not present as such, they are "being created" by a certain process, the creation takes time, and networks also change over time. Networks can emerge 'bottom-up', by a consequence of members' interactions, or can also be intentionally created 'top-down', by setting up rules that settle formal linkages. A mix of these two methods can also be present: for example, when regulatory changes encourage (e.g. financially motivate) single organisations to interact with each other and form a network. These two types are referred to as "voluntary" (or "emergent") and "mandated" networks.

Isett et al. (2011) make a differentiation between formal and informal networks. As they note, "[f]ormal networks are consciously created with some sort of binding agreement for participation, whereas informal networks are more organically derived" (ibid, p.i162). As McGuire (2006, p.36) notes, "[r]ecent empirical research suggests that a clear distinction between hierarchies and collaborative management is not always accurate. [...] Instead of a completely flat, self-organizing network, the presence of a lead organization, acting as system controller or facilitator, is often a critical element of effectiveness in collaborative management." In fact, it can be observed many times that the government plays an active role in coordinating the activities of members of a certain network by contracting towards the private or not-for-profit sector as well as by utilising bureaucratic control towards public organisations.

This thesis refers to networks in a similar way as Isett et al. (2011). A network is defined as a group of goal-oriented interdependent but autonomous actors that come together or being connected to produce outcomes that no one actor could produce on its own. Changes refer to the fact that network membership is not always voluntary but 
can be mandated (which is often the case with public services and networks created by policy changes). By applying the $4 \mathrm{E}+\mathrm{T}$ model of public service performance, collective outputs should be rather called as outcomes. This way, the approach to the network phenomenon is described by a utilitarian way: "networks are used to get something done", namely, to produce outcomes that could not have been produced otherwise. Regarding the issue of formal and informal networks, both are included in the research: the nature of interdependence (whether it is based on, for example, a formal contract or due to softer interpersonal relations) does not matter while parties contribute to performance improvement at network level ("getting something done" as regards to outcomes).

\section{Network types in the public sector}

Isett et al. (2011) and Rethemeyer-Hatmaker (2007) use a similar categorisation for separating the research approaches and corresponding types of networks in the public sphere. They define policy networks, based on Laumann and Knoke (1987), as "a set of public agencies, legislative offices, and private sector organisations [...] that have an interest in public decisions within a particular area of policy because they are interdependent and thus have a ıshared fater." (Isett et al., 2011, p.i158) Those who study policy networks are concerned with how decisions about public resource allocations are made (for a review and evaluation about policy networks, see, for example, Klijn and Koppenjan, 2000). Lecy et al. (2014) uses the term of "policy formation networks".

Collaborative networks "are collections of government agencies, nonprofits, and forprofits that work together to provide a public good, service, or »value« when a single public agency is unable to create the good or service on its own and/or the private sector is unable or unwilling to provide the goods or services in the desired quantities. [...] They may be formal and orchestrated by a public manager or they may be emergent, selforganizing, and ad-hoc, with many variants in between." (ibid, p.i158) Thus, the focus of collaborative networks is on public service provision. Turrini et al. (2010) summarise terms that are also used by other researchers instead of collaborative networks: 
providing networks (Bardach, 1994), provider groups (Benson, 1982), managed networks (Addicott et al., 2006, 2007), community care networks (Wagner et al., 2000), service implementation networks (Provan and Milward, 1995), organisational service delivery networks (Provan-Lemaire, 2012), or policy implementation networks (Lecy et al., 2014). If the network consists of public, private, and not-for-profit organisations, it is referred to as a 'hybrid network' sometimes. In this thesis service provision network is the preferred term.

Beyond the two types of networks described above, Isett et al. (2011) define a third type as well. Governance networks "are entities that fuse collaborative public goods and service provision with collective policymaking [...]. These networks focus on the coordination of organizations toward a common goal rather than the policies or products that the networks actually produce." (ibid, p.i158) Lecy et al. (2014, p.652) call these networks as "policy governance networks", and claim that they "emerge as a response to complex policy problems that cannot be effectively addressed by a single actor". From the point of view of the performance management model of public services, policy networks and governance networks are somewhat similar to each other in their function: both are aimed at formulating those objectives that shape how organisational managers should make decisions in the management cycle, or how network managers should govern the service provision network.

While policy and service provision networks have been separated in research tradition for a long time (Rethemeyer and Hatmaker, 2007), a difference between the European and the US research approach is also present. As Cristofoli et al. (2011, p.3) conclude, the "community of American scholars [...] seem to prefer taking a managerial approach at service delivery networks, investigate how to make them really work and use quantitative research methods, the European scholars [...] seem to prefer taking a governance approach at policy networks, investigating their formation and governance rules and using qualitative research methods." Most probably, the reason for this difference can be found in the historically different role of the state and the private sector in providing public services. However, in the future, more research is needed to 
bridge this gap, especially because policy making (and thus the functioning of policy networks) and implementation (or service provision networks) interact in all cases. Rethemeyer and Hatmaker (2007) urge further research that consider the case of the "policy-collaborative" network or the "network system".

Agranoff (2003) identified four types of networks:

- Informational networks for exchanging information and exploring solutions to problems but actions happen at organisational level;

- Developmental networks also include education that enhance implementation at organisational level;

- Outreach networks also develop common action strategies;

- Action networks do collective actions while delivering services.

Mandell and Keast (2007), in their article about network-wide performance measures, used the ' $3 C^{\prime}$ ' model, and hereby cited Brown and Keast (2003). According to this model, there are network types as follows:

- Cooperative networks are primarily aimed at information and experience exchange ('being aware of others' but no adjustment of individual organisational goals).

- Coordinative networks are aimed at improved integration of activities of individual and independent members, leading to a more efficient way of service provision (adjustment of individual goals on the 'margin').

- Collaborative networks are aimed at dealing with complex problems (e.g. economic development) where there is no serviced delivered by the network members but they are "trying to find new ways in which services can be delivered" (Mandell-Keast, 2007, p.577).

Network categorisations described above cannot be easily 'paired' since they deal with somewhat different dimensions of public networks. However, Figure 6, prepared for this thesis, gives an overview about how these concepts can be joint together as close as 
possible (it should be noted, however, that in reality the lines among various types are more blurred).

\begin{tabular}{|c|c|c|c|c|}
\hline $\begin{array}{l}\text { Rethemeyer- } \\
\text { Hatmaker } \\
\text { (2007) }\end{array}$ & $\begin{array}{l}\text { Isett et al. } \\
\text { (2011) }\end{array}$ & $\begin{array}{l}\text { Lecy et al. } \\
\text { (2014) }\end{array}$ & $\begin{array}{c}\text { Agranoff } \\
\text { (2003) }\end{array}$ & $\begin{array}{c}\text { Mandell-Keast } \\
\text { (2007) }\end{array}$ \\
\hline \multirow{6}{*}{$\begin{array}{c}\text { Policy- } \\
\text { collaborative } \\
\text { networks } \\
\text { (Network } \\
\text { system) }\end{array}$} & Policy networks & $\begin{array}{c}\text { Policy } \\
\text { formation } \\
\text { networks }\end{array}$ & & \\
\hline & $\begin{array}{l}\text { Governance } \\
\text { networks }\end{array}$ & $\begin{array}{c}\text { Policy } \\
\text { governance } \\
\text { networks }\end{array}$ & & $\begin{array}{l}\text { Collaborative } \\
\text { networks }\end{array}$ \\
\hline & \multirow{4}{*}{$\begin{array}{l}\text { Collaborative } \\
\text { networks }\end{array}$} & \multirow{4}{*}{$\begin{array}{l}\text { Collaborative } \\
\text { networks }\end{array}$} & $\begin{array}{l}\text { Informational } \\
\text { networks }\end{array}$ & \multirow{2}{*}{$\begin{array}{l}\text { Cooperative } \\
\text { networks }\end{array}$} \\
\hline & & & $\begin{array}{l}\text { Developmental } \\
\text { networks }\end{array}$ & \\
\hline & & & $\begin{array}{l}\text { Outreach } \\
\text { networks }\end{array}$ & \multirow{2}{*}{$\begin{array}{l}\text { Coordinative } \\
\text { networks }\end{array}$} \\
\hline & & & $\begin{array}{c}\text { Action } \\
\text { networks }\end{array}$ & \\
\hline
\end{tabular}

Figure 6. Network types in various models and their connections

Based on the organisation of the government and public services as well as the specific area of intervention, horizontal and vertical networks can also be identified. According to Bouckaert and Halligan (2008, p.31), “[a] horizontal network could be a level of government. A vertical network could be a value added chain of activities running through levels of government, and across the public sector organisations. It implies that public management is concerned with the effective functioning of whole systems of organisations (Metcalfe and Richards 1990:73)". The concept of horizontal networks refers to the concept of multi-level network management (which will be described later in this chapter) while the vertical networks concerns a policy area - and thus what was called as "policy-collaborative" network or the "network system" (see above) by Rethemeyer and Hatmaker (2007).

The primarily focus of the thesis proposal is on service provision networks, and on the issue of how service provision networks connect to the policy level (however, the process of policy implementation is examined to a greater extent, while the process of 
policy making is less in the focus). I do not differentiate between policy formulation and policy governance networks, I look at them both as policy network.

\section{The connection between policy networks and service provision networks}

Based on the policy network literature, the network approach is relatively often used to explain how policy objectives emerge from the clash of conflicting interests caused by competition for resources such as budget and legitimacy. On the other hand, the role of networks and network management is less understood in implementing those objectives (or: in the management of service provision networks). Health provision (with general practitioners, out-patient care, hospitals, rehabilitation centres, pharmacies and other providers) and transportation (with urban means of transportation, trains, buses etc.) are good examples of how public service provision is based upon network management: good performance in service provision requires coordination between network members (e.g. referral protocols in health care, or schedule harmonization in transportation).

When referring to the performance of public services, and about how this performance can be influenced and managed, an attempt is made, in fact, to make a connection between public policy and public management-or, in terms of networks, between policy networks and service provision networks. The standards of the public services are set up and maintained by public policy making (influenced by policy network members), through elaborating policy programs. Financial sources needed for service provision are mainly ensured by the policy level, too-but services, indeed, are carried out by the service provision network members. Their behaviour is influenced by rules and other (mainly financial) influential factors that are set up at policy level: policy makers are striving to shape the environment of local providers in a way that motivates them towards fulfilling policy goals. Additionally, local provision network members' behaviour is also affected by local circumstances such as territorial specialties or local politics. Monitoring the performance of service providers ensures that the performance of local providers can be evaluated. This evaluation may affect program objectives, and may lead to changing the 'rules of the game'. Performance levels of service providers is 
summed up in order to evaluate whether policy objectives are met-in this sense, this sum creates network performance (see Figure 7).

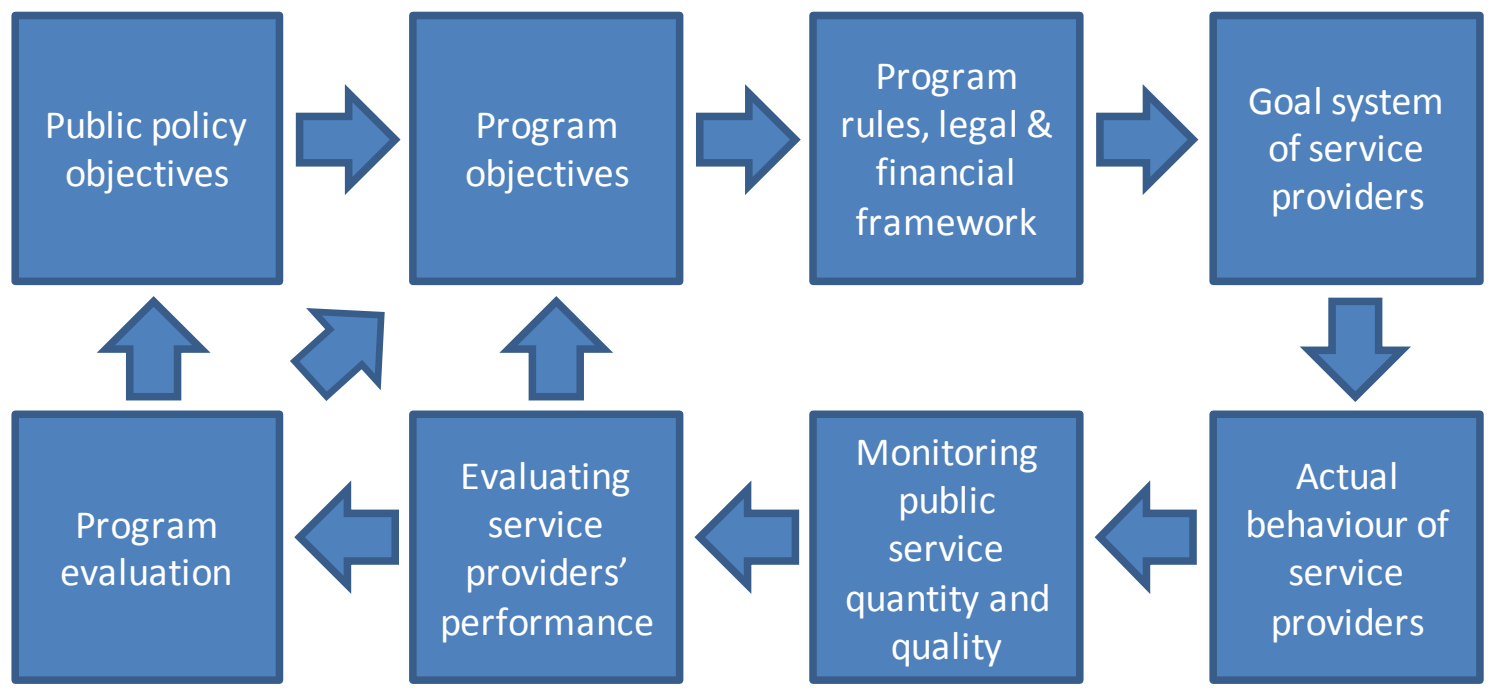

Figure 7. The connection between public policy making and service provision

Referring back to the performance management model, good network performance occurs when outcomes are consistent with policy expectations (and respective social needs). It might occur that certain local service provision networks perform well (producing the desired outcomes) but others do not. Generally, it is the "summary" of the outcomes that can make a policy successful. This idea is further developed in the thesis later, by building on Benson $(1975,1982)$ and Hudson $(2004)$.

\section{Boundaries of networks}

Drawing the boundaries of networks for analysis can be difficult. According to Isett et al. (2011, p.i166), "identifying a network and understanding who the relevant actors are poses a challenge for network researchers." They cite two cases for illustration: network members often have subcontractors in service implementation and formal network members may initiate informal relationships with other organisations (e.g. with community or voluntary ones). Moreover, network members does not 'exclusively' belong to one network or an other but may play multiple roles at several different networks (in graph theory this situation is described as overlapping communities). A 
public sector organization can often be treated as a member of several networks (or communities) during analysis.

As it was emphasised by Rethemeyer and Hatmaker (2007), policy and service provision networks may also interact thus members of any of these two networks will have connections with members of the other, further blurring network boundaries. The horizontal and vertical classification (see above Bouckaert and Halligan, 2008) categorises the same organisations of the public sector on two distinct dimensions. Public service providers can themselves pursue complex tasks, with different tasks belonging to different policy areas (for example, schools have their primary role in carrying out public education programs but are also considered as a distinguished place for health education in public health programmes). The most classical case that illustrates this phenomenon is economic development. As Agranoff and McGuire (1998, p.69) note:

"Like the hub of a multispoked wheel, the development manager is connected to all of the spokes-each representing a different strategic task; each consisting of networks of different composition, scope, and size; and each with its own set of management challenges and responsibilities. [...] Insofar as the performance of a particular policy sector is dependent on the effectiveness of organizational and network design, development of the capacity to organize and manage these processes is critical to both public policy and management."

Naturally, it is the network which serves as the unit of analysis in most network research. Formal networks are, of course, easier to describe than informal ones. Mostly, it comes to the question of what type of connection (e.g. contracts, communication linkages) is used during the analysis. Boundaries can be defined by the researcher or the network members, can be based on perceptions or hard data. Modern ICT solutions make the latter easier; Barabási (2002) describes several cases.

In the health care sector the boundaries of provider networks can be administrative (e.g. providers belonging to a health insurance corporation or a certain regional health authority) or can be defined by analysing patient flow and mobility data (where a great 
majority of patients is referred inside a network, with only a few of them leaving to get treatment from external providers).

\subsection{The performance of public service provision networks}

Measuring the performance of a single organisation can be often challenging: it is especially true in the case of organisations providing public services where the complexity of stakeholder interests, the complexity of services, and, most of the times, the long-term effects make performance measurement a difficult task. The complexity in a network is even greater. As Herranz (2010, p.315) notes,

"[o]ne key challenge in assessing network performance is defining and measuring the multiparty complexity of a network. While evaluating the performance of an individual agency or program is itself difficult, assessing network performance is even more difficult."

\section{Measuring collaboration}

It is common that researchers call for deeper analysis of how network performance differs from the performance of organisations participating in a given network. One approach is to evaluate linkages among network members. As Mandell and Keast (2007, p.583) note:

"[T]he effectiveness of collaborative networks cannot be based on the same criteria used for single organizations. Instead, based on their distinguishing characteristics, the measures of performance in collaborative networks should include the degree to which linkages among members are tight or loose, the degree to which members are committed to the collective whole rather than to just their own organizations, the degree to which all relevant parties are included in the network, the type of formal and informal rules agreed on, the degree to which participants are open in their communications with each other, and the degree to which the network is supported by key actors both inside and outside the network. Although traditional performance measures are also needed to measure the degree to which tasks are accomplished, these measures should not overshadow the emphasis on using relational or nontraditional performance measures." (italics added) 
This approach leads us to the issue of how to measure collaboration. As McGuire (2006, p.39) summarises, quantifying contacts and types of contacts, as done by the social network research stream, may be "imperfect [but] have been shown to be adequate proxies for collaborative management research." The fact of collaboration itself is often seen as a positive factor, regardless of how the actual outcomes change. According to Herranz (2010, p.324),

"collaborations are often perceived to be more effective with the presence of community-type coordination characteristics such as common values and interests, collective problem solving and decision making, negotiation and bargaining, shared resources, and reciprocal trust. In most instances, collaboration itself is often presented as an implicit dependent outcome variable. Evidence of collaboration is interpreted as an indication of effectiveness."

As McGuire (2006, p.39) summarised, based on Berry et al. (2004), "[t]he literature on collaboration is often celebratory and only rarely cautious". As regards to the case of public service provision networks, we must move beyond the measurement of collaboration: the "degree to which tasks are accomplished" must also be evaluated (see the text in italics in the citation from Mandell and Keast, 2007, above).

\section{Network performance vs. network effectiveness}

The 4E model of public sector performance has been applied in the case of networks as well. There are some further dimensions, however, stemming from the networked nature of services or from the public values of this sector. According to Christofoli (2011b, pp.7-8), variables that can be used to measure network performance are "network efficiency (in terms of ratio outputs/inputs), network effectiveness, network internal and external legitimacy [...], network stability (as the ability to develop long-term relationships with other network members), and concluded that the relative importance of those variables can vary according to the form of the network governance (i.e. participant-governed network, lead organizationgoverned networks and network administrative organization)." (ibid., pp.7-8) 
Dimensions ("width") of performance are mentioned elsewhere as well:

"Many collaboratives are designed not only to improve economy, efficiency, and effectiveness but also democratic quality and legitimacy, social learning, adaptability and developmental capacity, political integration and nation building, and common purpose and trust." (Gray-Jenkins, 2003, p.237; cited by: Herranz, 2010, p.312)

The literature review of Christofoli et al. (2011b) showed that the context greatly affects the mode of operationalization (ibid., p.15):

"[D]ifferences in performance operationalization and measurement occur depending on the network type (service delivery network or policy-making network), the network level (community, network, partner organizations), the focus on the network structure, the network process or the network outcome and the nature of the proposed indicators (objective or subjective measures of network performance)."

Kenis and Provan (2009) noted that performance evaluation should not be restricted to the question of finding 'measurements'. They claim that performance expectations against a network are dependent on who sets up the expectations and thus a wide range of criteria may be adequate. They examined what (exogenous) factors of the network influence performance expectations and thus the appropriateness of the criteria used for evaluation. They found that the type of network governance (see their categorisation later), the mandated (top-down) or voluntary (bottom-up) nature of the network, and the developmental stage will, at least in a part, determine what performance criteria are appropriate.

Most often, scholars who evaluate the performance of networks, refer to this task as "network effectiveness". They mainly examine whether the common goal of network members is fulfilled but also pay attention to factors that facilitate the operation of the network. In this case the term "effectiveness" does not refer to the same category as how it was used in the performance model of public services. Provan and Kenis (2008, p.230) defined network effectiveness as "the attainment of positive network level 
outcomes, that could not normally be achieved by individual organizational participants acting independently". Network effectiveness describes the attainment of network goals, while effectiveness in the $4 \mathrm{E}$ model refers to the performance of the public service provided. When network goals are properly defined in a service provision network, its effective operation contributes to the effectiveness of the public service to a great extent ("effectiveness dimension of the 4E model"). On the other hand, if goals are poorly set, the desired outcomes will not be produces. Policy networks can also be effective but, of course, they do not directly produce public services so that effectiveness of services can only be improved via the public service providers.

Provan and Milward (2001) set up a framework of network effectiveness at three levels of network goal attainment: community, network, and organisational, leading to the concept of 'multilevel network effectiveness'. Remaining on the same track, Turrini et al. (2009) carried out a comprehensive literature review about how network effectiveness is conceptualised as well as what determinants of effectiveness are analysed. They adopted their conceptual model from Provan and Milward (1995) as well as Provan and Sebastian (1998), and developed it further by incorporating the results of their literature review (see Figure 8 for an overview of the framework and Annex 1 for a detailed list of determinants examined in the literature).

Turrini et al. (2009) identified three broad concepts of effectiveness in the literature (hereby the levels refer to stakeholders from whose perspective the performance is evaluated and not to macro, meso, and micro levels of performance):

- Client level effectiveness: this level concerns what is actually delivered to clients (including the quality of services). They claim that the evaluation is based on "assessing the aggregate outcomes for the population of clients being served by the network". (ibid., p.533)

- Community level effectiveness: public services outcomes often affect others than clients as well. That is why "effectiveness have [also] been broadened [...] to an overall benefit for the community that goes beyond client-increased wellbeing [...]. Different authors have embraced this perspective measuring enlarged 
community outcomes such as distributional effectiveness and access [...] or participation and activation of the community [...]." (ibid., p.533)

- Network level effectiveness: effectiveness can also be evaluated from the aspect of the network members, referring "to the sustainability, legitimacy and maintenance of the networked structure per se." (ibid., p.533) To achieve longterm sustainability "a (real or perceived) capability of reaching network stated goals" (ibid., p.533) is essential. Conditions (the context) might change from time to time, making innovation ability and change an element of long-term network effectiveness, too.

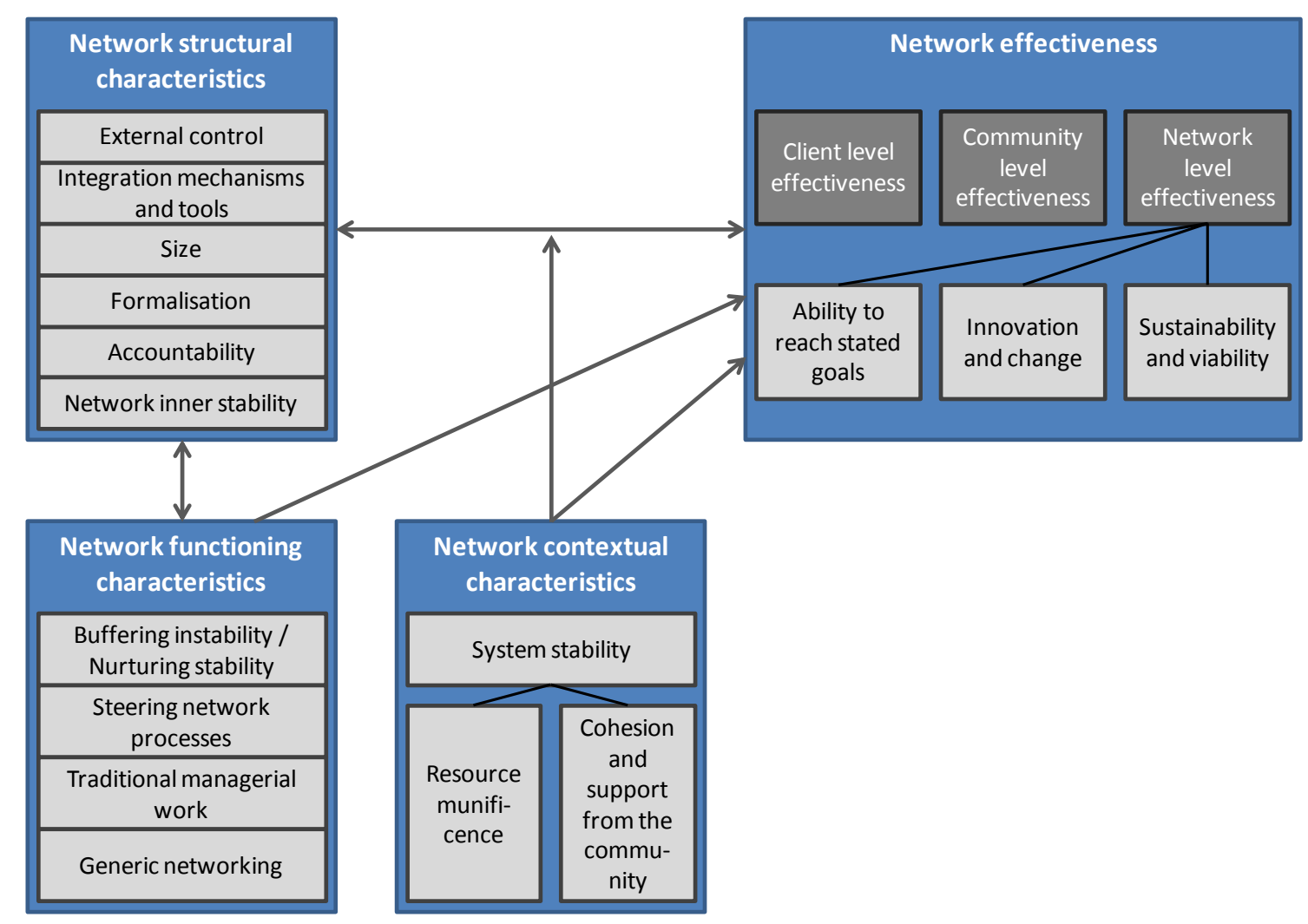

Figure 8. A framework of network effectiveness

(based on Turrini et al., 2009)

The literature review conducted by Turrini et al. (2009) supported the idea of these three levels: they found cases for all of them. They have also reviewed all the determinants examined in earlier studies and grouped them into contextual, network structural and network functioning characteristics (see Figure 8). The main element of the context is 
the issue of stability, with two potential sources: resource munificence as well as community support and cohesion. Resources include financial and other resources, e.g. the availability of technical assistance systems (Mitchell et al., 2002).

Structural characteristics include external control (of both fiscal and regulatory nature), integration mechanisms and tools (for example, the presence of a coordinative agency, a common information and communication technology system, joint staff activities, or service integration such as 'one-stop shopping'), size (and thus the heterogeneity) of the network, formalisation (rules and decision making procedures), accountability (towards external stakeholders) as well as network inner stability (stability of personnel and management, facilitating trust building). According to Vangen and Huxham (2003), trust can only built up through cyclical trust-building loops. First, partners should seek for 'easy wins', and thus early successes will give space for more ambitious goals.

Functioning characteristics cover traditional managerial work (thus their organisations can successfully contribute to the achievement of the common goals), generic networking (meaning greater interaction with peers and going beyond hierarchical relations, even facilitating or brokering deals), buffering instability / nurturing stability (building or rebuilding network governance mechanisms, formulating rules, rearranging structural processes, engendering participation, building commitment, and promoting information exchange) as well as steering network processes (establishing clear mission statement, and developing focused strategies).

Annex 1 (based on Turrini et al., 2009) shows in details how these characteristics were analysed in the literature, what variables were used for measurement, and how they contribute to network effectiveness.

\section{Accountability and performance measurement in public networks}

As performance orientation is central to NPM-based reforms in several countries as important it is for improving the performance of public networks. From a normative point of view, performance orientation is closely interrelated with the greater need for 
transparency. In the framework created by Turrini et al. (2009) accountability is one of the structural characteristics affecting network effectiveness. As they note, "the necessity of being accountable to external stakeholders (so-called horizontal accountability) forces the adoption of explicit and shared measures and techniques for evaluating the progress of the network." (ibid., p.542)

As it is in the case of single organisations, performance measurement matters, and the application of these shared measures drives the networks towards its shared goals. Herranz (2010, p.318) cites a case of a country government: “Krane (2008) examined the adoption of performance-based management by county governments that involve a variety of relationships with federal, state, local, and other counties. Krane found that the collaborative performance of intergovernmental initiatives was enhanced by collective use of strategic plans, development of performance information, and the procedures of results-based management." This is how collective goals are translated into collective action planning.

Turrini et al. (2009) mention a second way of improving effectiveness, too. External communication can be encouraging for communities to participate and provide support thus leading to a more favourable network context. Communication of (good) results with external stakeholders will certainly help in creating higher trust levels towards the networks; Bouckaert and Halligan (2008) showed how trust building is essential in the public sector.

\section{Connecting the performance of service provision and policy networks}

From an analytical point of view, researchers seek for 'proxy variables' that describe various network characteristics influencing network performance in a positive or negative manner. In this sense, network management consists of activities that support the build-up of 'enhancers' and limit the effects of 'obstacles'. From a public policy viewpoint this 'game' is exactly the same: policy makers try to set up rules that serve as 'enhancers' and prevail negative effects of 'obstacles'. Literature suggests that these enhancers can be, for example, the level of trust within the network, or the existence 
and use of better communication channels. This way, these factors can be considered as 'proxy variables' of network performance: if network members trust each other to a greater extent, network performance will be higher. In terms of institutional economics, researchers are seeking the factors that decrease transaction costs in the network (so that the networked mode of operation will be preferable to markets or hierarchies). In terms of public policy making and implementation, these factors are central to the rule setting process since these are the ones that influence the behaviour of public service providers - these are the factors that link policy networks and provider networks.

A general framework which describes this interrelationship is needed. According to Benson $(1975,1982)$ and Hudson (2004), effective local network partnership depends upon the factors that can be grouped into four dimensions: domain consensus (agreement regarding the appropriate role and scope of each agency), ideological consensus (agreement regarding the nature of the tasks faced), positive evaluation (or trust) towards other organizations, and work coordination (the alignment of working patterns and culture). Regarding the terminology, local networks are equivalent to service provision networks. Internal and external contextual factors that influence local level factors are as follows: the fulfilment of program requirements, the maintenance of a clear domain of high social importance, the maintenance of orderly, reliable patterns of resource flow, and application/defence of the organization's paradigm. These contextual factors are often subject to policy level actions.

While the authors originally used the term of 'super-structure' for the local network level, and 'sub-structure' for the contextual level (reflecting the fact that the superstructure is the network which actually provides services and sub-structure is the policy environment of these networks), it is worth redefining these two levels as service provision network and policy network, based on the fact how the dimensions at each level refer to relationships at service provision and policy levels. This change also decreases the confusion that the authors' original terminology could cause: this change reflects the terminology defined by Mintzberg (1996), and the terminology which is widely used by scholars. 
The model incorporates network dynamics as well. Networks reach a certain level of equilibrium in each dimension (for illustration purposes, without the intent of exact measurement, Benson uses low, moderate, and high levels). Dynamics can result in balanced systems where each dimension is at the same level (e.g. high-high-high-high), or imbalanced systems (e.g. high-moderate-low-high). The dynamics is brought into to model by stating that a system, left on its own (without network management efforts), will move into the direction of becoming balanced. It follows that managerial interventions must be directed at all dimensions because lower level dimensions might decrease network performance by influencing higher level dimensions in an unfavourable way (e.g. lack of trust might inhibit integration of work processes). Figure 9 gives an overview of the model.

\section{Service provision network: Operational relationships}

\begin{tabular}{|c|c|}
\hline $\begin{array}{l}\text { Degree of domain consensus } \\
\text { (= to what extent the roles and } \\
\text { responsibilities of different network } \\
\text { members are clear) }\end{array}$ & $\begin{array}{l}\text { Degree of ideological consensus } \\
(=\text { to what extent network members agree } \\
\text { on problem definition and problem } \\
\text { resolution) }\end{array}$ \\
\hline $\begin{array}{l}\text { Degree of positive evaluation } \\
\text { (= to what extent the workers of network } \\
\text { members trust in each other) }\end{array}$ & $\begin{array}{l}\text { Degree of work coordination } \\
(=\text { to what extent working patterns and } \\
\text { cultures are aligned in a network })\end{array}$ \\
\hline Policy network: Contextual influences & \\
\hline $\begin{array}{l}\text { Fulfilment of program requirements } \\
\text { (= to what extent provider networks } \\
\text { undertake tasks which are consistent with } \\
\text { present policy requirements) }\end{array}$ & $\begin{array}{l}\text { Maintenance of a domain of high social } \\
\text { importance } \\
\text { (= to what extent the agenda has public } \\
\text { legitimacy and support) }\end{array}$ \\
\hline $\begin{array}{l}\text { Maintenance of resource flows } \\
\text { (= to what extent the resource flow is } \\
\text { predictable and reliable) }\end{array}$ & $\begin{array}{l}\text { Application/defence of the organizational } \\
\text { paradigm } \\
\text { (= to what extent participants are } \\
\text { committed to the agency's way of doing) }\end{array}$ \\
\hline
\end{tabular}

Figure 9. Performance dimensions of service provision and policy networks (based on Benson, 1975 and Hudson, 2004) 
According to Benson and Hudson, the performance of a local service provision network will be better if the equilibrium reached in the four dimensions of the local level is at a higher level. A local network performs better if:

- the network members reach a consensus about the distribution of responsibilities for certain tasks, goals and objectives followed by the members are consistent with each other, and the unnecessary duplication of resources can be avoided (for example, in a health provision network the distribution of tasks between primary care and secondary care is clarified)-as described by the degree of domain consensus;

- the network members have a consent about the 'nature' of the problems they face as well as possible ways of solution (for example, in the case of health provision, the main goal is to improve the overall health status of the whole population - the task is not to manage hospitals and other institutions, or to treat diseases, but to focus on patients' health and relevant data, to improve health instead of treating disease episodes, and to take prevention activities into consideration as well)-described by ideological consensus;

- the network members trust each other, and relevant information is shared, the relationships between members is shaped by rather commitment toward common goals than differences in negotiating power (for example, joint development projects are initiated where asset specific investments are also made, or physicians trust in each other's diagnoses to a greater extent when an adequate quality assurance framework is in place)-described by positive evaluation;

- interorganizational processes are well coordinated (for example, treatment protocols that meet local requirements and possibilities are put in place, and the flow of both physical material and information is well-organized in a field where physicians traditionally have high autonomy and authority)-described by the degree of work coordination.

Performance levels of all the local service provision networks in a certain policy area (e.g. all the health districts) will be influenced by the aggregate of performance levels achieved by the whole 'community' of provision networks. It will be also influenced by 
the performance of the network administrative or supervisory bodies (how they succeed with managing the network). The reasoning behind is that the macro-level success of the whole public policy program will be decided upon whether expectations are met in service provision or not. All the local service provision networks may perform better if:

- public policy program requirements are fulfilled in a higher number of local provision networks, or to a greater extent (for example, it can be demonstrated that health care services work well in several regions and investments made towards the health care will have a social return);

- social legitimacy concerning a policy program is higher, that is the program is known and its importance is acknowledged wider in the public (for example, health care is notorious in need for a reform, however, what tools reformers may choose is dependent on what the society accepts better);

- financial and other resources are secured for the continuity of operations in a transparent manner, which encourages long term thinking (for example, how health care services are financed is transparent and calculable in the long term, given the need for investing in fixed assets to a great extent, for example, in the case of hospitals);

- local provision members 'use the same language' to describe problems and solutions as policy makers and the supervisory bodies do (for example, health providers do accept policy goals and provide support in communicating the need for reform towards local stakeholders; in Hungary the majority of health care providers never publicly accepted the newly introduced co-payment in 2006, leading to a referendum annulling it).

The framework describes well the interrelatedness of policy level and service provision level, and the performance of one policy program and its connected provision networks. In order to utilize the synergic opportunities between various provider networks (or taking into consideration that a single organisation can be the member of several different networks, "belonging to" several different policies), objectives set at various policies and at organizational strategies should be consistent with each other. The most obvious clash of consistency can be observed in the relation of local/regional networks and sectoral policies (e.g. country-wide network of education, or health provision). What 
is rationalization from one aspect might mean destabilization from the other: for example, innovations in health technology led to overcapacity in hospital beds - closing a hospital could be rational for the national government but may be disastrous for a local government. It should also be noted that elements of the model are significantly affected by the cultural context. For example, more individualistic societies will have more difficulties in building up trust, thus reaching higher degree of positive evaluation in the respective quadrant of the model. Education plays a role in forming the cultural context of the health care sector as well: whether university education emphasises team work, will also have an effect on how physicians will cooperate when they work.

The more inconsistencies exist between these objectives, the less synergic opportunities can be utilized between and within networks. This way, the consistency of goals and objectives of public policy programs and public service provision networks is an important influencing factor of network performance. It should be noted, however, that it would be illusionary to think that 'total consistency' can be reached in a sphere where politics and political actions are continuously bringing imbalance into the system.

\subsection{Network management and network governance models}

As we could see, there are network characteristics that have an impact over network performance. These network characteristics, in turn, are subject to various managerial actions: in order to improve network performance, network managers must initiate actions that change network characteristics in a favourable way; consequently, they must pursue the activity of 'network management'. As Rethemeyer and Hatmaker (2007) defined, "network management is the use of social "stools"' to steer social processes toward some set of goals or away from stagnation and «blockage« through joint problem solving" (ibid., p.630, italics in original).

Rethemeyer-Hatmaker (2007) use a resource-dependence theory (RDT) to examine network management. In their view, "network management is about manipulating (in the technical, not pejorative, sense) MIR and SSR endowments, the dependence relations that flow from those endowments, and the perception on the part of network 
members of what resources and relations are at stake in a game or the networks in which they are embedded" (ibid., p.636), where MIRs are material-institutional resources (e.g. money, employees, knowledge, authority) and SSRs are social structural resources (pattern of communication and resource exchange).

As public administration and public management have been rather distinct areas of research (see, for example, Berry et al., 2004) and as (new) public management moves towards (new) public governance (Bouckaert-Halligan, 2008), several researchers prefer to use the term of 'network governance'. Provan and Lemaire $(2012$, p.644) claim that "the main issue regarding management of a network is governance". According to Provan and Kenis (2007, p.230), governance refers "[...] mainly [...] to the funding and oversight roles of government agencies [...]. A critical role for governance [...], and consistent with principal-agent theory, is to monitor and control the behaviour of management, who are hired to preside over the day-to-day activities of running the organization [...]". Provan and Kenis (2008, p.230) refer to network governance as "the use of institutions and structures of authority and collaboration to allocate resources and to coordinate and control joint action across the network as a whole". Some authors also use the term of 'network coordination' (for example, Herranz, 2008, 2010).

In this sense, network management might be a broader concept, going beyond monitoring, oversight, and funding accordingly, including more active interventions (like common strategy making or standardisation of procedures). The terms of network coordination, network governance and network management are used interchangeably in this thesis since in a networked context all the three concepts are primarily directed at forming interorganisational processes to achieve common goals.

The very first question about network governance, however, is whether it is needed and possible or not. In the case of pieces of various ICT infrastructure the capability of selforganisation might be a principle (for example, how the internet built up is based on this principle). If there is apparently no one managing a network, we may refer to it as a selforganising or self-regulating network. While the term is more commonly used in natural 
sciences and engineering, social networks can also be self-organising ones. In the public administration literature, these types of emergent networks often become shared governance networks (see below).

Provan and Kenis (2008) and Kenis and Provan (2009) identified three types of network governance in the public sector, the first being to closest to self-organising networks:

- Shared governance (or participant-governed) networks: they define such networks as ones where there is no distinct governance entity and organisations work collectively. As they state, "[t]he strength of this model is the inclusion and involvement of all network participants and its flexibility and responsiveness to network participant needs. Its weakness is its relative inefficiency. It is a model that seems best suited to small, geographically concentrated networks where full and active face-to-face participation by network participants is possible." (Kenis-Provan, 2009, p.446)

- Lead organisation network: either by emerging as a result of a bottom-up process, or based on mandate (especially in the case of government services), there is a lead organisation which "has sufficient resources and legitimacy to play a lead role" (ibid., p.447). This form is common in vertical relationships (e.g. between a string buyer and its suppliers, or if there is a core public service provider agency). "The functionality of the lead organization model is its efficiency and the legitimacy provided by the lead agency. [...] The weakness of the model is that the lead organization may have its own agenda and can readily dominate the other network members, causing resentment and resistance. In addition, because the lead organization takes on many of the activities of governing the network, network members can readily lose interest in networklevel goals and focus instead on their own self-interest, undermining the viability of the network." (ibid., p.448)

- Network administration organisation network: according to the authors, "[t]he basic idea is that a separate administrative entity is set up specifically to manage and coordinate the network and its activities" (ibid., p.448) where the network administration organisation (NAO), unlike in the case of a lead organisation 
network, does not provide any service but solely embrace the responsibility of network governance. As they add, "[t]he strengths of this model are its sustainability and legitimacy, especially to outsiders and, to a lesser extent, its efficiency. Its weaknesses are that network participants may rely on the governance entity too heavily and it may adopt decision-making processes that seem overly bureaucratic." (ibid., p.448)

Under different circumstances different types of network governance may be beneficial. For example, "as a network becomes larger and more complex, [...] shared governance becomes less viable and overall network effectiveness more problematic. [...] Thus, network governance typically will shift to one of [the] two alternative forms" (ProvanLemaire, 2012, pp.644-645). The authors refer to these two forms as "brokered forms" since there is a member of the network with the task of network governance. They also claim that hybrid forms are also possible.

The main consequence for performance measurement, stemming from this categorisation, is that "[t]he performance criteria that are most appropriate for evaluating a network will depend, in part, on the type of network governance form adopted." (Kenis-Provan, 2009, p.449) It is also added that the voluntary or mandated nature as well as the developmental stage of the network will also influence how performance should be evaluated.

In the health care sector there are examples for each type of networks. Bigger hospitals tend to grab the leading role (lead organisation network model), sometimes based on mandate, as it is the case with hospital trusts in the UK or was the case with hospital-led managed care organisations in Hungary. Network administrative organisations are also frequently used, for example, as regional planning and managing authorities (this type of network model was planned to be used by the recent Hungarian reform initiative about the creation of regional health care managing bodies). The shared governance network is often used in the case of "wicked problems", for example, in drug prevention 
in local settings where the local players can effectively collaborate on a shared governance principle.

The role of network governance can be formally mandated to a member (either by a higher level authority like the central government or legislation, or by peer members on a contractual basis, for example, voting), or might be a role which is de facto pursued by a member (who has the power to govern the network). Since the network manager has some sort of authority over the other members and this authority can be stemmed from various sources (for example, legal power, or softer factors like being an opinion leader in common decision making), in most of the cases it is inaccurate to assume that there is one single network manager.

From an analytical point of view, it might be more punctual to refer to the strength of network management ability of all members. Rethemeyer and Hatmaker (2007, p.638) propose that "multiple network managers exist in any given network system and operate in a partly competitive, partly cooperative balance with one another". The roles of "non-governing" network members also tend to change: Provan and Lemaire (2012), building on Milward and Provan (2006) distinguish "manager of a network" from "manager in a network". How a network member can effectively contribute to a network changes the environment in which the organisational manager must act.

\section{Managerial skills and competencies for effective network management}

Beyond the main network governance types, the "personal side" of network management is also interesting for scholars. This area of research concerns what skills and competencies network managers should have in order to be able to successfully manage the networks. Hereby, the thesis does not review the literature about this issue in details, only indicates the importance of having the right managerial skills and competencies to be successful in network management.

What network managers do is network management so the term can be defined in correspondence with network management. Network managers are "one or more 
members of the network who take as their task guiding the network toward a set of goals and away from blockage" (Rethemeyer-Hatmaker, 2007, p.631). The functions of a network manager may be directed at several ways: "[a] public manager may be simultaneously involved in managing across governmental boundaries, across organizational and sectoral boundaries, and through formal contractual obligations; it is often difficult to distinguish where the boundary lies between these different environments." (McGuire, 2006, p.35) Network managers may be present in both formal and informal networks, however, as Isett et al. (2011, p.i164) notes, "[f]ormal networks may be somewhat easy to manage because they are fairly stable."

Concerning the nature of skills and competencies, there are two approaches. One claims that these skills are not significantly differ from those that are needed in a single organisational setting (consequently, a good manager of a single organisation should do better in a networked setting as well) while the other searches for skills that are specifically useful for interorganisational linkages. For example, McGuire (2006, p.39) concludes that "there are similarities between the skill demands of collaborative management and those of managing single organizations [...] [and while] new competencies are needed for collaboration, some of these are already inherent in the public manager."

Those who seek for network management skills, focus on characteristics what make networks different from single organisations and mainly derive the skill set from the need for shared network goals, and enhanced communication linkages. For example, according to Goldsmith and Eggers (2004, cited by McGuire, 2006, p.38) "the main elements of network management are big-picture thinking, coaching, mediation, negotiation, strategic thinking, interpersonal communications, and team building." Williams (2002) defined general competencies for network managers (or 'boundary spanners'): building sustainable relationships, managing through influencing and negotiation, managing complexity and interdependencies, and managing roles, accountabilities, and motivations, with corresponding skills as communicating to create shared meaning, understanding, empathy, conflict resolution, networking, creativity, 
innovation, empowerment, and building trust (based on McGuire, 2006). Isett et al. (2010) reviewed the determinants of network effectiveness and identified some studies which used managerial behaviour and underlying skills as variables (e.g. management capacity, ability to solve tensions, leadership, motivating staff).

\section{Network management processes and strategies}

Klijn and Teisman (1997) made a difference between two basic network management processes which can be considered as the most general ones:

- Game management: directed at a single issue, accepting the rules of the network (accepting the context);

- Network structuring: directed at setting the rules of the game (altering the context).

Similar to this one, Selden et al. (2006; cited by Herranz, 2010) identified two basic types of collaborative efforts:

- Systems change: these efforts are about altering the existing network structure, creating new linkages, and decreasing service fragmentation.

- Service change: these efforts are focusing on improving access, and providing more holistic service.

Rethemeyer and Hatmaker (2007) identified four perspectives about the task of network managers:

- political network management, directed at reaching goal consensus (or at least attain non-obstruction);

- implementation through collaboration;

- information processing and knowledge management to coordinate joint action;

- governance, based on the "idea that decision and implementation are not neatly divided" (ibid., p.631).

Concerning the latter, they propose that "network managers must have a perspective broader than their »home« network system[: n]etwork managers who focus myopically on their substantive network, ignoring the social, political, economic, and technological context within which their network operates, will fail." (ibid., p.640) Moreover, network 
managers must pursue their management functions not only in their home networks but adjacent ones as well.

Agranoff and McGuire (2001), based on a literature review, identified four network management processes:

- Activation/deactivation of members, directed at having the 'right' participants in the network.

- Framing the work of the network and particular games, directed at providing reasons for participation, defining roles, setting up principles, and creating 'network culture'.

- Mobilizing of organisational resources for a game or network, directed at enhancing commitment, ensuring participation as well as getting and sharing resources.

- Synthesizing conditions favourable for coproduction, directed at having 'proper' relationships among network participants, promoting information exchange, and building trust.

Herranz (2008 and 2010) focuses on various approaches to network coordination and identifies three types of strategic orientation, based on organisational control mechanisms identified by Ouchi (1979):

- Bureaucratically oriented strategy focuses on meeting legal and regulatory requirements. These networks are „characterized by tactics such as high degrees of formalized procedures involving written contracts, standardized information collection and reporting, and regularized services." (Herranz, 2010, p.316)

- Entrepreneurially oriented strategy focuses on maximizing financial revenue and innovation. Tactics used here include "high degrees of quid pro quo contracts and agreements, strategic data analysis, and contingent fee-based services." (ibid., p.316)

- Community-oriented strategy focuses on building collaborative capacity, with tactics like "high degrees of agreements and contracts based on social 
relationships, sense-making information, and personalized services." (ibid., p.316)

As Herranz (2010) noted, these three approaches do not only correspond with the organisational control mechanisms but also with underlying values of the government, for-profit, and non-profit organisations: they have different organising logics and performance expectations. It is suggested "neither that all three strategic orientations are necessarily associated with high performance nor that they are mutually exclusive." (ibid., p.326) He also added that "[t]he framework provides a guide for public managers to help them to consider and select which coordination strategies and tactics may be associated with improved network performance-and under what conditions." (ibid., p.328) However, these three orientations cannot be perceived as distinct ones in reality. As regards to bureaucratic/hierarchical and non-hierarchical coordination, Herranz (2010, pp.318-319) added:

"Indeed, many network studies tend to overemphasize the nonhierarchical structures and collaborative processes of interorganizational relationships, and underemphasize the hierarchical arrangements (e.g., contract relationships, bureaucratic red tape paperwork requirements, legal authority and sanctions, and political power dynamics) that characterize many interorganizational relationships that involve government agencies. [...]

Research also finds that government-supported networks that involve public and nonprofit agencies are more effective when they also include some bureaucratic attributes. Indeed, such networks are more likely to be effective when the formal control mechanisms of government are combined with the informal coordination mechanisms of interpersonal relational trust."

As regards to strategy types identified by Herranz, it must be noted that it might be worth redefining what entrepreneurially oriented strategy should label. Building on the original thoughts of Ouchi (1979), it is recommended to use this strategic orientation as one which focuses on setting performance expectations for outputs and outcomes (while a bureaucratically oriented strategy is directed at processes and a communityoriented one is at building collaborative culture). 
Benson (1975) identified four basic strategies network members may use in order to induce network change:

- Cooperative strategy: it might be the most frequently used strategy where changes are reached by joint planning and agreements. This strategy can be effective if each member has some degree of power and voluntary exchanges can create positive value for them.

- Disruptive strategy: change is enforced by threatening the resource-generating capacities of a target organisation, accomplished in one of three ways. Domain violations are more or less equivalent to entering the market of another company in business life. Fund diversions are focused on acquiring resources intended to 'normally' go to the other member. Program circumventions include actions which interfere with the activities and thus diminish the effectiveness of the target organisation. A disruptive strategy might be pursued when there is a substantial power imbalance among members, or resource channels are fragmented.

- Manipulative strategy: this strategy is analogous to regulation where change is motivated by altering the ways how resources flow to target organisations. This is how legislation, the executive offices and agencies govern networks. In order to be effective the network manager must have some autonomy in initiating, maintaining or terminating programs and network linkages (this kind of autonomy often comes together with decentralisation).

- Authoritative strategy: this strategy builds on the precise specification of linkages (relations) among network members. Rules are set up, or executive decisions are made to define resource sharing, contacts, referrals, and so on. While the manipulative strategy was using encouragement and motivators, authoritative strategy builds on the dominant position of the network manager thus it can only be effective if the manager has clear authority over financial and other resources.

According to the author, these strategies can be applied sequentially or in a combined way, too. 


\subsection{Managing network performance at multiple levels}

Except for the case of the smallest counties, almost all of the public services is organised in a more or less decentralised manner. The vertical dimension of public performance was defined in Chapter 2.2, and it must be indicated that several layers can add up the meso level. The issue of centralisation and decentralisation in the health care sector was also mentioned in Chapter 2.4. The multi-level nature of how public services are organised must be taken into consideration in further analysis of networks. Having various levels of governments is an inherent characteristics and tradition of federal states. As Isett et al. (2011, p.i167) noted, "networks can be found within and across the federal, state, and local levels." Agranoff and McGuire (2003, cited by McGuire, 2006, p.34) added that "[a]merican federalism, for example, is perhaps the most enduring model of collaborative problem resolution."

Higher levels (for example, health policy and regulation at country level) set the context for middle levels, by assigning tasks and responsibilities to meso-level organisations and their managers (ideally, together with the authority needed). Managers at meso-level organisations, in turn, set the context for local networks and/or individual public service organisations. Higher policy level managers not only have to face with the problem of how to influence what goals the lower level networks adopt (which determines potential outcomes and network effectiveness). Processes of networks can also be improved with the right regulations and toolsets so that the work of the meso-level network managers made easier (and the network becomes more effective). If Milward and Provan (2006) and Provan and Lemaire (2012) referred to "management in networks" and "management of networks", then these activities, profoundly belonging to policy formulation, could be called "management for networks". And if there are more than one layer of networks between the policy maker and the individual service provider organisations, network management tasks also multiply, and "management for network" type roles become more important. When this occurs, it is actually a sort of multi-level network management or multi-level network governance. It should be noted that this issue somewhat resembles the phenomenon of multi-level governance as used in the literature of international relations. Multi-level governance was originally 
and is primarily attributed to European Union and integration (see, for example, KohlerKoch-Rittberger, 2007). However, Bouckaert and Halligan (2008), as a consequence of what they call the performance governance regime, also referred to the need for "the largest possible depth of performance from micro, over meso to the macro level of government and society. Multi-level governance has a depth of performance that includes single organisations, their networks across jurisdictional boundaries, policy networks and consolidated government-wide or societal scopes". (ibid, p.187)

Meso-level networks in the health care system may take various forms: federal states, regions (either with public administration functions or created especially for health sector planning and management), insurance funds, or other bodies. These actors usually have a role in planning and financing health services in the area they manage, and they constantly look for ways to better coordination of services. What is important in the end is that health care providers must work in a coordinated way. Better interorganisational coordination of the individual health care providers plays a significant role (see, for example, Gittel-Weiss, 2004) in the application of the principle of collaborative management in the health care sector.

There is no clear answer for how much is needed from networks. But it seems that the solution to the problems of the health care sector must move beyond markets and hierarchies, as it was stated by Mintzberg and Glouberman (2001), naming collaborative networks as one of the possible answers. In their book about the US health care, Porter and Teisberg (2006) emphasised that the competition in the industry, with corresponding performance measurement, should be placed on outcomes. Expected results should be centred on patients, and not on costs and efficiencies of single health care providers. Performance measurement has been a long tradition in the NHS, too (Smith, 2005), where health regions as well as general practitioners and hospital trusts are often used as units of analysis. In a growing complexity and deeper specialisation in health care services it is an essential question who and how coordinates (various parts of) the system, and how the performance of (these parts of) the system can be measured. 


\section{Research aims and methodology}

\subsection{Research gaps and research interest}

The 4E(+T) performance model for public services (Bouckaert-Halligan, 2008) suggests that the span of performance could be measured differently at micro, meso, and macro levels but still in an integrated way. The ideal type of Performance Governance builds on direct involvement of a wide range of stakeholders in the society, including networks. The question of how networks fit into the model, how the micro, meso, and macro levels are connected when networks are present, has a wider area for research.

Studying public networks has become an important stream in public administration and public management research for a decade. The key concepts and key definitions seem to become more universally understood (O'Toole, 1997; Berry et al., 2004; Turrini et al., 2009; Isett et al., 2011; Provan-Lemair, 2012) but there is still a lot to do, primarily due to the high complexity of the problem. Policy (formation) networks and policy implementation (or service provision) networks have been separated for a while in the literature, complemented with governance networks, (Lecy et al., 2014), all having their own research streams and approaches (Berry et al., 2004).

Several authors called for research that joins the somewhat separate research traditions of policy networks and service provision networks; for example, as Rethemeyer and Hatmaker (2007, p.641) noted, "future research should attempt to link policy networks with collaborative networks [...]." These two levels are interdependent so the mechanisms how one effects the other should be defined. Isett et al. (2011) claims that public network studies cannot be easily generalised because they are specific to the policy area, country, or culture. Earlier, I introduced the model developed by Benson (1975) and further propagated by Hudson (2004). Hudson finishes his article by stating that "[w]hat is needed now is application of the framework to empirical explorations of specific problems and contexts." (ibid., p.92) Provan and Lemaire (2012, p.646) also proposes that "comparing multiple networks in a variety of settings with respect to key 
differences in such areas as governance, task, sector, and design" would be a desirable way for further research.

The research on health care provision networks, by using network analysis, is scarce. There is, for example, limited research on clinical networks from the UK (for example, Addicott et al., 2007; Ferlie et al., 2012) or on integration forms in the US (for example, Burns-Pauly, 2002; Strandberg-Larsen-Krasnik, 2009), or in Swedish local health care (Ahgren-Axelsson, 2005). The topic of cooperation and collaboration and networking appears under the title of integrated care in the health care management research (an overview is provided by Lyngs $\varnothing$ et al., 2014) but without referring to the tradition and results of network research in public administration and public management. Coordination mechanisms studied in the integrated care literature cover "referrals, guidelines, chains of care, health information technology systems, network managers, and pooled resources" (Lyngsø et al., 2014, p.4), somewhat similar to the transitional formats between market (referrals) and hierarchy (pooled resources).

My research interest lays in the intersection of these issues. Currently available theories do not adequately address how health care policy relates to organisational networks in the health care sector, how networks can be "better used" to improve performance, and how the performance of these networks could be measured. The application of network research, carried out by public administration and public management scholars, to describe and analyse health service provision is scarce. Thus, I defined my central research question as a broad one, to reflect these gaps in the current literature:

\section{How can we better understand what role networks play in the organisation of health care services, and how networks contribute to better performance of health care?}

This research interest in this field is further strengthened by the fact that organisation of health services is considered as highly problematic in Hungary. While technical efficiency of certain providers has improved (Dózsa, 2010), and health care expenditure, especially public expenditure, in relation to the GDP is considered as low in Hungary 
(Orosz, 2013), so that the Hungarian health care system is a relatively "cheap one", system-level efficiency is low. Both life expectancy and the number of healthy life years (HLY) are lower than it could be expected based on the average per capita PPP spending, meaning that, on average, other countries are able to produce "more health" by using the same level of financial resources. (OECD, 2011 and 2012) The health provision system is fragmented and full of dysfunctional patterns (Sinkó, 2009 and 2013). It is expected that better organisation of the Hungarian health provision network could contribute to better system-level performance.

The research was party descriptive, partly exploratory. To provide answers to the research question, concepts of the public performance management model $(4 E+T)$ and the public service provision network research were applied to Hungarian cases of policy interventions. The empirical research had no preliminary hypotheses but the research process was guided by such questions as:

- What policy goals and programme objectives can be identified that guide policy implementation?

- How the logic of performance measurement of implementation relates to policy expectations?

- Do networks and network-level performance indicators appear at meso levels?

- What types of networks can be identified during the implementation?

- How are these networks governed?

- What types of network management strategies can be identified?

The exploration process intended to contribute to the refinement of theories and models that describe the performance of public services and service provision networks. Since the research was carried out in the context of the Hungarian health sector, policy implications for the development of the Hungarian health care could be also given. 


\subsection{Methodology}

The research used a case study methodology. Case studies are effective tools when the research is still in the exploratory phase and theory building is on the agenda (Eisenhardt, 1989). According to Yin (2009), case study is an applicable research method if the field of research is broad enough and the context of the research object has significance, too. Herranz (2010, p.327) also holds case study as one of the "most common methods employed in examining organizational networks."

Considering the main research question, and the ambition to know more about the relation between policy level and service provision level performance, the unit of analysis is the policy intervention. Policy interventions may appear in several forms such as regulatory changes, budgetary changes, complex or specific reform programs, or development programs. Constructs (Eisenhardt, 1989) or propositions (Yin, 2009) that are used to describe cases had been a priori identified based on the review of performance management and network literature, covered in Chapters 2 and 3 . A list is provided in Table 1.

An embedded, multiple-case study design (Yin, 2009) was chosen. The common use of constructs was, of course, essential for the multiple case analysis, and every effort was made to describe the cases by using the same structure, but small variations, reflecting the context or the area of the specific policy intervention, are possible. Embedded units in the cases are twofold: primarily, policy, network, and organisational levels were distinguished, and secondarily, each policy intervention was applied to multiple service provision networks. First, the performance measurement model of the interventions were overviewed, based on Bouckaert and Halligan (2008), and then a network-based analysis was provided. The latter was largely built on the framework created by Benson $(1975,1982)$ and Hudson (2004), and previously tested in the Hungarian health care sector for the case of managed care organisations by Dankó et al. (2005). Different types of cases were selected in terms of network level (community level vs. regional level) and intervention aim (redefining roles in primary care vs. implementing IT to support cooperation mainly in secondary care). 


\begin{tabular}{|c|c|}
\hline & Constructs / propositions \\
\hline \multirow{6}{*}{ Performance management } & Social needs, policy goals, programme objectives \\
\hline & Macro, meso, micro levels \\
\hline & Input, output, outcome, effect, impact, results, trust \\
\hline & Economy, efficiency, effectiveness, equity, trust level \\
\hline & Measurement and indicators, level of integration, coherence \\
\hline & $\begin{array}{l}\text { Performance Administration, Managements of Performances, } \\
\text { Performance Management, Performance Governance }\end{array}$ \\
\hline \multirow{12}{*}{ Network performance } & National, regional, county, microregional levels \\
\hline & $\begin{array}{l}\text { Networks, network membership, network boundaries, network } \\
\text { lifecycle }\end{array}$ \\
\hline & Cooperation, collaboration, integration \\
\hline & Formal, informal networks \\
\hline & Mandated, emergent networks \\
\hline & $\begin{array}{l}\text { Shared governance, lead organisation, network administration } \\
\text { organisation }\end{array}$ \\
\hline & $\begin{array}{l}\text { Relationship between the service provision level and the policy } \\
\text { level }\end{array}$ \\
\hline & $\begin{array}{l}\text { Domain consensus, ideological consensus, positive evaluation } \\
\text { (trust), work coordination }\end{array}$ \\
\hline & $\begin{array}{l}\text { Fulfilment of program requirements, maintenance of social } \\
\text { importance, resources flows, application/defence of the } \\
\text { organisational paradigm }\end{array}$ \\
\hline & Cooperative, disruptive, manipulative, authoritative strategy \\
\hline & Activation/deactivation, framing, mobilising, synthetizing \\
\hline & Bureaucratically, entrepreneurially, community oriented strategy \\
\hline
\end{tabular}

Table 1. Constructs/propositions used for the case studies

The empirical research used two cases from the Hungarian health care sector. The first case describes a regional e-health development project. Between 2004 and 2008 integrated inter-organisational IT networks have been developed in three Hungarian regions in the framework of the development program financed by EU structural funds (Lukács, 2007). Beyond being an IT network itself, health information technology is interesting from the perspective of health provision because it has the potential to promote new ways of cooperation between organisations: "ICT also helps not only to blur organisational borders but also to create synergies beyond these borders." (West, 2005, cited by Bouckaert-Halligan, 2008, p.184) A tool that may change how organisations interact in a service provision network is an important subject of analysis. The regional implementation is also interesting in this case: when intercommunicability is key for IT networks, the role of regions is also worth researching. The relevance of studying this project is further increased by the fact that the Hungarian e-health 
programme has been lagging behind even since the end date of the regional projects, and most of the questions about system implementation are still relevant.

The second case describes a pilot project in primary care, supported by a grant from Switzerland through the Swiss Contribution (no: $\mathrm{SH} / 8 / 1$ ). Four general practitioner clusters were created. Each cluster consists of six general practices, and the district health visitors (community midwives) from "pre-existing" primary care providers, and a new staff with public health orientation: two public health professionals, a community nurse, a physiotherapist, a dietician, and a health psychologist. Community involvement is supported by Roma assistant health mediators. Team working or group practices are considered as new phenomena in the Hungarian health care, having individual practices all over the country. The project began the implementation of the GP cluster activities in the summer of 2013, and is expected to run till 2016. Data collected for the monitoring of the GP clusters and the preparation of the midterm review was used in this thesis.

Case studies used mixed methodology of document analysis, interviews, and quantitative analysis. Detailed methodology of how data was collected and used can be found in each case description in Chapters 5.1 and 5.2.

Case studies are always dependent on the context. From the point of view of public network research, the context includes both Hungary and the health care sector. As Isett et al. (2011, p.i164) noted that "[n]etworks are embedded in a specific policy context, and the behavior of network actors is defined by that context (Heikkila and Isett 2004). [...] Networks are thus shaped and constrained by institutional rules as well as regulatory procedures and norms that are specific to the policy arena." Therefore, generalisation of results will be limited as regards to other sectors, agencies, or countries. However, Isett et al. (2011, p.i167) add that "[i]nstead [of this], we need to be more attentive to the specificity of the processes and dynamics in those substantive areas and be clear about what aspects transfer to new contexts." Generalisation of the results is supported by using the terminology of public network management (instead of or parallel to health care management) as much as possible. 
The cross-case analysis was primarily used for theory building. The conclusions of the thesis mainly consist of theoretical implications (Chapter 6.1), but policy implications, specific to the Hungarian context, are also provided (Chapter 6.2). 


\section{Case studies}

\subsection{Case 1: regional e-health developments}

This case analyses the HEFOP 4.4.1 program. Between 2004 and 2008 health information system development projects were carried out in three Hungarian regions (out of the seven geographic regions in Hungary). In the scope of a single program (HEFOP 4.4.1) three regional projects were supported. The total amount of financial support was about 16 million euros, covered by EU funding. The project included the introduction of electronic health records in participating organisations as well as an inter-organisational communication system component with functionalities as follows: access to medical data in all the participating organisations, e-referrals and e-consultations, telemedicine in some areas, and patient authorisation. (Lukács, 2006)

The majority of the financial support was used for renewing organisational-level IT systems. The inter-organisational component gained much less attention, and several components where central support would have been needed was not implemented. A survey among patients that was carried out as part of the evaluation showed modest use of the system. (Megakom, 2008) This picture has not changed much since that time (and a currently running national e-health development program addresses the same issues). While the project contributed to use of modern health information systems in hospitals, it was a failure from the perspective of providing support for better interorganisational cooperation.

\section{Context}

E-health has been an issue for European countries for more than a decade. It made its wider scale appearance in an EU-level action plan in 2004. It was defined as "the application of information and communications technologies across the whole range of functions that affect the health sector." (EC, 2004:6) As for its effects on health care performance, the action plan noted that "eHealth systems and services can reduce costs and improve productivity" (ibid:6-7). While there were several advancements after 2004, the action plan was only partially carried out, and common (EU-wide) elements 
were especially lacking from the support of national implementations. In the latest EU level action plan, dated in 2012, the definition of e-health became more elaborated and included a more complex approach to performance expectations: "eHealth is the use of ICT in health products, services and processes combined with organisational change in healthcare systems and new skills, in order to improve health of citizens, efficiency and productivity in healthcare delivery, and the economic and social value of health. eHealth covers the interaction between patients and health-service providers, institution-toinstitution transmission of data, or peer-to-peer communication between patients and/or health professionals." (EC, 2012:3)

The EU level context is essential for the understanding of the Hungarian e-health developments because all these programs have been and are being financed from EU structural funds. For about a decade, it has been characteristic to the Hungarian health care development policy that it is highly dependent on EU financing. In several cases there are no distinct sectoral development policies, planning of sectoral developments is a subset of the national development policy. Although, there may be sectoral policies, for example, a health care strategy, with various policy goals and intervention areas but the financial sources they build the interventions on are predominantly EU funds.

Around this time, there were no national data handling and communication standards for organisational health information systems or inter-organisational networks. Only a few health care providers had integrated internal systems so that information could be shared inside the hospital. Information collection and flow was primarily governed by the financing rules and reports of the National Health Insurance Fund: what was need for getting reimbursement from the social insurance fund was collected and recorded by health care providers (and was developed by IT suppliers) but other areas of health information systems did not receive enough attention. There was no support for managing workflows or making clinical decisions. The hardware infrastructure was outdated in several places. (MITSESZ, 2003) Investment costs are normally not reimbursed by the health insurance fund but rather considered as a liability of the owner and operator of the hospital. That time, hospital owners were primarily local and county governments, with very limited funds available for buying infrastructure (including IT). 


\section{Data sources and data processing}

This case was written by using document analysis: publicly available government documents (plans and reviews) and journal articles were used. Since the project was carried out several years ago, and the implementation (and the not-too-high impact) did not differ a lot among the three participating regions, it was decided that desk research would adequately address the research aim. Not directly related to this research, but related to the evaluation of recent e-health developments in Hungary, I conducted three background interviews with key experts (NFÜ, 2013) which helped me in following the "after-life" of the HEFOP project.

Four policy documents were analysed in details: the framework strategy of health IT (MITSESZ, 2003), the Human Resources Development Operational Programme which described the EU-funded program (HEFOP, 2004), two midterm reviews (ExAnte, 2006; Megakom, 2008; the latter was actually finalised after the project close date). While all these documents cover a wider area than the subject of this case, the focus of data gathering was kept on those elements which were relevant to this program.

The following elements have been identified in texts:

- Social needs

- Policy goals, program objectives, and immediate objectives of this specific intervention

- Planned and actually used indicators:

- Indicators published in the situation analysis of the documents were not gathered because the focus of this case is on the implementation of a specific policy intervention, and not on policy formulation.

- Only those indicators were collected where a mode of measurement was defined, and most of the cases, the indicator had been or was planned to be measured. Indicators that were labelled in the texts as "potentially useful" but not actually used were not collected. 
- When the original categorisation in the texts was incompatible with the categories this thesis uses (e.g. output indicator was labelled as result), indicators were moved to the "right" category.

- Data about the implementation process of the projects

Goals and objectives as well as indicators were initially collected in a table in Hungarian language (which is the original language of these documents), except for the HEFOP (2004) document which was available in English. Similar constructs within the same document were grouped and "compressed" into shorter expressions which kept the meaning and the main message of the text but made it possible to present them in a shorter table.

In order to facilitate the networked-type analysis of the case, a short background paper was prepared about the dimensions of network performance, defined by Benson (1975, 1982) and Hudson (2004), applicable to e-health application - see Annex 7.2 where this background paper is reproduced.

\section{Policy goals and program objectives}

The framework strategy about health IT (MITSESZ, 2003) contained a chapter which directly addressed the question of what social needs are. I compacted these into four issues that are relevant to the policy action analysed:

- Collecting, processing and using data with respect to privacy - increase information sharing within the system and promote mobility

- Teamworking in order to promote effectiveness and cost-effectiveness

- Patients should be partners in decisions about what care they get

- Intersectoral approach is needed, need for holistic medicine

The policy goals as well as the objectives of the e-health program and this specific regional intervention were mapped based on the sectoral strategic documents; results are summarised in Table 2. 


\begin{tabular}{|c|c|c|c|c|}
\hline Document & Type & Main policy goals & Overall program objectives & Objectives of the intervention \\
\hline $\begin{array}{l}\text { Information } \\
\text { society strategy - } \\
\text { health care and } \\
\text { social services } \\
\text { (MITSESZ, 2003) }\end{array}$ & $\begin{array}{l}\text { framework } \\
\text { strategy }\end{array}$ & $\begin{array}{l}\text { Improve health status of the population } \\
\text { Improve access to care, decrease } \\
\text { geographical inequalities } \\
\text { Improve and standardise quality of care } \\
\text { Improve allocative and technical efficiency } \\
\text { (improve efficiency of providers and the } \\
\text { health care system) by using databases } \\
\text { Build "patient-friendly" environment, provide } \\
\text { more information and freedom of choice for } \\
\text { patients }\end{array}$ & $\begin{array}{l}\text { Develop e-health standards centrally (e.g. e- } \\
\text { prescription, EHR) } \\
\text { Provide secure identification services } \\
\text { Regulate data access and privacy } \\
\text { Build broadband internet access infrastructure } \\
\text { Develop organisational IT systems } \\
\text { Develop capacity for the use of telemedicine } \\
\text { Enhance the use of electronic documents }\end{array}$ & $\begin{array}{l}\text { Carry out regional e-health pilot projects in } \\
\text { order to build and disseminate best practice }\end{array}$ \\
\hline $\begin{array}{l}\text { IT strategy of the } \\
\text { National Health } \\
\text { Insurance Fund } \\
\text { (MITSESZ, 2003) }\end{array}$ & $\begin{array}{l}\text { organisational } \\
\text { strategy of a } \\
\text { central } \\
\text { agency }\end{array}$ & & $\begin{array}{l}\text { Standardised and integrated information flow helps } \\
\text { avoiding the cost of unnecessary diagnostic } \\
\text { procedures, and contributes to higher quality of } \\
\text { care. Standardization requires cooperation with } \\
\text { external parties as well. } \\
\text { Collection of reliable information provides } \\
\text { opportunities for feedback and benchmarking, and } \\
\text { in the long run will be available for citizens }\end{array}$ & $\begin{array}{l}\text { Accreditation of the financial reporting } \\
\text { modules of HIS } \\
\text { E-prescription }\end{array}$ \\
\hline $\begin{array}{l}\text { Human Resources } \\
\text { Development } \\
\text { Operational } \\
\text { Programme } \\
\text { (HEFOP, 2004) }\end{array}$ & $\begin{array}{l}\text { development } \\
\text { program }\end{array}$ & $\begin{array}{l}\text { More balanced regional development } \\
\text { Improve health status of the workforce } \\
\text { Improve access and quality of care in } \\
\text { deprived regions }\end{array}$ & & $\begin{array}{l}\text { To create health informatics infrastructure for } \\
\text { the fast and regional level availability of } \\
\text { health information } \\
\text { To improve IT conditions of institutional } \\
\text { management and to ensure cost effective } \\
\text { operation for the regional healthcare } \\
\text { institutions } \\
\text { To shorten patient pathways, thus enabling } \\
\text { faster recovery of working capacity }\end{array}$ \\
\hline
\end{tabular}

Table 2. Policy goals and programme objectives of the regional e-health developments 


\begin{tabular}{|c|c|c|c|c|c|c|c|c|c|}
\hline Document & Type & Input & Economy & Efficiency & Output & Effectiveness & Outcome/Effect/ Impact & Equity & Trust \\
\hline $\begin{array}{l}\text { Information society } \\
\text { strategy - health } \\
\text { care and social } \\
\text { services (MITSESZ, } \\
\text { 2003) }\end{array}$ & $\begin{array}{l}\text { framework } \\
\text { strategy }+ \\
\text { action plan } \\
(2003-06)\end{array}$ & & $\begin{array}{l}\text { IT expenditure per } \\
\text { total hospital } \\
\text { revenue }\end{array}$ & $\begin{array}{l}\text { Number of } \\
\text { procedural errors (- } \\
50 \%) \text { in } \\
\text { applications, better } \\
\text { applications (+10 } \\
\text { score) }\end{array}$ & $\begin{array}{l}\text { Number of users, visitors, } \\
\text { downloads on the central } \\
\text { health portal } \\
\text { Use of central code lists in } \\
\text { regional projects } \\
\text { Ratio of newly developed } \\
\text { applications using the } \\
\text { standards } \\
\text { Use of prototype e- } \\
\text { signature in regional } \\
\text { implementations }\end{array}$ & & $\begin{array}{l}\text { Completeness of central } \\
\text { standardised databases } \\
(90 \%) \\
\text { Rate of successful } \\
\text { projects }(50 \%) \\
\text { Public awareness of } \\
\text { health IT developments } \\
(25 \%)\end{array}$ & & \\
\hline $\begin{array}{l}\text { Human Resources } \\
\text { Development } \\
\text { Operational } \\
\text { Programme } \\
\text { (HEFOP, 2004) }\end{array}$ & $\begin{array}{l}\text { development } \\
\text { program }\end{array}$ & $\begin{array}{l}\text { Size of financial } \\
\text { support }\end{array}$ & & & $\begin{array}{l}\text { Number of end-users of the } \\
\text { IT services in health care } \\
(+3000) \\
\text { Number of IT workstations } \\
\text { at health service providers } \\
(+2550)\end{array}$ & $\begin{array}{l}\text { Average number of } \\
\text { treatment days/case (- } \\
5 \%)\end{array}$ & $\begin{array}{l}\text { Persons regaining their } \\
\text { working abilities as a } \\
\text { percentage of people in } \\
\text { need of rehabilitation } \\
(+7 \%)\end{array}$ & & \\
\hline $\begin{array}{l}\text { HRDOP midterm } \\
\text { review about } \\
\text { indicators (ExAnte, } \\
\text { 2006) }\end{array}$ & monitoring & & & & $\begin{array}{l}\text { Number of new IT } \\
\text { workstations } \\
\text { Number of upgraded IT } \\
\text { workstations }\end{array}$ & Average length of stay & $\begin{array}{l}\text { Number of user who can } \\
\text { access the inter- } \\
\text { organisational IT system }\end{array}$ & & \\
\hline $\begin{array}{l}\text { HRDOP midterm } \\
\text { review (Megakom, } \\
\text { 2008) }\end{array}$ & $\begin{array}{l}\text { monitoring, } \\
\text { ex post }\end{array}$ & \begin{tabular}{|l|} 
Project \\
expenditure \\
Annual \\
maintenance cost \\
of the IT system
\end{tabular} & & $\begin{array}{l}\text { Number of work } \\
\text { stations per project } \\
\text { expenditure }\end{array}$ & \begin{tabular}{|l|} 
Number of new IT \\
workstations \\
Number of upgraded IT \\
workstations
\end{tabular} & $\begin{array}{l}\text { Average length of stay } \\
(-5 \%)\end{array}$ & \begin{tabular}{|l|} 
Patient satisfaction \\
Use of the inter- \\
organisational IT system \\
Patients' awareness \\
about the system
\end{tabular} & $\begin{array}{l}\text { Location of } \\
\text { providers } \\
\text { connected to the IT } \\
\text { system } \\
\text { (urban/rural areas) }\end{array}$ & \\
\hline
\end{tabular}

Table 3. Indicators used for planning and monitoring the regional e-health developments 


\begin{tabular}{|c|c|c|c|c|c|c|c|c|}
\hline & Input & Economy & Efficiency & Output & Effectiveness & Outcome/Effect/ Impact & Equity & Trust \\
\hline Macro & & & & & & $\begin{array}{l}\text { Persons regaining their } \\
\text { working abilities as a } \\
\text { percentage of people in } \\
\text { need of rehabilitation }\end{array}$ & & \\
\hline Meso: policy & $\begin{array}{l}\text { Size of financial } \\
\text { support }\end{array}$ & & \begin{tabular}{|l} 
Number of \\
procedural errors in \\
applications, better \\
applications
\end{tabular} & $\begin{array}{l}\text { Number of users, visitors, } \\
\text { downloads on the central health } \\
\text { portal } \\
\text { Use of central code lists in } \\
\text { regional projects } \\
\text { Ratio of newly developed } \\
\text { applications using the standards } \\
\text { Use of prototype e-signature in } \\
\text { regional implementations }\end{array}$ & $\begin{array}{l}\text { Average length } \\
\text { of stay }\end{array}$ & $\begin{array}{l}\text { Completeness of central } \\
\text { standardised databases } \\
\text { Rate of successful projects } \\
\text { Public awareness of health } \\
\text { IT developments }\end{array}$ & & \\
\hline Meso: network & \begin{tabular}{|l|} 
Size of financial \\
support \\
Project expenditure \\
Annual maintenance \\
cost of the IT system
\end{tabular} & & $\begin{array}{l}\text { Number of work } \\
\text { stations per project } \\
\text { expenditure }\end{array}$ & $\begin{array}{l}\text { Number of end-users of the } \\
\text { inter-organisational IT services in } \\
\text { health care } \\
\text { Number of new IT workstations } \\
\text { Number of upgraded IT } \\
\text { workstations } \\
\text { Use of central code lists in } \\
\text { regional projects } \\
\text { Ratio of newly developed } \\
\text { applications using the standards } \\
\text { Use of prototype e-signature in } \\
\text { regional implementations }\end{array}$ & $\begin{array}{l}\text { Average length } \\
\text { of stay }\end{array}$ & $\begin{array}{l}\text { Patient satisfaction } \\
\text { Patients' awareness about } \\
\text { the system }\end{array}$ & $\begin{array}{l}\text { Location of } \\
\text { providers } \\
\text { connected to the IT } \\
\text { system } \\
\text { (urban/rural areas) }\end{array}$ & \\
\hline Micro & $\begin{array}{l}\text { Annual maintenance } \\
\text { cost of the IT system }\end{array}$ & $\begin{array}{l}\text { IT expenditure per } \\
\text { total hospital } \\
\text { revenue }\end{array}$ & $\begin{array}{l}\text { Average length of } \\
\text { stay }\end{array}$ & $\begin{array}{l}\text { Number of new IT workstations } \\
\text { Number of upgraded IT } \\
\text { workstations } \\
\text { Number of end-users of the IT } \\
\text { services in health care }\end{array}$ & & \begin{tabular}{|l|} 
Patient satisfaction \\
Patients' awareness about \\
the system
\end{tabular} & & \\
\hline
\end{tabular}

Table 4. Regional e-health development indicators, according to depth and span of performance

Indicators, actually used in midterm and ex post evaluations, are in italics 
The framework strategy contained a three-year-long action plan, too, with lots of planned central activities that would support the regional e-health implementations (e.g. standard developments, regulation of privacy law). Actions that were planned to be implemented at central level included developments of the National Health Insurance Fund Administration as well (for example, the new regional e-health systems must have been able to send the reimbursement claims to the fund administration, or e-prescriptions must have been recognised by pharmacies). Positive effect on performance was also expected from the health IT interventions: by using shared data more intensively, efficiency improvement was envisioned at both system and provider levels. However, the question of how much improvement would be attributed to ehealth (and how much to other factors) was not dealt with. The "user perspective" was addressed by the main goal of building a "patient-friendly" system. Selection of regions where the pilot program was planned was also governed by a high-level policy goal. Each development action was perceived as tool for deal with regional disparities and health inequalities, and that was the case with regional e-health developments as well, consequently the most deprived regions were chosen as places for implementation.

One could argue, based on international experience of "never ending" e-health projects, that the timeline for the proposed actions was not adequately planned, or financial sources allocated to the program objectives were limited. It seems that the high level goals and objectives were defined in a coherent way in the planning phase. The casual effects were not justified in all cases, for example, how exactly e-health contributes to health status improvement. This is typically the case when individual actions can hardly be connected to higher level social outcomes and impacts. It is not a problem when a policy document makes assumptions about cause-and-effect relationships (actually, this must be a central element of a policy), problems arise when this final outcome is tied to individual interventions during performance measurement.

The actors of the intervention at various levels could be defined as:

- Macro-level: government (various departments), and the committee on health care and social care IT strategy 
- Policy (meso) level: e-health program management office, health development management office, National Health Insurance Fund Administration

- Network (meso) level: the development projects and their members, and all those health providers in the regions who connect to the regional interorganisational IT system

- Micro level: health care providers (hospitals, outpatient care facilities, GPs, pharmacies and others)

\section{Performance measurement}

Indicators had been defined ex ante (MITSESZ, 2003; HEFOP, 2004), used during monitoring (ExAnte, 2006), and measured ex post (Megakom, 2008). The latter document, in its tile, is a "midterm review", however, it was completed after the end date of the projects so it should rather be considered as an ex post evaluation (although, naturally, long-term impacts cannot be measure right after project closure). The indicators are presented by source in Table 3 and by depth and span of performance in Table 4.

The sectoral framework strategy required using indicators for action planning, and it is also a requirement of EU funding that interventions must be supported by adequate indicator sets. The specialised performance measurement systems, thus, were in place during these two planning processes but were disconnected from general health care planning and other changes in the sector (in the $4 \mathrm{E}+\mathrm{T}$ model: environmental factors). A midterm review about the indicators (ExAnte, 2006) showed that beneficiaries were satisfied with the project indicators: it was about the number of IT workstations they purchased, the number of physicians accessing the system, and the change in average length of stay. The latter indicator got a little bit lower "satisfaction score" (3.46) than the others $(3,71 ; 3,81 ; 3,79)$ but was not deemed problematic that time. It was only the ex post evaluation (Megakom, 2008) that realised that some expected outcomes cannot be traced back to a specific policy action like this (for example, the average length of stay was not measured in the end). The situation of this indicator is also interesting because it is considered as efficiency measurement at the hospital level - but the 
original project proposal claimed that improved cooperation would lead to decrease of length of stay all over the network members.

Other elements were removed from (postponed in) the e-health program (e-signature, e-prescription) so they were removed from project objectives as well. Regulation was not modified to support original project objectives in several cases, for example, Király (2008, p.55) claimed that "should we wanted to comply all the data protection regulations, the system would not work at all".

As for the results, the health care providers of the consortia successfully modernised their IT infrastructure: as compared to the original project plans, 3243 new workstations were purchased instead of the expected 750 (while additional 1800 workstations were planned to upgrade, and in the end only 95 upgrades were made). Patient satisfaction and awareness of the IT system was measured later, but only in one location in each region. It showed a rather modest use of the inter-organisational features: only $15 \%$ of patients were asked to give authorisation for physicians to access their medical history, and only $2 \%$ had the experience of a physician accessing medical data from another provider in the region. (Megakom, 2008)

Subsequent expert evaluations could not show progress either: while the major HIS suppliers adopted the intra-organisational communication elements into their systems, no steps towards a nationwide introduction has been made so far. Király $(2010,2011)$ identified the main limiting factors as follows:

- Lack of financing of additional costs of operations: running the system requires additional resources from the participants while benefits are lower, especially in the beginning. It must be also noted that lots of benefits are external to providers, and social cost savings are not shared with them. A more beneficial cost/benefit sharing would require central coordination; a regional project was not able to provide this type of coordination. (Király, 2010)

- Communication protocols should be standardised and issues of liabilities should be regulated centrally. (Király, 2010) 
- Use of the system will not "spread" to new actors on its own, given the lack of financial support. (Király, 2011) Only a small part of GPs and around $82-85 \%$ of hospitals joined the networks in these regions. (Megakom, 2008)

During the planning period, it was expected that enrolling more and more providers will also contribute to the financial sustainability of the systems developed since more and more organisations will provide the budget for future maintenance. Since no major clinical benefits could have been realised by joining the system, it was not worth doing for external parties.

It can also be added that the three pilot projects were carried out in three of the four least developed regions of Hungary, and the use of ICT services is correlated with the level of regional development. From the point of view of "quick wins", the least developed regions might not have been the best places for highly innovative IT pilot projects. The next EU development cycle (2007-13) initially had plans for "rolling out" the regional systems but then decided to start a new national program (which should partly build on software elements of the HEFOP 4.4.1 program). This new program is in serious delay, with no apparent signs of progress.

What happened in the project was very rational at the organisational management level (at the level of the management cycle): it was an opportunity to modernise the IT infrastructure within hospitals and outpatient facilities. The policy cycle, however, failed to implement those changes that would have been required to provide adequate support for the regional networks in reach their objectives.

\section{Network performance}

When evaluating this policy intervention by using the network approach, (at least) two types of networks should be distinguished: the development networks (consisting of the project consortium members), and the regional health service provision networks (consisting of all the health care providers in the region). The three development networks are formal networks since the members are contractually tied to each other 
in the consortium in order to achieve the pre-defined project goal (and, possibly, to sustain the results even after the formal closing date of the project, however, the network itself may formally cease to exist). These organisations are also part of the three regional health provision networks, together with all those institutions and persons who provide health care services to the local population. These networks are rather considered as informal, there is no formal creation or end date of the network, and membership is not so easy to define: it is essentially the movement of patients and their health related information among these organisations which connects them. (Administrative boundaries of counties and regions might help in determining who the members are, but this may not be satisfactory in all cases. It might also be the case that there are actually more than three local networks could be defined.) The shared goal of this network is to improve the health status of patients and the community but "who should do what" is much less operationalised in this case.

In the case of the development network the evaluation of network performance focuses on how effectively the development project could be accomplished. Probably, a lot can be learnt from how the project management was set up, how members coordinated their activities and so on - thus the analysis of how the three projects differed, and what the effect of those differences was over network effectiveness is a valuable question for network management. But, taking the policy goal into consideration (namely, to enhance cooperation in order to improve the quality and efficiency of health care services as a whole), the service provision network must also be analysed. During this analysis the main question is how the regional implementation of the e-health systems changes the characteristics network members cooperate - and how the new means of cooperation improve health system level outcomes in the end. How these expected positive outcomes can be measured is another set of questions, with which health system measurement studies deal with. I do not go into details about this issue in this thesis but note that "average length of stay", which was selected as a main indicator in the project, may not be the best indicator for that purpose. (Actually, a much wider set of indicators should be used.) 
The development networks had a formal process for governance: they were led by a consortium leader (the biggest and most central health care providers in the respective regions) but also utilised common decision mechanisms. Thus the network governance type can be identified as a mixture of lead organisation type and shared governance type. One of the networks also contracted an external party for project management (somewhat resembling the network administration organisation type governance) which, according to the project evaluation (Megakom, 2008) had a positive impact on the implementation process. The health provision network, however, was selforganising, based on bilateral relationships between providers and physicians, and referring patients among them, without any formal governance mechanisms.

Network characteristics that may have had an influence over network performance were analysed by using the framework of Benson $(1975,1982)$ and Hudson $(2004)$.

There was domain consensus about the roles of network members in the development project: each organisation should develop its own IT systems, and a central player should deal with the inter-organisational issues. Actually, the three consortia joined up for the development of the inter-organisational elements, and commissioned this task from the same vendor (and the hardware, supporting this function, had also been placed in a single location, in Budapest; STRAPI, 2008). The domain consensus, however, is something very different for health care providers when providing medical services is in the focus. What role a hospital doctor or a general practitioner should play in the diagnostic and treatment processes of various patients, and thus what information and how should be shared and when should be accessed is not clear. This is problem is further enlarged by the lack of solid data protection regulation (see above).

The ideological consensus was also present in the development network, however, the whole problem was primarily perceived as an IT development problem, consequently, it was mainly IT experts from the various hospitals who worked together on the project, and the involvement of physicians and hospital management was limited. (Fehér, 2006) From the point view of users, physicians and patients, this whole problem is rather a 
problem of how to better support health service provision. A possibility to access information, stored at an other provider, is not so important when the patient is here, and earlier results are available on paper. Accessing information inside the hospital quickly, however, was something the physicians could relate to: they ordered a lab test, and could see the results on their computers.

The positive evaluation (or trust towards each other) was easier to attain during the development project. There might have been debates but the predetermined budget helped in deciding "who should get what". IT suppliers were also closely working together with providers. From a clinical perspective, however, trust is directed towards other members ("can I trust in the diagnosis/results of the others") or towards the system ("can I trust in getting all the relevant data"). Not all the hospitals in the regions joined the program (only $64-88 \%$ of hospital capacity), and only a few outpatient clinics and GPs.

The issue of work coordination was defined for the IT developers as information sharing and scheduling of provisions (booking appointments). For physicians, information must be made useful and valuable: they must be seamlessly integrated into work processes. For example, providing an opportunity to make a request about patient information data download is totally different from a system which provides automatic warning messages when a conflicting piece of data is detected at any other providers' database. Integration with GP systems was only partially carried out, so even if all GPs wanted to join the system, they had not been able to.

As for the policy network level factors, beneficiaries fulfilled the program requirements, at least in the short term: the budget was spent, the inter-organisational communication protocols had been created (however, they had not been made into official national standard but since practically all the hospital medical system suppliers incorporated these elements into their software, it became a "quasi-standard"; Király, 2011), and all the indicators that could have been measured in the short term were met (number of IT workstations and users). Defence of the organisational paradigm was also strong: the 
mutual interest of the central program management and the regional networks led in a direction of showing a "success story": they all showed satisfaction with the program in official communications. Actual usage data was not analysed, and reasons for low participation were not examined. As for the social importance of the project, important policy decisions were delayed or postponed (for example, about data protection and privacy regulation). This was also the time when a failed reform attempt to introduce a competitive social insurance model and implement visit fee put other health policy questions into the focus of the public and health policy makers. It was also demonstrated earlier that the maintenance of the resource flow was not guaranteed, only for the introductory development phase. Table 5 summarises the results of analysis about the network characteristics.

\begin{tabular}{|c|c|c|}
\hline & Development network & Health provision network \\
\hline Network type & formal & informal \\
\hline Network governance type & $\begin{array}{l}\text { shared governance / lead } \\
\text { organisation }\end{array}$ & self-organising \\
\hline $\begin{array}{l}\text { Time period (network } \\
\text { lifecycle) }\end{array}$ & definite & indefinite \\
\hline \multicolumn{3}{|c|}{ Service provision network - Operational relationships: } \\
\hline Domain consensus & $\begin{array}{l}\text { organisational IT systems are } \\
\text { modernised }\end{array}$ & $\begin{array}{l}\text { unclear roles of providers in the } \\
\text { wider health care system }\end{array}$ \\
\hline Ideological consensus & perceived as an IT problem & $\begin{array}{l}\text { perceived as a health care support } \\
\text { problem }\end{array}$ \\
\hline Positive evaluation & $\begin{array}{l}\text { determined budget makes resource } \\
\text { allocation easier }\end{array}$ & $\begin{array}{l}\text { the system is not complete, thus } \\
\text { cannot be trusted }\end{array}$ \\
\hline Work coordination & $\begin{array}{l}\text { create a possibility for inter- } \\
\text { organisational information sharing }\end{array}$ & $\begin{array}{l}\text { inter-organisational information } \\
\text { sharing was not made useful }\end{array}$ \\
\hline \multicolumn{3}{|c|}{ Policy network - Contextual influences: } \\
\hline $\begin{array}{l}\text { Fulfilment of program } \\
\text { requirements }\end{array}$ & \multicolumn{2}{|c|}{ short-term objectives are met } \\
\hline $\begin{array}{l}\text { Maintenance of a domain of } \\
\text { high social importance }\end{array}$ & \multicolumn{2}{|c|}{ policy-level decisions delayed } \\
\hline $\begin{array}{l}\text { Maintenance of resource } \\
\text { flows }\end{array}$ & \multicolumn{2}{|c|}{$\begin{array}{l}\text { only for the introductory phase, maintenance and extension was not } \\
\text { supported }\end{array}$} \\
\hline $\begin{array}{l}\text { Application/defence of the } \\
\text { organisational paradigm }\end{array}$ & \multicolumn{2}{|c|}{ short-term indicators indicate success } \\
\hline
\end{tabular}

Table 5. Network characteristics of the e-health developments

According to the categorisation of Benson (1975), the whole construct of the policy intervention tried to apply a cooperative network management strategy, hoping that, 
eventually, all the local players will reach the conclusion that it is worth joining the system so that a full scale integration will be attained. However, it can be suggested that the large number of potential parties involved and individualistic organisational interests would have required an authoritative strategy. Of course, in order to be effective from the point of view of the expected end results, good IT systems must be developed, with the interest of physicians, nursing staff, and patients kept in mind. A cooperative strategy, when taking all the stakeholders into consideration, can be advantageous in the innovative product development phase but not suitable for a wider scale implementation of a program that, in its nature, require the presence of all the providers.

According to the categorisation of Agranoff and McGuire (2001), the activation process did not work: in this case, the "right" participants of the network should have been all the providers in the area. This issue also prevented the process of synthesizing favourable conditions for coproduction. When using the typology of Herranz (2008, 2010), it seems that an entrepreneurially oriented network management strategy was chosen instead of a bureaucratically oriented one, which would have been more advantageous. It must be noted, however, that the network manager did not have this strategic option because it was ruled out by policy level choices about the program design.

\section{Case summary}

As regards to the mode of managing performance, the case provides an illustration for "Managements of Performances" state in the design of the framework, but with several shortcomings in implementation. It is clear that the policy level knows that "something should be done" with outcomes and results, and interventions should be planned in a way that shows their contributions to the expected end results, but the selection of indicators was not substantiated. With improvement in indicator selection it could be closer to the ideal of "Managements of Performances" but a better connection between policy and implementation would be needed to move beyond that stage. The question, however, arises: what can we learn from the network approach? 
First, about the question of forming regional networks. In some countries, the regional level may play an important role in e-health development. For example, Denmark, where health care services are organised on regional level, is considered as a pioneering country in e-health advancements. After having several HER projects carried out at county-level, and facing the problems of incompatibility between these systems, regions took a bigger role in implementation projects. (Bernstein et al., 2005) Burton et al. (2004) also called for "regional governance structures to encourage the exchange of clinical data". WHO recommendations about e-health strategy put emphasis on the regional level as well: "While eHealth strategies are primarily developed to deliver health benefits for countries, they can also be an important mechanism for facilitating cooperation at the regional level and driving investment in ICT infrastructure, research and development." (WHO, 2012:31) Since cooperation among health care providers is more frequent (and more needed) inside the regions, creating regional development networks seems a logic idea.

However, there are some prerequisites for regionally formed networks to be effective. There are a few tasks that the policy must do, and networks cannot replace the policy level in this role (for example, standardization of communication protocols, or regulatory steps). When the number of network members is high, an adequate network governance structure is also needed. The shared governance / lead organisation mixed model could work in the case of the development project but proved to be unsuccessful during the attempts of expansion. Probably, a network administration organisation model and an authoritative strategy would have been needed.

If there is no powerful enough player in a region (either an organisation which is dominant so that able to implement the lead organisation network model, or a network administration organisation) to induce network-level changes, then the regional network will not be effective. This result is also supported by the findings of Tótth (2008) who analysed the role of regional health boards, and found that they did not have the capacity to carry out their regional planning and capacity management tasks. The model 
of the health boards was also built on a cooperative network governance idea with some 50-100 representatives of the local providers and local stakeholders.

It was also demonstrated that making an inter-organisational system component available for physicians, will not automatically lead to the use of the system. McClellan et al. (2013) described organisational factors that impeded individual physicians in using health information technology after adoption by the organisation. Inter-organisational components can be a case when the usefulness of the technological innovation is even harder to prove for physicians, and well-integrated software solutions are needed. The authors also claimed that financial incentives only work for organisational level adaptation but not for physician level use.

When a policy intervention involves development projects, it is worth differentiating between at least two different types of networks: one that implements the project, and the other which represents the local public service provision network. Both the policylevel program management and the project management will be "success-oriented" in terms of indicators used for measuring project performance, leading to the predominance of easily reachable output indicators. Meanwhile, it would be important to define success criteria and performance indicators for a wider span of performance but it would also be important not to tie these indicators to the performance evaluation of the project. Outcomes and results, and thus effectiveness, are often an accountability of the policy level. One set of indicators should describe what we want to achieve with the projects, and an other set should describe how the policy envisions the changes of the service provision network. It is also essential to have better knowledge about how the service provision network operates in reality, and involve the stakeholders/users into defining the requirements of the development project. 


\subsection{Case 2: GP clusters}

This case analyses the GP cluster pilot program. ${ }^{1}$ It is a pilot program, titled "Public Health Focused Model Programme for Organising Primary Care Services Backed by a Virtual Care Service Centre", and aims to contribute to the Hungarian primary care reform by building cooperation among GPs as well as providing additional public health capacities for local communities. The total funding is 130 million CHF from the Swiss Contribution. The project is carried out by a consortium: the members are the National Primary Care Institute, the National Institute for Quality and Organizational Development in Healthcare and Medicines, the National Health Insurance Fund, representatives of the physicians' and district health visitors' associations, and the Hungarian medical university faculties. The project has been running from 2012, with beginning the "field operations" in 2013.

Four locations were selected in deprived microregions where $30 \%$ of the community are of Roma ethnicity. The model is "based on the acceptance of the Health 2020 concept that the primary care system, in addition to traditional patient care services, should focus on health promotion, disease prevention and health restoration within the affected community, as well as on the effective rehabilitation of chronically ill individuals." (Ádány et al., 2003, p.529) Each GP cluster consists of 6 general practices, and the district health visitors (community midwives) from pre-existing primary care providers, and a staff with new roles: two public health professionals, a community nurse, a physiotherapist, a dietician, and a health psychologist. Community involvement is supported by two Roma assistant health mediators per GP (twelve assistants per GP cluster). Additional services provided by the GP clusters were planned to include health status assessment, medical risk assessments, lifestyle counselling, chronic care and rehabilitation as well as health promotion activities in the local community. (Sándor et al., 2013; OALI, 2013)

\footnotetext{
${ }^{1}$ Funding: The project is supported by a grant from Switzerland through the Swiss Contribution (no:
} $\mathrm{SH} / 8 / 1)$ 


\section{Context}

Health status of the Hungarian population is much worse than the economic development of the country would justify. Life expectancy and healthy life years (HLY) were 3-5 years below the EU27 average. According to an OECD Working Paper prepared by Eris (2012, p.2), "the health status of the Hungarian population is among the poorest in the OECD, including countries with a similar level of income per capita. While this outcome has been driven by the socioeconomic status of the population and lifestyle risks, it also reflects the relatively limited effectiveness of the health care system, for which relatively low levels of resources have been available[.]" Low level of resources is especially true for the case of public health initiatives: the state budget had been allocating less and less financing for public health programs, reaching only $1.2 \mathrm{~m}$ EUR in 2010, according to NEFMI (2011, p.100).

Under the former state-socialist model health care institutions received a fixed annual budget, adjusted by a certain percentage each year, or negotiated otherwise. The budget was not linked to performance but to input norms and individual political bargaining power. The reforms of the 1990's brought significant changes: patient capitation financing was introduced for GP services; fee-for-service system for outpatient care; a DRG-based system for acute in-patient care; and day-fee for chronic care, with a transformation period (Orosz, 1998; Gaál, 2004). Although the new financing system was intended to be more performance-related, both the efficiency and the effectiveness of the health care system have been rather disappointing ever since. Due to the pressure of the financing system, technical efficiency of health care providers improved in general, however, rather unequally (Dózsa, 2010). While certain individual organisations perform well, system level performance is lagging behind. " $[T]$ he health care system is generating significant health care outputs, such as doctor's consultations and hospital discharges, problems with the quality of health services and the need to reallocate resources where they would contribute most to health outcomes suggest a need for reforms." (Eris, 2012, p.2) 
According to the health care strategy (NEFMI, 2011), primary care should be one area of reforms. (It must be noted, however, that the health care strategy basically labelled all areas of the health system as being in need for reform.) The primary care is characterised by individual general practices where a GP typically employs a nurse (bigger practices also employ a second assistant but this is rare). Providing primary care is a legal obligation of the local governments, however, the vast majority of GPs works as an entrepreneur and has a direct contract with the National Health Insurance Fund. In principle, people are free to choose their own GP but the availability may be limited, especially in rural areas. Most GPs has a geographic territory assigned to the practice, meaning that the GP must accept all patients from that territory. This also comes with a concession: new GPs can buy a concession from retired GPs so the concession can be valuable - but there are certain (rural, deprived) areas in the country where general practices are not lucrative at all. The age structure of GPs indicates that an increasing number of practices will be left without a physician during the next decade.

While outpatient care providers and hospitals were motivated to increase volume of services due to the financing mechanisms, the capitation-based payment had an adverse effect on primary care. "The capitation-based financing of general practices without severely considering performance indicators results in that the GPs financially motivated to maximize the size of the practice and to minimize activities." (Ádány et al., 2003, p.529) It does not necessarily mean that GPs do not work a lot: there are lots of cases when patients visit them for administrative purposes (e.g. to renew a prescription), and several GPs also work for other providers beyond their normal office hours (for example, at policlinics). The Health Insurance Fund has been operating a quality indicator system for general practices since 2009, and pays bonuses to GPs based on their results (representing a few percentages of the average income of a general practice).

\section{Data sources and data processing}

This case was written by using document analysis, semi-structured interviews, and statistical data analysis. To map the formal performance measurement system of the project and the primary care system, the health care strategy (NEFMI, 2011), the 
relevant project documents (OALI, 2013, 2014, 2014b), and the quality indicator system of the health insurance fund (OEP, 2014) was analysed. The following elements have been identified in texts:

- Policy goals, and program objectives

- Planned and actually used indicators:

- Indicators used by the health insurance fund in the case of all GPs (having adult patients)

- Indicators listed in the Log Frame Matrix of the operations manual

- Indicators used in the midterm review for reviewing the performance of GPs and GP clusters, in comparison with "non-clustered" GPs

Goals and objectives as well as indicators were initially collected in a table in Hungarian language (which is the original language of these documents), except for the operation manual (OALI, 2013) document which was available in English. Similar constructs within the same document were grouped and the final text was shortened, keeping the original meaning.

In order to understand how GP clusters actually operate, and what the relationships among cluster members look like, a qualitative analysis was carried out. The qualitative research consisted of three elements:

- Site visits at all the four locations, conducted between February and April, 2014.

- 64 semi-structured interviews with cluster members on sites, covering all the head GPs and public health coordinators (two coordinator in each cluster), all the "new" professional staff, several GPs, district health visitors, and assistant health mediators (for a detailed description, see Table 6).

- Reading staff reports from March, 2014 to September, 2014, monthly sent to the central project management team (the project management team had already compiled summary reports each month).

The team, carrying out the site visits and preparing the interviews, consisted of five members (Dózsa Csaba, Kiss Norbert, Kuntár Ágnes, Sinkó Eszter, Wéber András). 


\begin{tabular}{|l|c|c|c|c|c|c|}
\hline GP cluster & Head GP & $\begin{array}{c}\text { Public health } \\
\text { coordinator }\end{array}$ & $\begin{array}{c}\text { General } \\
\text { practitioner }\end{array}$ & Practice nurse & Dietician & Physiotherapist \\
\hline Heves & 1 & 1 & 4 & 2 & 1 & 1 \\
\hline Jászapáti & 1 & 1 & 2 & 2 & $-*$ & 1 \\
\hline Borsodnádasd & 1 & 1 & 1 & 2 & 1 & 1 \\
\hline Berettyóújfalu & 1 & 1 & 2 & 2 & $-*$ & 1 \\
\hline
\end{tabular}

\begin{tabular}{|l|c|c|c|c|c|}
\hline GP cluster & $\begin{array}{c}\text { Health } \\
\text { psychologist }\end{array}$ & $\begin{array}{c}\text { Public health } \\
\text { expert }\end{array}$ & $\begin{array}{c}\text { Community } \\
\text { nurse }\end{array}$ & $\begin{array}{c}\text { Assistant } \\
\text { health } \\
\text { mediator }\end{array}$ & $\begin{array}{c}\text { District/school } \\
\text { health visitor }\end{array}$ \\
\hline Heves & 1 & 1 & 1 & 4 & 4 \\
\hline Jászapáti & 1 & 1 & 1 & 6 & 0 \\
\hline Borsodnádasd & 1 & 1 & 1 & 2 & 1 \\
\hline Berettyóújfalu & 1 & 1 & 1 & 2 & 2 \\
\hline
\end{tabular}

* The position was not filled in at the time of site visits.

Table 6. Interviews with GP cluster members

The semi-structured interviews have covered the following areas (OALI, 2014):

- Work activities carried out by each member ("what do they actually do")

- Mapping internal communication and coordination in the GPs practice clusters (e.g. "communication network", the role of meetings)

- How the new staff members change/complement the work of the GPs

- Perceptions about managing and coordinating roles in the model

- What the cluster members think about the role of GP in the Hungarian health care system

- Perceptions about the patient-provider relation (patients' inclusion into therapy choice, factors influencing patients' compliance)

- Use of IT solutions

- Evaluation of project trainings

- Personal motivation to participate in the model

- Perceptions about key success factors of the pilot model

Interview questions were modified after each visit as dictated by the feedback received. The interviews were also used for getting feedback about the development of a planned online survey (to be used in the future). 
The researchers took written notes of the interviews (no record was made). Interviews at the first site visited were conducted by two researchers per interviewee, but later, due to resource constraints, one researcher per interview was assigned. The notes were summarised in a structured matrix (topic / interviewee), and then one structured table was created about each cluster (the table was structured by topics). Statements in the four tables were verified by all the researchers. Anonymity was granted for the interviewees so that feedback from the cluster coordinators was only asked for the summary tables. Further evaluation work, for the purposes of contributing to the midterm review of the project (OALI, 2014), was done by using the summary tables. For the purposes of this research, statements from the midterm review were partly used, but the summary tables were also reprocessed where needed. Although evaluative statements have also been made for the midterm review (OALI, 2014), the material was considered as suitable for the purposes of this research, too: namely, to explore what characteristics the GP clusters bear as service provision networks.

Statistical data was also collected from the project reports and from the database of the National Health Insurance Fund. Data from the health insurance fund also contained information about a control group (158 individual GPs, randomly selected, but representing the Hungarian population by sex and age). Project activities "in the field" started in August, 2013, but data was acquired from January, 2013. Changes in indicator values, compared to historical GP cluster data as well as to total changes in the control group were quantified. In the case of those indicators which were included in the log frame matrix of the project changes were also compared with target value. All the analyses were prepared by the author of this thesis.

It must be emphasised that this research primarily looked at statistical data as elements of a performance measurement system used during a policy intervention, and, at least at this early point of the project implementation, did not make an attempt to use the statistical data as explanatory or dependent variables to test hypotheses. In particular, no attempt was made to find statistically justifiable relations between certain network characteristics, registered in a number of the four GP clusters, and results of 
performance indicators. Nevertheless, it was hoped that exploration of the situation would provide some initial insights for the research programme of the second half of the project. It was registered, however, based on the overall picture of the performance indicators (see Annex 7.3), that no univocal trend of performance improvement could be found in any of the four GP clusters - see further details in the analysis.

\section{Policy goals and program objectives}

The policy goals are defined in the overall health care strategy, published in 2011 , just before beginning of the detailed planning of the GP cluster project (the feasibility study of the project is dated at November, 2011). The strategy calls for a stronger role of primary care, and considers GPs and their improved gatekeeper function as a desirable outcome of reforms. The policy also calls for a higher level cooperation among the primary care and social care as well as other local stakeholders, thus proposes an integrated care approach (with a stronger focus on public health and prevention). Potential organisational formats, at least for the "health-related part" of the integrated care approach, are also named but no further details are given about the preferred format. This is consistent with the approach of using a pilot project to know more about the effects of the proposed policy.

The program objectives, defined for the pilot project, build on the policy goals to a great extent, however, two further elements were added:

- Greater emphasis was put on reducing health inequalities and promoting social inclusion, so that deprived areas with a higher share of Roma population were suggested to be chosen as intervention areas.

- A strong IT component was included to provide support for the collaboration of the GP cluster members.

The policy goals and the pilot project objectives are summarised in Table 7. 


\begin{tabular}{|c|c|c|c|}
\hline Document & Type & Main policy goals & Objectives of the policy intervention \\
\hline $\begin{array}{l}\text { Semmelweis } \\
\text { Health Care } \\
\text { Strategy } \\
\text { (NEFMI, } \\
\text { 2011) }\end{array}$ & $\begin{array}{l}\text { health } \\
\text { care } \\
\text { strategy }\end{array}$ & $\begin{array}{l}\text { Increase the ratio of definitive care provided by } \\
\text { GPs and encourage active involvement in } \\
\text { prevention and health education - develop } \\
\text { capacity and strengthen motivation } \\
\text { Motivate higher-level local cooperation of } \\
\text { providers by forming group practices (GP } \\
\text { clusters), or primary care centres, and build } \\
\text { integrated services, including heath visitors } \\
\text { (midwives), home care, hospice, and social } \\
\text { care, provided by local governments, civil and } \\
\text { religious organisations } \\
\text { Involvement of public health experts, } \\
\text { psychologists, and mental health experts in } \\
\text { primary care } \\
\text { Decrease administrative burden, and provide } \\
\text { support for buying up-to-date equipment } \\
\text { To implement the public health programme, } \\
\text { build partnership with society: involve local } \\
\text { governments, private sector, civil organisations, } \\
\text { and citizens }\end{array}$ & \\
\hline $\begin{array}{l}\text { Pilot project } \\
\text { description } \\
\text { (OALI, } \\
\text { 2014b) }\end{array}$ & $\begin{array}{l}\text { project } \\
\text { brief }\end{array}$ & & $\begin{array}{l}\text { To improve the health status of the population by } \\
\text { the reorientation of GP primary care: promote } \\
\text { prevention services and equity in access (expected } \\
\text { impact) } \\
\text { To develop and test a new, community-oriented } \\
\text { primary care model by focusing on prevention and } \\
\text { chronic care, and involving local communities, } \\
\text { especially the Roma minority } \\
\text { To cooperate with local governments, minority } \\
\text { representatives, local health and social care } \\
\text { providers, and medical faculties } \\
\text { To implement IT support for the activities, } \\
\text { promoting better cooperation } \\
\text { To formulate recommendations for national health } \\
\text { policy }\end{array}$ \\
\hline
\end{tabular}

Table 7. Policy goals and programme objectives related to the GP cluster pilot project

The actors of the intervention at various levels could be defined as:

- Macro-level: government (various departments)

- Policy (meso) level: program management office (located at the two participating national institutes), participating association representatives, and university experts

- Network (meso) level: GP clusters

- Micro level: GPs, district health visitors, local staff members (plus possibly other local stakeholders, affected by the GP clusters, like local governments, pharmacies, home care providers, social care providers, schools etc.)

It must be underlined that the analysis of the project organisation (as a meso-level network) is not part of the research. Of course, questions could be raised concerning 
how the development project worked as a network - but my research interest lays in the study of health service provision networks, thus I focus my attention on the GP clusters. (This situation is different from the first case in which the consortium members of the regional projects were health service providers.)

\section{Performance measurement}

The indicators collected are presented by source in Table 8 and by depth and span of performance in Table 9. The framework for the performance measurement of primary care is set by the National Health Insurance Fund and its quality indicator set (OEP, 2014). Its content is attacked from time to time by the physician organisations or other experts (ÁSZ, 2011) but it has been part of the primary care financing system since 2009, and its further development is planned. (Actually, one of the expected outputs of the GP cluster project is to contribute to the refinement of the quality indicator system.) The central part of the indicator set consists of indicators that measure the quality of care processes of several chronic conditions. These indicators are considered as process indicators in the health care (according to the most frequently used categorisation by Donabedian, 1988, who distinguished structure, process, and outcome indicators), but the public service performance model would rather categorise them as outcomes. It would be so because good quality care depends on secondary care providers, pharmacies, or the social support system so it is not a direct outcome of the GP activities (although, a GP has a considerably significant influence over it). For example, annual eye care exam of diabetic patients becomes more problematic when there is a long waiting list at the eye care clinic.

The log frame matrix of the project (OALI, 2003) consists of two types of indicators: one set measures the development activities of the project (e.g. papers and protocols are produced, and used in policy making later), and the other measures the performance of the GP clusters. Beyond a few project-related indicators (stakeholder involvement, IT system use), several indicators are selected from those that are regularly used to measure GP activities (including those that are part of the national quality indicator 
system). The midterm review (OALI, 2014) used the Primary Care Monitor Framework (Kringos et al., 2010), after adaptation to the GP clusters (Dózsa et al., 2014).

The PCMonitor follows the "structure-processes-outcomes" logic, and was originally formulated to serve as a tool for international comparisons of primary care systems. It was chosen as a base for performance evaluation of the GP clusters because its dimensions covered all the relevant areas: organisational issues, financial and human resources, operating processes, as well as outcomes. (Pay-for-performance schemes or quality standards tend to focus on certain elements of the "whole performance".) Naturally, the dimensions had to be adapted to the level of GP clusters. See in Figure 10 what areas of GP cluster operations were covered by each dimension. This structure was used for midterm review reporting (OALI, 2014). Several dimensions of the model (for example, governance) was not measured by using indicators but rather was described qualitatively. In several other dimensions the monitoring system has not reached the status of full development, yet. Experience from the project, however, is not described by these dimensions in this thesis - but rather the constructs of the network literature are used.

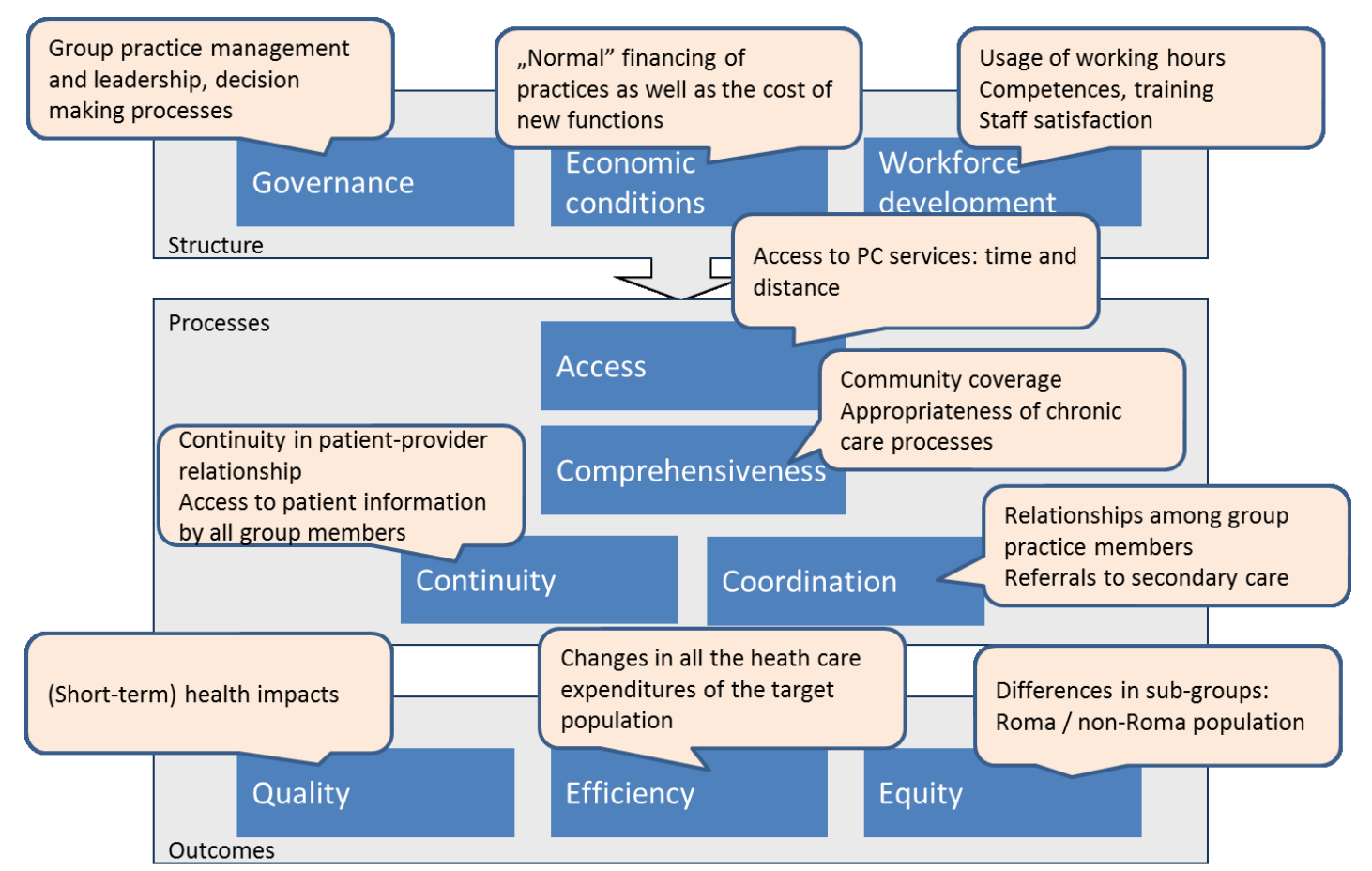

Figure 10. The adaptation of the primary care monitoring system (PCMonitor) to GP clusters (Dózsa et al., 2014, based on Kringos et al., 2010) 


\begin{tabular}{|c|c|c|c|c|c|c|c|c|c|}
\hline Document & Type & Input & Economy & Efficiency & Output & Effectiveness & Outcome/Effect/ Impact & Equity & Trust \\
\hline $\begin{array}{l}\text { Quality indicators of } \\
\text { the National Health } \\
\text { Insurance Fund (OEP, } \\
\text { 2014) }\end{array}$ & $\begin{array}{l}\text { national } \\
\text { quality } \\
\text { indicator } \\
\text { set }\end{array}$ & $\begin{array}{l}\text { Expenditure on } \\
\text { quality indicator } \\
\text { based GP bonuses }\end{array}$ & & $\begin{array}{l}\text { Hypertension } \\
\text { detection rate } \\
\text { Use of antibiotics } \\
\text { Average daily cost of } \\
\text { pharmaceutical } \\
\text { therapy }\end{array}$ & Flu vaccination rate & $\begin{array}{l}\text { Secondary care } \\
\text { utilisation rate }\end{array}$ & $\begin{array}{l}\text { Mammography screening } \\
\text { participation rate } \\
\text { Heart attack aftercare quality } \\
\text { Hypertension care quality } \\
\text { Diabetes care quality } \\
\text { COPD care quality }\end{array}$ & & \\
\hline $\begin{array}{l}\text { Operations manual of } \\
\text { the project - } \\
\text { LogFrame matrix } \\
\text { (OALI, 2013) - project } \\
\text { implementation } \\
\text { indicators }\end{array}$ & $\begin{array}{l}\text { project } \\
\text { document }\end{array}$ & $\begin{array}{l}\text { Expenditures for } \\
\text { project management, } \\
\text { methodology } \\
\text { development, IT, } \\
\text { training, research, } \\
\text { analysis, and project } \\
\text { communication }\end{array}$ & & & $\begin{array}{l}\text { Number of methodologies, } \\
\text { protocols, studies, reports, } \\
\text { training materials produced } \\
\text { Number of people trained } \\
\text { IT application developed }\end{array}$ & $\begin{array}{l}\text { Use of } \\
\text { recommendations in } \\
\text { policy making and } \\
\text { education }\end{array}$ & & $\begin{array}{l}\text { Stakeholders' (Roma } \\
\text { representatives') } \\
\text { participation in } \\
\text { decision making }\end{array}$ & \\
\hline $\begin{array}{l}\text { Operations manual of } \\
\text { the project - } \\
\text { LogFrame matrix } \\
\text { (OALI, 2013) - health } \\
\text { provision indicators }\end{array}$ & $\begin{array}{l}\text { project } \\
\text { document }\end{array}$ & $\begin{array}{l}\text { Expenditures for GP } \\
\text { cluster operations, } \\
\text { and on special } \\
\text { programmes for } \\
\text { Roma communities }\end{array}$ & & $\begin{array}{l}\text { Ratio of definitive } \\
\text { care }\end{array}$ & $\begin{array}{l}\text { Number of people accessing } \\
\text { additional services } \\
\text { Number and rate of client- } \\
\text { health care professional } \\
\text { visits } \\
\text { Use of IT application }\end{array}$ & $\begin{array}{l}\text { Improvement of data } \\
\text { collection for chronic } \\
\text { care/disease } \\
\text { management }\end{array}$ & $\begin{array}{l}\text { Heart attack aftercare quality } \\
\text { Hypertension care quality } \\
\text { Diabetes care quality } \\
\text { Organised screening } \\
\text { participation rate } \\
\text { The knowledge, attitude and } \\
\text { behaviour of the population } \\
\text { related to the services } \\
\text { Life style (tobacco, alcohol } \\
\text { etc.) related morbidity }\end{array}$ & $\begin{array}{l}\text { Stakeholders' (Roma } \\
\text { representatives') } \\
\text { participation in } \\
\text { decision making } \\
\text { Number and rate of } \\
\text { client- health care } \\
\text { professional visits in } \\
\text { Roma population }\end{array}$ & \\
\hline $\begin{array}{l}\text { Midterm review of } \\
\text { the project (OALI, } \\
\text { 2014) - health } \\
\text { provision indicators }\end{array}$ & $\begin{array}{l}\text { project } \\
\text { document }\end{array}$ & \begin{tabular}{|l|} 
Average costs of GP \\
clusters \\
Number of enrolled \\
patients \\
Staff turnover
\end{tabular} & & $\begin{array}{l}\text { Average number of } \\
\text { clients per session } \\
\text { Ratio of definitive } \\
\text { care }\end{array}$ & $\begin{array}{l}\text { Number and rate of } \\
\text { participation in health } \\
\text { status assessments } \\
\text { Number of client- GP visits } \\
\text { Number of client- health } \\
\text { care professional visits }\end{array}$ & & $\begin{array}{l}\text { Heart attack aftercare quality } \\
\text { Hypertension care quality } \\
\text { Diabetes care quality } \\
\text { Organised screening } \\
\text { participation rate }\end{array}$ & & \\
\hline
\end{tabular}

Table 8. Indicators used for monitoring the GPs nationally and the GP cluster pilot project 


\begin{tabular}{|c|c|c|c|c|c|c|c|c|}
\hline & Input & Economy & Efficiency & Output & Effectiveness & Outcome/Effect/ Impact & Equity & Trust \\
\hline Macro & & & & & & $\begin{array}{l}\text { Life style (tobacco, alcohol etc.) } \\
\text { related morbidity }\end{array}$ & & \\
\hline Meso: policy & $\begin{array}{l}\text { Expenditure on quality } \\
\text { indicator based GP } \\
\text { bonuses }\end{array}$ & & \begin{tabular}{|l|} 
Hypertension \\
detection rate \\
Use of antibiotics \\
Average daily cost \\
of pharmaceutical \\
therapy \\
\end{tabular} & Flu vaccination rate & $\begin{array}{l}\text { Secondary care } \\
\text { utilisation rate }\end{array}$ & \begin{tabular}{|l|} 
Mammography screening \\
participation rate \\
Heart attack aftercare quality \\
Hypertension care quality \\
Diabetes care quality \\
COPD care quality \\
\end{tabular} & & \\
\hline Meso: project & $\begin{array}{l}\text { Expenditures for } \\
\text { project management, } \\
\text { methodology } \\
\text { development, IT, } \\
\text { training, research, } \\
\text { analysis, and project } \\
\text { communication }\end{array}$ & & & $\begin{array}{l}\text { Number of methodologies, } \\
\text { protocols, studies, reports, } \\
\text { training materials produced } \\
\text { Number of people trained } \\
\text { IT application developed }\end{array}$ & $\begin{array}{l}\text { Use of } \\
\text { recommendations in } \\
\text { policy making and } \\
\text { education }\end{array}$ & & $\begin{array}{l}\text { Stakeholders' (Roma } \\
\text { representatives') } \\
\text { participation in } \\
\text { decision making }\end{array}$ & \\
\hline Meso: network & $\begin{array}{l}\text { Expenditures for GP } \\
\text { cluster operations, } \\
\text { and on special } \\
\text { programmes for Roma } \\
\text { communities } \\
\text { Average costs of GP } \\
\text { clusters } \\
\text { Number of enrolled } \\
\text { patients } \\
\text { Staff turnover }\end{array}$ & & \begin{tabular}{|l|} 
Ratio of definitive \\
care \\
Average number of \\
clients per session
\end{tabular} & $\begin{array}{l}\text { Number of people accessing } \\
\text { additional services } \\
\text { Number and rate of } \\
\text { participation in health } \\
\text { status assessments } \\
\text { Number and rate of client- } \\
\text { health care professional } \\
\text { visits } \\
\text { Use of IT application }\end{array}$ & $\begin{array}{l}\text { Improvement of data } \\
\text { collection for chronic } \\
\text { care/disease } \\
\text { management }\end{array}$ & $\begin{array}{l}\text { Heart attack aftercare quality } \\
\text { Hypertension care quality } \\
\text { Diabetes care quality } \\
\text { Organised screening } \\
\text { participation rate } \\
\text { The knowledge, attitude and } \\
\text { behaviour of the population } \\
\text { related to the services } \\
\text { Life style (tobacco, alcohol etc.) } \\
\text { related morbidity }\end{array}$ & \begin{tabular}{|l|} 
Stakeholders' (Roma \\
representatives') \\
participation in \\
decision making \\
Number and rate of \\
client- health care \\
professional visits in \\
Roma population
\end{tabular} & \\
\hline Micro & $\begin{array}{l}\text { Number of enrolled } \\
\text { patients }\end{array}$ & & $\begin{array}{l}\text { Average number of } \\
\text { clients per session } \\
\text { Ratio of definitive } \\
\text { care }\end{array}$ & $\begin{array}{l}\text { Number of client-GP visits } \\
\text { Use of IT application }\end{array}$ & $\begin{array}{l}\text { Improvement of data } \\
\text { collection for chronic } \\
\text { care/disease } \\
\text { management }\end{array}$ & \begin{tabular}{|l|} 
Heart attack aftercare quality \\
Hypertension care quality \\
Diabetes care quality \\
Organised screening \\
participation rate
\end{tabular} & & \\
\hline
\end{tabular}

Table 9. GP cluster pilot project indicators, according to depth and span of performance 
Regarding the results of the quantitative analysis (historical changes in performance data of GP clusters as well as comparison to control group), only the main trend is registered and the way how performance information could be used to describe PC clusters is analysed in this thesis. See Annex 7.3 for the overview of the midterm results of those indicators that are included in the log frame matrix of the project. Based on available data, no univocal trend of performance improvement could be found in any of the four GP clusters. A possible explanation might be that the GP clusters has not been matured enough, thus initial organisational issues must be dealt with first.

There might be differences in performance, according to various indicators, among the four GP clusters, but how the overall performance of the GP clusters should be evaluated is not yet clarified. Questions arise such as how to summarise the indicator values, whether there are trade-offs between objectives and respective indicators, or what GP cluster characteristics is likely to influence one or more performance indicators. The midterm review (OALI, 2014) adopted this point of view, and did not claimed any of the four local implementations of the model to be less or more successful than the others. Nevertheless, several research questions were raised for further and deeper analysis. For example, the geographical composition of GP clusters should be analysed ("is there a difference between GP clusters spread over several villages vs. concentrated in one or two settlements"), or the connection to local stakeholders ("which forms of cooperation with local governments, schools, etc. can be more successful"), or the management structure ("what are the organisational consequences of the dual leadership, having a head GP and a public health coordinator in each cluster"). It must be emphasised, however, that these questions, that were deemed to be worth raising by the researcher team, are mainly not the products of the quantitative analysis of performance indicators but rather were based on the qualitative research findings. Quantitative information is simply not detailed and context-specific enough to enable us to formulate hypotheses about the factors that may influence the performance of GP clusters.

Indicators, describing the performance of the GP clusters, were actually referring to two units: 
- A few indicators was only measured at the level of clusters. For example, the number and rate of participation in health status assessments can be considered as a joint product of several cluster members: GPs provide a list of patients, mobilise with the help of assistant health mediators, and two or three members of the professional carry out the assessment, and manage the further pathway of the clients. Another example can be staff turnover which describes the cluster as a workplace.

- The majority of indicators were available at the level of individual GPs (data from the health insurance fund). By using the raw numbers (e.g. not the percentage of visits, but the actual number of GP-patient visits and registered population per GP), the performance indicators were recalculated at the level of the GP cluster. It was decided that no breakdown to individual GPs would be given (however, discussions are ongoing in the project team whether the monthly or quarterly reports to be produced by the management control system of the GP clusters should contain GP-level performance data or not). Naturally, how well GPs can perform depends on the other cluster members as well; for example, the number and rate of detected chronic patients will be, of course, influenced by how efficient the health assessment process is in identifying new chronic patients.

It can be concluded that "summing up" the performance indicators of individual network members can describe the performance of the GP cluster fairly well in several cases but, of course, cluster level processes should be described by cluster level indicators.

At the time of preparing this thesis, there is no information available about how the management cycle uses the information provided. Further research would be directed at how the GP clusters built the results of the midterm review into their future plans, and how the central project management used the information for initiating changes in the second half of the project implementation. As regards to the management cycles of the GP clusters, it must also be noted that no cluster-level targets have been set (so far): targets (e.g. 20\% relative improvement of care quality indicators) are specific to the whole of the pilot program, and not to the individual GP clusters. This, of course, might change in the future, especially because the target definition ("relative change in 
percentage") is not really coherent with project aims. A relative $20 \%$ improvement (e.g. from $30 \%$ to $36 \%$ ) could be more easily achieved by those who have lower historical values. While the project itself might keep summary performance targets, higher role could be given to local planning.

While there are lots of unknown factors about the management cycle(s), there is an interesting development at the level of the policy cycle. Without having and reviewing the midterm results of the pilot project, health policy leaders seem to promote the idea of GP clusters as the way of primary care reform. This development might put a much higher pressure on the pilot project: it might be expected that project experience (including performance indicators) will support policy formulation.

\section{Network performance}

According to the research aims of this thesis, the development network (consisting of the consortium members) is not analysed: the focus is on the service provision networks. The pilot project created four GP clusters at four locations. Although there is communication between the GP clusters (e.g. all the head GPs and public health coordinators regularly meet), and there are some shared goals about the project as a whole, they should be considered as four distinct service provision networks. The shared goal in each network concerns the improvement of the health status of the local community. There is, obviously, interdependence among network members in reaching these outcomes (public health problems are "wicked" problems).

The members kept their relative autonomy: GPs signed a contract about joining the cluster and they receive extra payments for participation, but health insurance fund reimbursements of their "normal" activities are as separated as before. Even if the GP clusters have a positive impact on the quality indicators of the national indicator set, GPs will receive their bonuses separately. District health visitors have also maintained their autonomy in terms of managing their on practices as well as receiving payments (most district health visitors are employed and salaried by local governments, however, there are a few visitors who work as entrepreneurs and have direct contractual 
relationships with the health insurance fund). The professional staff (public health professionals, community nurse, physiotherapist, dietician, health psychologist) and the Roma assistant health mediators are employed and salaried by the central project management office. All of them are directly supervised by the local public health coordinator who is responsible for every day management issues. It is an interesting setup for the network: they are employees of National Primary Care Institute, and an employment contract is usually a strong sign of bureaucratic coordination.

The question of network membership also arises for community involvement and local stakeholders. Programme objectives include better involvement of local communities, especially the Roma minority. The GP clusters have already signed numerous cooperation agreements with local stakeholders (local governments, minority representatives, schools, kindergartens, social care providers). Should more elaborated actions be defined together with the social care sector (applying the principles of integrated care, which is one of the policy goals), network membership would definitely go beyond present boundaries. Even the name of the local networks may easily become questionable: if it is a wide-scale cooperation among those who have influence over the community health status, and includes non-medical organisations, why is it named after general practitioners?

GP clusters show a strong sign of being a shared governance type network and a network administrative organisation type network at the same time. On the one hand, regular meetings are held for the local network members, shared decisions are made in several cases, and practically all the interviews praised the model for providing opportunities for meeting with each other, and discussing the issues of the local health system. On the other hand, however, the National Primary Care Institute supervises the members, employs the staff and requires detailed monthly individual activity reports from all the participants. Local planning is also heavily influenced by the central project management: target numbers for health assessments are not decided by the clusters but rather perceived as an assignment, "coming from Budapest". Again, this mode of network governance is most probably the consequence of being a pilot project (and 
definitely a consequence of being a Hungarian development project, with all the administrative rules to follow). But the question is there: what happens when the GP cluster model is rolled out to other areas without the presence of the network administrative organisation?

Network characteristics, again, are described based on the categorisation of Benson $(1975,1982)$ and Hudson (2004). It seems that the domain consensus is still being formulated in the GP clusters. The roles and the job descriptions of the new staff members have not been fully defined, yet, and it is still not fully clear how they fit into the processes of primary care. It is still under consideration what a health psychologist can do in the community (he or she is certainly not a replacement for clinical psychologists), or what types of activities the physiotherapist should organise. Based on the activity reports of the staff, it seems that types of provided services differ among the locations (for example, on the scale of individual vs. group therapy). The case of health status assessment is less problematic since it results in clear outputs, individual health assessment reports, based on well-defined methodology. In fact, it could also be the task of GPs to perform these assessments (actually, it would be a legal requirement but most GPs in Hungary do not have the resources and the willingness to do that), so that the output is well understood by them, and the help from the staff is greatly appreciated.

What district health visitors do is more or less well defined by the legal background as well as their traditional role - however, the question arises how they fit into the model of the GP cluster, and how their activities should change in order to reflect common goals. And the situation of general practitioners is interesting, too: while the higher level policy goals were based on the presumption that the role of GPs in the primary care must be reformed, it is far from clear to define what role the GPs should play in the GP cluster model. Based on the experience of the interviews, we concluded that the work of GPs has not changed much since the beginning of the pilot project. They are doing what they are used to do, attend monthly meetings, and can refer their patients to a few more people. For example, the local physiotherapist is often seen as a replacement 
capacity to the physiotherapy outpatient care centre. The motivation of GPs, joining the model, is varied: having access to extra health provision capacities, try something new, bringing in some extra income, or following the advice of a neighbouring doctor (the prospective head GP) were common answers. How their roles is changing and why it is beneficial for a formerly individual GP will be a key question for policy - and a key topic for further research. The role of other stakeholders has not been defined, either, and it is not trivial what scenarios there are as regards to, for example, integration with social care. This issue will certainly mean a redefinition of the domain consensus between health care and social care.

Another important feature of the domain consensus concerns the role of primary care in the health provision system. There has been a long ongoing debate about the gatekeeper role of GPs as well as their (lacking) abilities to provide definitive care in a higher number of cases. While not being part of this analysis, it must be emphasised that those primary care providers who are part of the GP cluster network are also part of a bigger health provision network. Redefining the role of primary care within these networks would also mean that a new domain consensus must be reached. The GP cluster pilot project, in the perspective of the multi-level networks phenomenon, would certainly redefine the roles, if it wanted to contribute to a higher ratio of definitive care as expected by policy goals, thus the present domain consensus would have to be renegotiated.

The ideological consensus about the common goal, at least at the highest level, is present: practically all the members we interviewed said that the project would be successful, if health status would improve, and people would do a lot more for their own health. Beyond this, a common answer was that the project would be successful if we screened all (or a given percentage, say $80 \%$ of) the population. The number of people participating in heath assessments seemed to be a central topic of the GP cluster. It may also be a consequence of the fact that setting target numbers for this specific activity was one of the few areas where the central project management put pressure on the clusters by requiring the accomplishment of "hard targets" month by month. Several 
interviewee defined the main role of their own planning process to find ways to "deliver the numbers", regarding the number of health assessments completed. Lacking agreements with neighbouring laboratories to run the diagnostics of the initial health assessments, a common tactic applied by the clusters was to first invite those patients who already had valid lab results, not older than a year. When a wider network will evolve with more stakeholders and higher community involvement, debates about the ideological consensus will certainly be interesting to follow.

Currently, local planning, directed at defining common goals for the local networks (cluster members and stakeholders), is restricted. Clusters have to follow central protocols in several areas, for example, there is very little room for local financial management (almost everything must be centrally purchased by using the public procurement procedure which makes the purchasing process very slow and unresponsive to local needs). The plan of health development activities had been prepared in several versions and iterated between GP clusters, the project management and university experts. When members were asked about their roles in the planning processes of the clusters, most respondents simply referred to this issue as something which is the task of the head GP and the public health coordinator. A few staff members have participated in elaborating the plans of health development activities but it seems that planning (setting common goals) has not become an integral part of the networks as a whole.

The degree of positive evaluation is uneven. Naturally, every organisation has its own conflicts, so does a local network. Both the interviews and the monthly activity reports made referrals to conflicts about keeping deadlines or complying with certain rules and expectations. What is more important in this model is the trust of GPs in the work of the new professionals. A formal satisfaction survey has not been carried out, yet, but based on the experience of the interviews we concluded that GPs generally consider the work of the new staff useful and adequate. We also heard a story of a GP telling the health assessment crew about how they saved a patient. Problems concerning the central project management (e.g. delayed procurement, delayed reimbursements of costs 
incurred and pre-paid, administrative burden, problems with IT development), however, caused some frustration in GP cluster members. If the network administrative organisation fails to adequately support the activities of the local networks, trust deteriorates, and performance potentially decreases. An evident cause of performance decrease is when members leave: a few members of the staff left the project due to the delays in procurement of the basic infrastructure. A special trust issue was raised during interviews with Roma assistant health mediators: they reported having problems with mediating with non-Roma members of the community from time to time, and claimed that a photo ID might help their work by building trust. Local governments and mayors usually evaluate the project and the team very positively, and several local governments supported the project by providing renovated offices (however, we also heard stories about mayors trying to ask for higher rental fees).

The work coordination mainly builds on personal relations: staff members meet with each other, with GPs and others, and deal with the necessary issues. It also means that having a "headquarter" office, or travelling together between villages, is an important factor in facilitating work coordination. Those who work part-time have difficulties in communicating with the others. Information technology could probably help a lot but both the software development and the hardware purchasing have been suffering from extremely long delays. The first phase of the software development was primarily directed at introducing a solution for recording and communicating the health assessment results (with some additional internal communication functions) - it was released for general use only in October, 2014, more than a year later than health assessment activities started. The second phase plans to implement a common GP cluster software, replacing all earlier versions of GP software. GPs univocally claim that introducing a new software, and migrating everything to this new software is unnecessary, and are afraid of usability issues. While a common software would certainly have the potential of better supporting team working and collaboration, there apparent risks of implementation. (Not to mention that a wider-scale roll out of the model would have to deal with the variety of GP software all over country.) 
A special aspect of work coordination refers to the question of "who the boss is". There is a special kind of dual leadership: in principle, the head GP should coordinate and be responsible all the activities, while the public health coordinator should be a supervisor of the new staff and responsible for the additional services provided by the clusters. The term "head GP" is somewhat misleading: the official English-language project documents use this term but in the Hungarian version this position is called "GP cluster coordinator". It reflects that GP members (who all have individual practices) would not endure "having a boss", thus calling him a coordinator was a compromise. In fact, project documents prove that the head GP often has difficulties with managing the others. New staff members named the public health coordinator as their superior, often referring to her as the "organiser", and to the head GP as the "representative" of the cluster. The importance of their cooperation was also often mentioned. Having two top managers could be problematic if it was a single organisation. Network governance, however, may cope better with this situation - or it might even be a natural way of governance in cooperative networks. Regarding this issue, further research interest is warranted.

Regarding the policy network level characteristics, fulfilment of program requirements seems ambivalent. The pilot project has not been reviewed and evaluated but policy making seems to "like it", and has (not so elaborated) plans about the expansion. As for the policy-level support towards the service provision network, this factor should be considered as an enhancer. Integration with social care may, however, be a challenge in the future, as well as the implementation of a few program elements (like the advanced GP cluster IT system). Application of the organisational paradigm is strong - no wonder, the network administration organisation's role is played by the central project management. The social importance of the issue is given: Westward migration of Hungarian physicians and high average age of GPs are two commonly known facts that call for action in this area. How exactly the GP cluster model will address the shortage of human resources is, however, not fully clarified. Maintenance of resource flows is granted till the end of the pilot project (of course, pending also on the midterm review) but how the budget of the national health insurance fund would allocate resources for a potential expansion is questionable. Most probably, a "cheaper version" of the model will have to be implemented, should an expansion occur. Therefore, carefully analysing 
the implementation of the current pilot model not just by applying the standard tools of health economics and health technology assessment but also using organisational and network studies may have a great contribution to policy formulation. Table 10 summarises the results of analysis about the network characteristics.

\begin{tabular}{|c|c|}
\hline & GP cluster \\
\hline Network type & formal, with informal ties to local stakeholders \\
\hline Network governance type & shared governance / network administration organisation \\
\hline Time period (network lifecycle) & definite (for the project) \\
\hline \multicolumn{2}{|c|}{ Service provision network - Operational relationships: } \\
\hline Domain consensus & $\begin{array}{c}\text { new members' roles are formulating, traditional GP roles and } \\
\text { district health visitor roles are mainly kept, new members' services } \\
\text { are often considered as "extra resources" }\end{array}$ \\
\hline Ideological consensus & $\begin{array}{c}\text { goals are primarily seen as externally set by the network } \\
\text { administration organisation, local planning is underdeveloped }\end{array}$ \\
\hline Positive evaluation & $\begin{array}{l}\text { high level of trust towards the new members, positive evaluation } \\
\text { by the local governments, some internal conflicts are detected }\end{array}$ \\
\hline Work coordination & $\begin{array}{l}\text { relies heavily on personal communication channels, IT support is } \\
\text { inadequate, dual leadership in local network governance }\end{array}$ \\
\hline \multicolumn{2}{|c|}{ Policy network - Contextual influences: } \\
\hline $\begin{array}{l}\text { Fulfilment of program } \\
\text { requirements }\end{array}$ & $\begin{array}{l}\text { not all policy goals have been met in the pilot project, but there } \\
\text { are plans for expansion }\end{array}$ \\
\hline $\begin{array}{l}\text { Maintenance of a domain of } \\
\text { high social importance }\end{array}$ & $\begin{array}{l}\text { general poor HR situation of primary care is widely known, but } \\
\text { support for this specific model is not granted yet }\end{array}$ \\
\hline $\begin{array}{l}\text { Maintenance of resource } \\
\text { flows }\end{array}$ & $\begin{array}{l}\text { granted for the pilot program, but an expansion would most } \\
\text { probably require a "cheaper version" }\end{array}$ \\
\hline $\begin{array}{l}\text { Application/defence of the } \\
\text { organisational paradigm }\end{array}$ & $\begin{array}{l}\text { the network administration organisation's role is played by the } \\
\text { central project management }\end{array}$ \\
\hline
\end{tabular}

Table 10. Network characteristics of the GP cluster pilot project

By applying the categorisation of network management strategies, developed by Benson (1975), GP clusters apply a mix of cooperative strategy (for governing local processes, e.g. involving community stakeholders) and authoritative strategy (by having a strong central management with guidelines and administrative rules to follow). A potential disadvantage of this setup may be that an extension of the model most probably require the sole implementation of cooperative strategy at local level networks. According to the categories defined by Agranoff and McGuire (2001), the local level networks have been mainly preoccupied by mobilising the resources, and less attention has been paid to activation of external stakeholders. But this is changing, thus the activation process 
will likely be more significant in the future. Synthesizing conditions favourable for coproduction also began, but mainly focused on the enhancement of interpersonal communication. Using the typology of Herranz (2008 and 2010), the central project management (as NAO) utilised a bureaucratically oriented strategy while local coordinators rather had a community-oriented strategy.

\section{Case summary}

As regards to the mode of managing performance, the case provides an illustration for "Performance Management". At least, up to the point when the policy seemed to decide about the way of primary care reform without seriously building on the results of the respective pilot project. The policy level and the service provision level became a bit disconnected, and from this point, the situation could rather be described as "Managements of Performances". It must be noted that the "Performance Management" state was not perfect, either, since several improvement opportunities could have been identified for the content or the target setting of the performance indicators.

This pilot project has also showed a strong sign of bureaucratic coordination between the project management, including the "centrally located" university expert team, and the local staff. Increased "invasion" of the project management into local network management processes may be a feature of pilot projects. From the one hand, it can be understood because vast interest lays in securing that each location implements (more or less) the same program. But on the other hand, it also means that the pilot project does not truly test the model which is planned to be rolled out: when local networks are "left on their own", network management characteristics may be totally different from the ones experienced during a pilot. While the current practice was identified as a mixed model of shared governance and network administration organisation type governance, a potential expansion of the model most certainly would not have employees all over the country, directly employed by the national institute. Thus, the application of a shared governance mode would me more likely. 
A network-based approach also showed that there is a possibility for having four (sub)models instead of one GP cluster model. The original performance measurement system was constructed in a way that looked at the four GP clusters as four locations of the implementation of the same model (where, of course, certain contextual factors may be different, having an influence over the changes in performance indicators at each location). A network-based analysis may lead to a conclusion that the four GP clusters are four implementation of the generic model, thus differences in how these four pieces of implementation operate in terms of network characteristics must also be taken into account when looking for explanations of performance variations. While no special attention was paid in this analysis to the model variations, further research could focus on the measurement of the network characteristics in each cluster as explanatory and outcomes as dependent variables. It is not only the cost-benefit ratio of the medical and public health activities that should be quantified in the end of the project, but how these local networks are governed does also matter.

While this analysis only focused on the network characteristics of the GP clusters, it is important to keep in mind that the primary care is not disconnected from other levels of the health care sector. A multi-level network management approach should also evaluate how GP clusters fit into the "big picture", and how the redefinition of the role of primary care changes the network dynamics at the higher level. For example, more emphasis of definitive primary care would rearrange domains, would require new patters for work coordination, or could change the ideological consensus about the goals of the health care system. Further research should also include the overview of how the GP cluster model is perceived by other health care providers. Further reallocation of the domains would occur, if the public health approach in primary care proved to be successful, and higher level of integration with social care was implemented. Should wider integration and collaboration be present, even the name of the model may be questionable since it emphasises one role from the health care sector. 


\section{Conclusions}

The thesis aimed to contribute to better understanding of what role networks play in the organisation of health services, and how networks can contribute to better performance in the health care sector. Literature about performance measurement and management of public services as well as network research in public administration and public management was reviewed, and served as a solid theoretical base for the empirical research. Examples from the health care sector were provided throughout the literature review, building on the findings of health care management. Network performance research in public management scarcely examines health service provision networks, and the health care management literature about integrated services does not build on the concepts of public administration and management as regards to network governance and network performance.

The main ambition of the research was to contribute to the refinement of theories and models that describe the performance of public services and service provision networks. Since the research was carried out in the context of the Hungarian health sector, policy implications for the development of the Hungarian health care could be also given. Based on the research aim and the current state of art, a mix of descriptive and exploratory approach was used. The thesis analysed two cases from the Hungarian health sector: the case of regional e-health developments and the formation of general practitioner clusters.

Conclusions are drawn based on a cross-case analysis and its application to the literature reviewed. First, implications for theory are presented, proposing a modified framework for describing public service performance in cases when service provision networks are present at meso level. Limitations of this research and further research areas are also identified. Second, implications for Hungarian health policy are overviewed. Due to the partly descriptive, partly exploratory aim of this research, though, these implications should not be treated as policy recommendations - but rather as an input for further evaluation research studies for the Hungarian health management researchers. 


\subsection{Implications for theory}

Based on the findings of the two case studies and the review of literature about performance management and governance and public networks, a modified framework of the public service performance management model was created. How the performance of service provision networks, as an addition to the meso level, fits into the public performance model (Bouckaert-Halligan, 2008) is summarised in Figure 11.

The network appears in the middle, between the organisational micro level and the policy level. Networks may be of various types. The e-health case described a development project where the three regional networks consisted of the consortium member health service providers, mainly hospitals - but an other regional network could have been defined as well, consisting of all the health service providers of the region who were supposed to be connected by the interorganisational IT network. The GP cluster pilot project also had a network for project implementation but the focus of analysis was on the local health network, consisting of GPs, district health visitors, public health and other professionals, and assistant health mediators. Network building with local stakeholders was also present. A common feature of the two cases was that policy level actors and central agencies were collaborating with local network members. An implication for theory could be that a better distinction within the meso levels is needed. While the macro level performance and macro level actors can be identified at countrylevel and government-wide (and respective performance indicators refer to countrylevel indicators as results of policy), the specific policy area and program objectives may also involve central agencies (like the E-health Programme Office or the National Primary Care Institute). These actors represent certain slides of the whole health care policy. Additionally, developmental networks may operate in a different way than service provision networks, even when the members of the developmental project are the same as in the service provision network. The main difference might lay in having pre-defined network goals (as expected results of the project) and a definite deadline (when the network ceases to exist). Development networks warrant further research. 


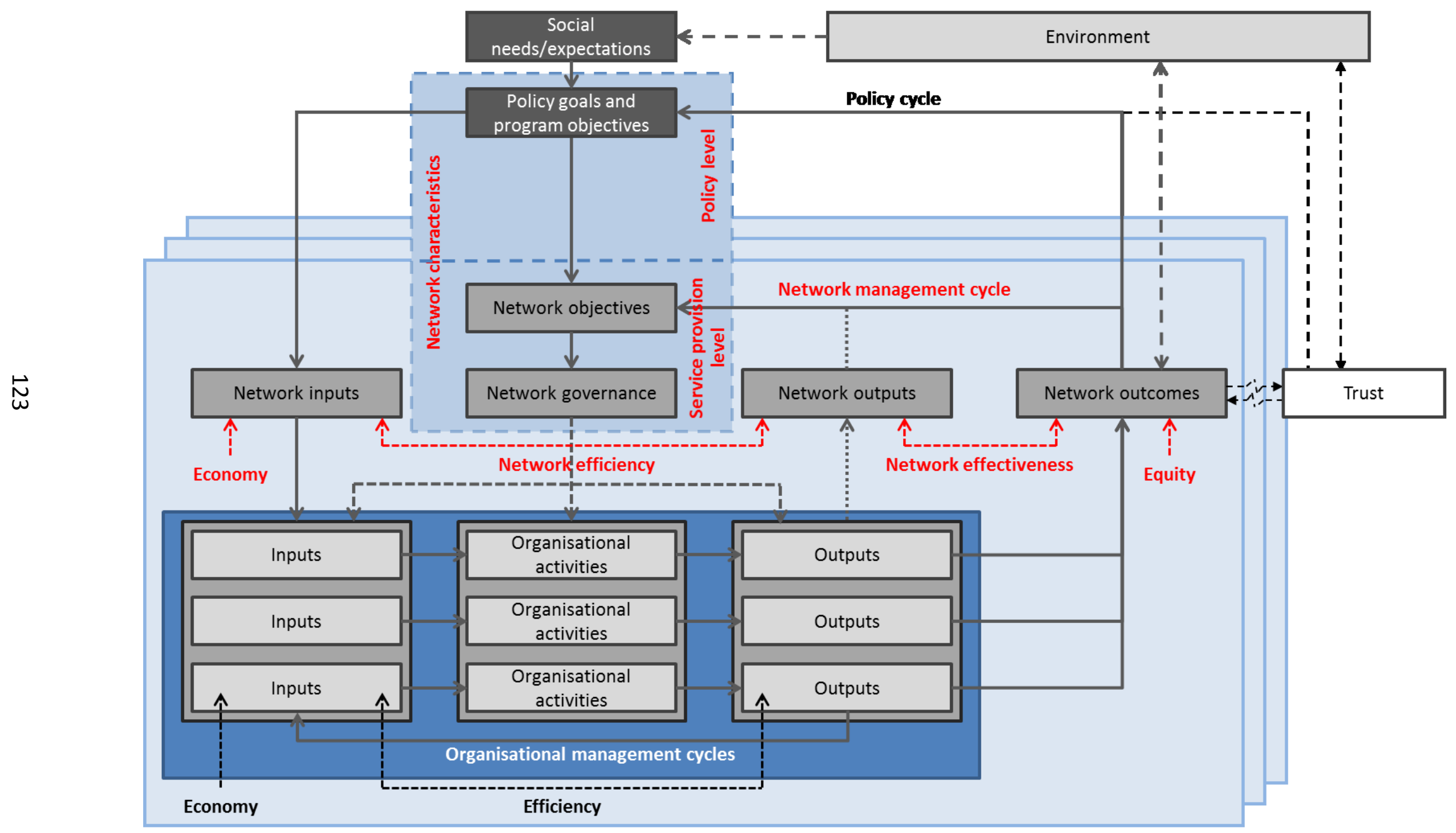

Figure 11. Service provision networks in the $4 E(+T)$ performance model 
Per definition, networks are goal-oriented. The thesis, building on Isett et al. (2011), defined networks as a group of goal-oriented interdependent but autonomous actors that come together or being connected to produce outcomes that no one actor could produce on its own. Common goals of networks in the public sector cannot be independent of the policy but the extent of influence may differ. Mandated networks' goals are more externally (policy-)driven; and members of emerging networks have greater freedom in defining the network-level objectives. Both cases showed signs of both mechanisms: predefined project results, action plans, central indicators and target values as well as detailed rules for project implementation put limitations on local goal setting, but networks were also expected to build wider relationships with other providers and the local community. To some extent, network objectives are set by members, taking earlier results (service outcomes of the network) into consideration. When networking is something new for the members, a few cycles of learning might be needed to better understand what they can and should do as network members - thus, network management is cyclical.

Drawing the boundaries of networks is always problematic (Isett et al., 2011), and defining membership for health provision networks can be a difficult task. Those who call for better integration of health services (Lyngs $\varnothing$ et al., 2014) are primarily concerned about finding mechanisms that drive all the providers towards the common goal of producing "better health status" for citizens in an efficient way. A network can be considered as a coordination mechanism, laying between markets and hierarchies, better suited for this task. (Huxham-Vangen, 2005) Setting common goals for networks is not easy in the health care. Short and long term interests of individual organisations can differ much. Even if the very high level common idea of creating "better health" is present, economic interest and the domains currently controlled can lead to conflicts of interest: redefining the role of primary care would certainly lead to imbalance in current domains of operations. Interventions by policy will also be directed at helping (or forcing) members together; creation of regional planning boards is an example for this. Multiple membership in networks also occurs: for example, health providers were members of the e-health project as well as the regional health provision network, and GP clusters are also part of a larger health provision network. Conflicting interests and 
attitudes towards differing expectations and values of multiple networks may be an element of what makes "Management in the network" (Milward-Provan, 2006) difficult.

How much input resources are available for networks and network members are mainly decided by policy. It is a transparent decision in the case of development projects (where there is a set budget), and may be more problematic in budgeting for ongoing operational expenses. A part of resources may be at the disposal of the network as a whole (provided there is legal entity which can handle common resources) but individual budgets of network members are also part of the resource pool the network can "use" in order to solve problems. Network governance (Kenis-Provan, 2009) may have a role in (re)allocating resources among network members but the effect of policy decisions can also be significant. For example, the e-health development project had an allocation in the project plan, so did the GP cluster project as regards to the resources covered by the grant. On the other hand, "normal" health care financing channels of participating hospitals or GPs have not changed. The GP cluster case showed that resource allocation was primarily done by the central project management (acting as network administration organisation), with little room left for local network managers.

How organisational activities are carried out is also influenced by the network and network governance. For example, higher use of interorganisational e-health system depends on how well coordination mechanisms are built into the software as well as the minds of participants. The e-health development projects were dominated by institutional logic and interest: hospital managers and physicians could see what benefits the organisational processes could get from the project, but support for the need of interorganisational cooperation was missing.

Network governance can also be directed at better defining the outputs that are expected from network members. This mechanism builds on the idea that expected outcomes can only be delivered if all the network members are able to produce the right outputs. While the policy is also concerned about this task, a network may be closer to the local level, and may know better what specific mix of outputs is needed to 
adequately address local problems. This is not a replacement of the bureaucratic coordination in the sector but rather an addition to it (Davis-Rhodes, 2000). Local planning can also deal with the expected output from each member. In the case of the GP cluster the network administration organisation had a significant impact over what outputs were to be delivered by local networks: targets were centrally set for health assessments but more freedom was given to local networks to decide what physiotherapists, dieticians, and health psychologists would do.

Therefore, in the framework of the public service performance model network governance could be directed at input allocation, rule setting for "network-compatible" organisational processes, or defining the desirable mix of organisational outputs. These options could be considered as strategic network management options from which network managers can choose. Further research is needed into the question whether these three strategic options can be individual choices (so that it can happen that a network manager uses only one of the three options), or a mixture of these network management activities is always needed. Choices made in this regard might also influence network performance - this issue should also be studied in more details. The e-health project focused on resource allocation, and these resources were mainly perceived by hospital managers as a support to solve their own organisational IT problems. The project had not changed care processes, neither rearranged expected organisational outputs. The GP cluster pilot channelled a high amount of extra resources into the primary care, began to reshape care processes, but, at least up to this point, had little effect over outputs, mostly leaving GP outputs as they were.

What type of network governance should be chosen has been highly discussed in literature. (Rethemeyer-Hatmaker, 2007; Provan-Kenis, 2008; Kenis-Provan, 2009; Provan-Lemaire, 2012) The mode of effective network governance depends on several factors, including the objectives of the network, the number of participants (larger networks tend to use "brokered" forms of governance), or distribution of power. The developmental and pilot projects analysed in the case studies had well-defined objectives, definite lifecycle and deadlines, and tended to apply a brokered form of 
governance (lead organisation or network administrative organisation format) mixed with shared governance for local level decisions. When policy level decisions are also needed for the projects to be successful (such as creating adequate legal regulation for e-health, redefining the roles of GPs), the NAO model, directly connected to policy may be beneficial. On the other hand, when the NAO fails to address the policy level issues, local network performance will also deteriorate.

The network characteristics, relevant for choosing appropriate modes of governance and network management strategies, most probably depends on both local collaboration and policy-level support. To map network characteristics, the two case studies applied the categorisation of Benson $(1975,1982)$ and Hudson (2004). The dimensions of the local service provision network (domain consensus, ideological consensus, positive evaluation, and work coordination) proved to be useful to describe the factors that influenced network performance. The analyses also demonstrated that local level network characteristics are not independent of the policy level (RethemeyerHatmaker, 2007), policy level support for local networks is valuable. While there are certain difficulties with management in the network as an organisational leader and management of the network as network manager (Milward-Provan, 2006; ProvanLemaire, 2012), a third management role can also be identified: management for the network. While certain local network level characteristics can definitely be improved by network members (for example, trust building is essential), there is a policy-level role, too: what policy making or trusted agencies can do to support the local level networks (the "network population") could be called "management for the networks".

Based on the empirical experience with the model of Benson and Hudson, there is still a lot of room for research to better measure the relevant characteristics, and analyse how they influence each other. For example, diminishing trust will most probably set back work coordination, or prohibit members from reaching a new (and from the perspective of expected outcomes: better) domain consensus. Network characteristics that could be probably tested during future research are not shown in Figure 11, more research is needed in this field. Nevertheless, the interrelatedness of the policy and service 
provision levels (Rethemeyer-Hatmaker, 2007) were demonstrated by the case studies. If we think of networks as an alternative to hierarchy and market, and deliberately create networks to tackle with "wicked" problems or with those where network coordination is expected to deliver better results, it might also be an imperative for the policy maker to provide support for the networks created. Therefore, management for networks is not optional. Success of policy depends on how well the whole population of local networks perform.

As regards to the performance indicators to be used (or the span of performance; Bouckaert-Halligan, 2008), a few illustrations could be collected from the two cases. Taking the interrelatedness of organisational outputs, contributing to network outcomes, into consideration, economy and efficiency indicators are becoming primary indicators for measuring organisational performance. The cases also showed that "summing up" organisational performances is a possible way to calculate network performance, as regards to economy and efficiency. Network outcomes and effectiveness (and equity) were also calculated this way in the cases. However, if it is true that outcomes are those results that no one actor could produce on its own, this practice is questionable. The case studies may represent an early stage in network development, so that attributing outcomes to the network level might be an issue for later development. Still, there are clear signs in the GP cluster case for this issue: several performance measures (e.g. quality of chronic care) could be improved with better care coordination at network level and/or inclusion of other service providers and social care services. The latter is clearly a task for which networks are better suited than individual GPs or central bureaucracy. Defining performance indicator for the local networks might also drive us closer to the inclusion of stakeholders in measurement, as proposed by the "Performance Governance" ideal type of measuring performance (Bouckaert-Halligan, 2008).

An alternative interpretation for the data collected must also be taken into consideration: is it possible to treat the networks as the micro level in the performance model? Defining the development projects or the GP clusters as something similar to 
single organisations, and place them at the micro level, would certainly make the problem easier. A central problem to the regional e-health development projects was that not all the members of the regional health provision system was a member of the development project (and later the project could not give good enough reasons for others to join the network). In the case of the GP clusters the general practitioners and the district health visitors kept their individual status (and their individual businesses), and even the network managers are called "coordinators". Health care financing rules apply to individual practices, so does the national quality indicator set. Treating the projects or the GP clusters as actors of the micro level would miss this issue, and keep those network characteristics that influence expected outcomes hidden from policy.

There are also a few but evident limitations to this research. The empirical work has been carried out in the context of the Hungarian health care sector so that generalisation of the results to other countries and other public services might be limited. Both projects, studied in the research, were development/pilot projects, funded by external parties (EU and Swiss Fund), with well-defined objectives, definite lifetime, and intensified "success orientation" in terms of the need for delivering the numbers required by the project plan. Both projects, however, included members from the service provision network but "pure" service delivery networks might behave in alternative ways. Policy interventions (as the unit of analysis) were in the focus of the research but the wider policy context of the interventions studied may also be relevant, calling for an even wider use of policy networks: governments usually look at policy goals in "packages". The level of individual physicians was also left out of the analysis. Care processes, however, are often organised by using interpersonal, collegial relationships, thus social network analysis could also contribute to better understanding of this field. Finally, the issue of public trust could not be incorporated into the cases. Trust is an important characteristic of service provision networks, and network members' trust in each other is an important factor of network performance. How clients and the local community trust in networks, and what relationship is there between network outcomes and public trust, were not part of this analysis. This is not a result of a premeditated act but rather a consequence of missing data in the cases. 


\subsection{Implications for policy}

A few policy implications for Hungarian health policy making can also be derived from the research. Due to the partly descriptive, partly exploratory aim of this research, though, these implications should not be treated as policy recommendations but rather as an input for further evaluation research studies.

The performance measurement practice, reflected by the two cases, was characterised by the "Managements of Performances" state. Better integration of measurement systems across policy and service provision levels could be considered. Careful definition of outputs and outcomes is essential, and could build on the network-approach to a greater extent. The level of local networks, their role, performance expectations towards them, and supporting policies could be beneficial in policy implementation. How network boundaries are defined, is also important. It seems that regional networks could not perform successfully, maybe because of the lack of tradition, maybe because of lack of policy support.

Where the boundaries of networks are defined in the future primary care reform, will be an important factor of how performance expectations should be defined. The need for "managing for networks" applies, too. If networks are created, the adequate support should also be provided for network members and network managers - without the rigidity of too much bureaucracy and hierarchy. Most probably, a "cheaper version" of the model will have to be implemented, should an expansion occur. Therefore, carefully analysing the implementation of the current pilot model not just by applying the standard tools of health economics and health technology assessment but also using organisational and network studies may have a great contribution to policy formulation. How the proposed GP clusters, with a shift in traditional domains of health providers as well as social care, fit into the "bigger picture" is also an interesting question for public policy analysis before the details of implementation are elaborated. 
EU-funded projects in the area of health care tend to tackle with policy problems, let it be e-health development, or reforming the primary care sector. It must be kept in mind that the logic of development projects, with pre-defined goals and strong successorientation in terms of "project indicators" drives both the network members and the policy towards using easily reachable targets, with less focus on the expected outcomes. Even if this "project-logic" cannot be overwritten, longer-term policies and strategies should be put in place to provide a roadmap for the service provision network (and not just a roadmap or action plan for the development projects). The situation can be especially tricky when network development projects are essentially encouraged (or required) to formulate policy. 


\section{Appendices}

\subsection{Determinants of network effectiveness}

\section{Determinants of network effectiveness (based on Turrini et al., 2009)}

\begin{tabular}{|c|c|c|c|c|c|c|c|}
\hline \multirow[b]{2}{*}{ Concept } & \multirow[b]{2}{*}{ Variable } & \multirow[b]{2}{*}{ Relationship } & \multirow[b]{2}{*}{$\begin{array}{l}\text { Client level } \\
\text { effectiveness }\end{array}$} & \multirow{2}{*}{$\begin{array}{l}\text { Community } \\
\text { level } \\
\text { effectiveness }\end{array}$} & \multicolumn{3}{|c|}{ Network level performance } \\
\hline & & & & & $\begin{array}{c}\text { Ability to reach } \\
\text { stated goals }\end{array}$ & $\begin{array}{l}\text { Innovation } \\
\text { and change }\end{array}$ & $\begin{array}{l}\text { Sustainability } \\
\text { and viability }\end{array}$ \\
\hline \multirow{2}{*}{ Resource munificence } & $\begin{array}{l}\text { Existence of local financial } \\
\text { resources }\end{array}$ & + & 0 & 0 & 0 & & \\
\hline & Technical assistance systems & + & & & & & 0 \\
\hline \multirow{2}{*}{$\begin{array}{l}\text { Cohesion and support } \\
\text { from the community / } \\
\text { Participation }\end{array}$} & $\begin{array}{l}\text { Extent and measure of previous efforts of } \\
\text { collaboration / Participation }\end{array}$ & + & & 0 & 0 & & \\
\hline & Extent of geographic and cultural diversity & + & & 0 & & & \\
\hline System stability & $\begin{array}{l}\text { No change in the regime where the } \\
\text { networks work }\end{array}$ & + & 0 & & & & \\
\hline \multirow{5}{*}{$\begin{array}{l}\text { Traditional managerial } \\
\text { work }\end{array}$} & $\begin{array}{l}\text { Provision of electronic client service } \\
\text { systems }\end{array}$ & + & 0 & & & & \\
\hline & Adjusting administrative systems & + & & 0 & & 0 & \\
\hline & $\begin{array}{l}\text { Establishing consequences to motivate } \\
\text { staff performance }\end{array}$ & + & & 0 & & 0 & \\
\hline & Management capacity & + & 0 & & 0 & & \\
\hline & Appropriateness of service delivered & + & & & & & 0 \\
\hline \multirow[b]{2}{*}{ Generic networking } & $\begin{array}{l}\text { Time spent in interactions among network } \\
\text { constituencies }\end{array}$ & + & 0 & & & & \\
\hline & $\begin{array}{l}\text { Behavioural networking activity (time } \\
\text { spent in interactions among network } \\
\text { constituencies) }\end{array}$ & + & & & & 0 & \\
\hline
\end{tabular}




\begin{tabular}{|c|c|c|c|c|c|c|c|}
\hline \multirow{3}{*}{ Concept } & \multirow[b]{2}{*}{ Variable } & \multirow[b]{2}{*}{ Relationship } & \multirow{2}{*}{$\begin{array}{l}\text { Client level } \\
\text { effectiveness }\end{array}$} & \multirow{2}{*}{$\begin{array}{l}\text { Community } \\
\text { level } \\
\text { effectiveness }\end{array}$} & \multicolumn{3}{|c|}{ Network level performance } \\
\hline & & & & & $\begin{array}{l}\text { Ability to reach } \\
\text { stated goals }\end{array}$ & $\begin{array}{l}\text { Innovation } \\
\text { and change }\end{array}$ & $\begin{array}{l}\text { Sustainability } \\
\text { and viability }\end{array}$ \\
\hline & $\begin{array}{l}\text { Ability to solve tensions - finding a way to } \\
\text { blend various participants to fulfil the } \\
\text { strategic purpose of the network }\end{array}$ & + & 0 & 0 & 0 & 0 & 0 \\
\hline $\begin{array}{l}\text { Buffering instability / } \\
\text { nurturing stability }\end{array}$ & Mobilizing and creating commitment & + & o & 0 & 0 & 0 & 0 \\
\hline \multirow[t]{3}{*}{$\begin{array}{l}\text { Steering network } \\
\text { processes }\end{array}$} & $\begin{array}{l}\text { Shaping the operating context of the } \\
\text { network, by influencing its operating } \\
\text { rules, its prevailing values and norms, and } \\
\text { the perceptions of the network } \\
\text { participants }\end{array}$ & + & 0 & 0 & 0 & 0 & 0 \\
\hline & Leadership - Activating & + & 0 & 0 & 0 & 0 & 0 \\
\hline & Ethical decisions making & + & & & 0 & & 0 \\
\hline \multirow{4}{*}{ External control } & Centralization of external control & + & 0 & & & & \\
\hline & $\begin{array}{l}\text { Stakeholders influence on managers' } \\
\text { networking activity }\end{array}$ & + & & 0 & & & \\
\hline & State regulatory agency control & ? & & & 0 & & \\
\hline & Existence of a central coordinating agency & + & 0 & & & & \\
\hline \multirow{5}{*}{$\begin{array}{l}\text { Integration mechanisms } \\
\text { and tools }\end{array}$} & Information and communication systems & + & o & & 0 & & 0 \\
\hline & $\begin{array}{l}\text { Joint staff activities (marketing, funding, } \\
\text { planning) }\end{array}$ & + & 0 & & 0 & & \\
\hline & $\begin{array}{l}\text { Coordination a service level (seamless } \\
\text { continuum of care) }\end{array}$ & + & 0 & o & & & \\
\hline & Existence of steering committee & + & & 0 & & & \\
\hline & $\begin{array}{l}\text { Partnership synergy (combination of } \\
\text { perspectives, knowledge and skills) }\end{array}$ & + & & & 0 & & \\
\hline \multirow{2}{*}{ Size } & $\begin{array}{l}\text { Cap to growth by selecting participants } \\
\text { that are new }\end{array}$ & + & & & 0 & & 0 \\
\hline & $\begin{array}{l}\text { Breadth and heterogeneity of } \\
\text { membership }\end{array}$ & + & 0 & & 0 & & 0 \\
\hline
\end{tabular}




\begin{tabular}{|c|c|c|c|c|c|c|c|}
\hline \multirow[b]{2}{*}{ Concept } & \multirow[b]{2}{*}{ Variable } & \multirow[b]{2}{*}{ Relationship } & \multirow[b]{2}{*}{$\begin{array}{l}\text { Client level } \\
\text { effectiveness }\end{array}$} & \multirow{2}{*}{$\begin{array}{l}\text { Community } \\
\text { level } \\
\text { effectiveness }\end{array}$} & \multicolumn{3}{|c|}{ Network level performance } \\
\hline & & & & & $\begin{array}{l}\text { Ability to reach } \\
\text { stated goals }\end{array}$ & $\begin{array}{l}\text { Innovation } \\
\text { and change }\end{array}$ & $\begin{array}{l}\text { Sustainability } \\
\text { and viability }\end{array}$ \\
\hline Formalization & $\begin{array}{l}\text { Formalized rules, meeting organization, } \\
\text { written agenda and decision-making } \\
\text { procedures }\end{array}$ & + & 0 & & & & \\
\hline \multirow{2}{*}{ Accountability } & $\begin{array}{l}\text { Use explicit ongoing outcome } \\
\text { measurement }\end{array}$ & + & 0 & 0 & 0 & 0 & 0 \\
\hline & $\begin{array}{l}\text { Incorporate diverse community voices in } \\
\text { partnerships }\end{array}$ & + & & & 0 & & 0 \\
\hline \multirow{5}{*}{ Network inner stability } & $\begin{array}{l}\text { Management personal stability, tenure of } \\
\text { network manager }\end{array}$ & + & 0 & & & & \\
\hline & Life-time spent in the network & + & o & & & & \\
\hline & Trust, reciprocity, norms of cooperation & + & 0 & 0 & 0 & & 0 \\
\hline & Competitiveness among staff & - & & 0 & & & \\
\hline & $\begin{array}{l}\text { Presence of institutional, resource and } \\
\text { structural links }\end{array}$ & + & & & & o & \\
\hline
\end{tabular}




\subsection{E-health developments: a network-performance based approach}

This appendix examines the effect of (potential) e-health developments on the "network performance enhancers" as defined by Benson $(1975,1982)$ and Hudson $(2004)$ in general. Figure 1 summarises how the elements of e-health might improve the performance of local health provision networks via improving domain consensus, ideological consensus, positive evaluation, and work coordination among network members. The most important contextual factors at higher (policy) levels are also listed.

\section{E-health elements for improving performance of health provision networks}

\begin{tabular}{l|l|}
$\begin{array}{l}\text { Degree of } \\
\text { domain } \\
\text { consensus }\end{array} \quad \begin{array}{l}\text { IT support for clinical pathways } \\
-\end{array}$ & $\begin{array}{l}\text { Inclusion of patients into the } \\
\text { process of care in the era of e- } \\
\text { health }\end{array}$ \\
\hline
\end{tabular}

\begin{tabular}{|l|l|}
$\begin{array}{l}\text { Degree of } \\
\text { ideological } \\
\text { consensus }\end{array}$ & $-\begin{array}{l}\text { Clinical guidelines and decision } \\
\text { support systems } \\
-\begin{array}{l}\text { Consumer health information on } \\
\text { the internet }\end{array}\end{array}$ \\
\hline
\end{tabular}

Degree of - Quality assurance and quality positive

evaluation

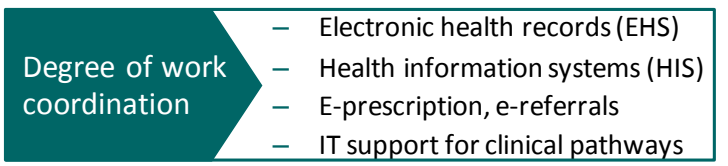

Contextual factors of e-health developments

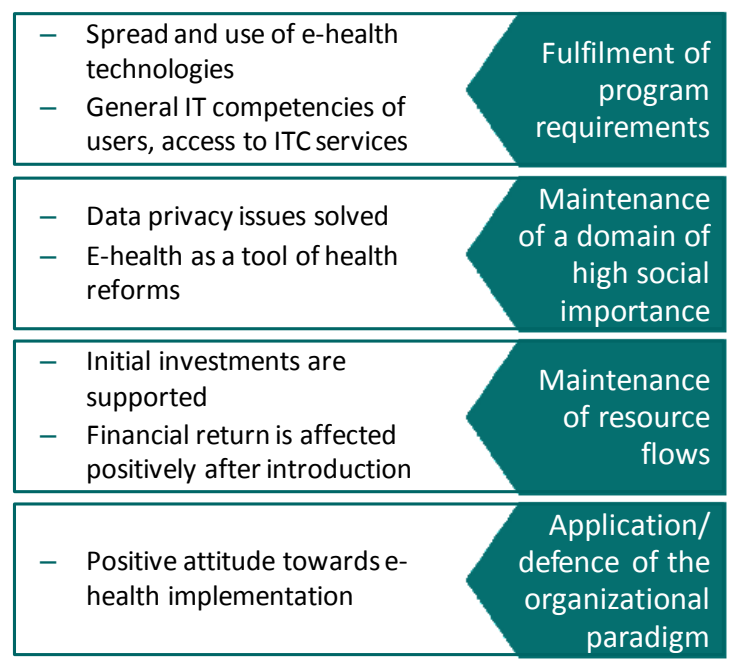

Figure 1. E-health developments as network performance enhancers and their context

Degree of domain consensus was defined as to what extent the roles and responsibilities of different network members are clear. It can be improved by:

- Providing IT support for clinical pathways: it was demonstrated that clinical pathway conformance can be improved by the use of IT (see, for example, Lenz et. al., 2007). Clinical pathways are implementations of guidelines in a specific setting, and they "consider available resources like staff, level of education, available equipment, and hospital topology" (ibid:S397). Clinical pathways are thus essential in setting the roles and responsibilities of local health provision network members in order to improve performance of care. (Clinical pathways are also serving the purpose of better work coordination.)

- Better inclusion of patients into the process of care: modern technology provides better opportunities for home care by, for example, using telemonitoring, or might improve adherence of patients (WHO, 2003). These developments change how the roles and responsibilities are shared between the physician and the patient. Physicians must not only accept this "shift of power" but support them in the future.

Degree of ideological consensus was defined as to what extent network members agree on problem definition and problem resolution. It can be improved by: 
- Clinical guidelines and decision support systems: clinical guidelines summarise the experience about clinical outcomes from a very wide range of cases thus essentially representing the most important knowledge management tool for clinical decisions. Clinical decision-support systems "can formulate treatment suggestions based upon treatment guidelines" (Jaspers, 2011:327). Although the authors in their literature review conclude that few studies have demonstrated positive effects on patient outcomes so far, however, advancements in IT technology and Al will likely lead to significant improvements in this field.

- Consumer health information on the internet: patients have been significantly empowered since the appearance of medical information on the internet. Patients, professionals, companies, or government agencies create and share huge loads of information. Web 2.0 turns the internet into a communication tool in the field of medicine as well. It is promoted that health care personnel adapt to these changes and actively participating in information sharing (MeskóDubecz, 2007).

Degree of positive evaluation was defined as to what extent the workers of network members trust in each other. It can be improved by:

- Quality assurance and quality information: availability of information about the performance of providers may improve trust in both physicians and patients. Information gathering, processing and publication can be supported by e-health solutions. Quality information might be restricted to internal use of clinicians (for example, clinical audits), used by reimbursement (for example, pay-forperformance schemes use quality information as well), or available for public use. In the case of public information there are two pathways of performance improvement (Shekelle, 2009): patients prefer choosing better quality providers ("selection pathway"), or providers are able to identify weak points in their care processes and react ("change pathway"). There are several examples of quality information publication in Europe or in the US. Demonstrating quality of care contributes to trust in service providers.

- Teleconsultation and virtual communities of physicians: more frequent communication is usually considered as a "trust builder" element. While making relationships less personal is a risk of telemedicine applications, this is only true in cases when it replaces traditional face-to-face meetings. Teleconsultation services among physicians might add further opportunities to discuss patient results or care issues compared to when they communicate only in writing. Virtual communities can also contribute to positive evaluation.

Degree of work coordination was defined as to what extent working patterns and cultures are aligned in a network. Since e-health solutions are mainly targeted at electronisation of processes in a complex environment, most e-health tools will contribute to better coordination of operational processes of providers. Degree of work coordination can be improved by:

- Electronic health records (EHS): "[h]ealth information technology (HIT) has the potential to improve coordination by making information electronically available at the point of care [...]", as noted by O'Malley et al. (2010:177). They carried out a qualitative survey which showed that there is still "a gap between policy- 
makers' expectation of current EMRs' [= electronic medical records'] role in the coordination of care and clinicians' real-world experience with them." (ibid:183) They also found that within-office coordination works better than coordination between clinicians and settings. Surveys show that the use of EHR is lagging behind (for example, Jha et al., 2010). We might also consider EHS as the "base infrastructure" of collaboration and coordination among health care providers.

- Health information systems, e-prescriptions, e-referrals: while EHS is the basic infrastructural element for e-health, several applications build these pieces of information into workflows of providers and clinical decisions of physicians as well as into standard messages among various providers. Hospital systems or GP systems are examples for provider-level applications, facilitating coordination among organisational members while e-referrals and e-prescriptions are the most frequently used examples of standard messages among physicians or between physicians and pharmacists. These systems might incorporate support for clinical pathways, decision support system modules, telemedicine applications, or virtually any kind of tools that connect the actors. This way, better coordination might lead to better performance in the other dimensions of the model as well.

As for the contextual factors of the performance model, they might enhance or limit how well local networks perform (definitions for contextual factors are not repeated here). If spread and use of e-health technologies is quicker and higher in at least a few of local or regional networks, it may prove that the nationwide e-health policy is viable. It might make sense for the policy maker to initiate pilot projects and focus on areas where "quick wins" are easier to get. How providers undertake tasks required by the new applications will depend on several factors. On the one hand, general IT competencies of users (physicians, other professionals as well as patients), and access to ITC services are decisive contextual factors (hence there is a role for education). On the other hand, main purposes of system introductions will also determine how supportive health care providers will be: a positive attitude is very much needed, and it will be more likely granted if the system is perceived as a supportive one instead of a controlling one. E-health might also be seen as an element of health care reforms: if there is a higher level of public support for health care reforms, e-health projects are more likely to be welcomed (and financed). Since personal medical data is very sensitive, e-health projects will be more successful if the rules are unambiguous and transparent and data privacy issues are solved in advance. Costs associated with introduction are usually high. If initial investments (and pioneering organisations) are supported, it is easier to get to the point where the network effect can be utilised. In the beginning financial returns on introductions can be poor so that supportive financial schemes or other financial motivators are needed. 


\subsection{Performance measurement of the GP cluster project}

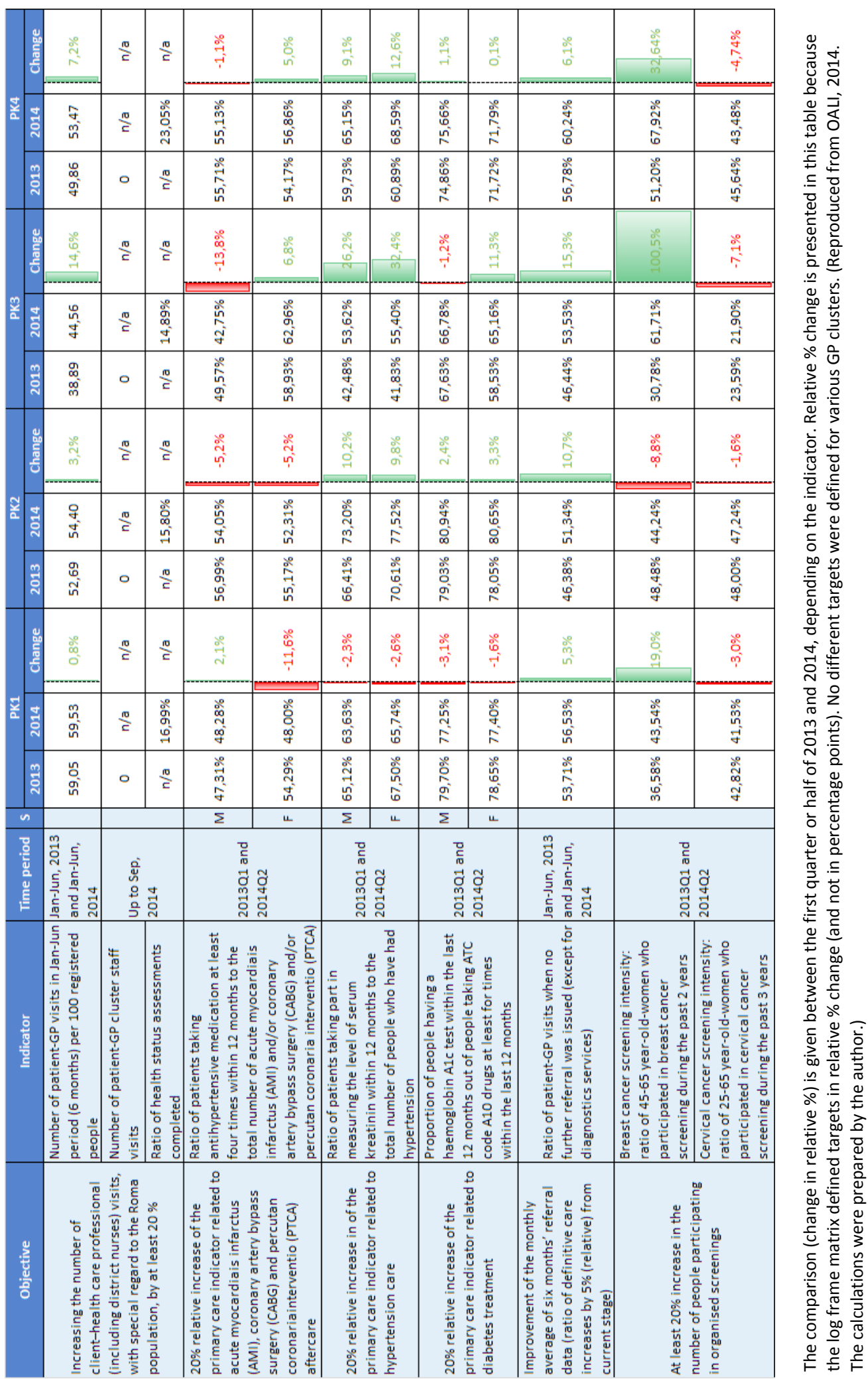




\section{References}

Ádány, R. - Kósa, K. - Sándor, J. - Papp, M. - Fürjes, G. (2013): General practitioners' cluster: a model to reorient primary health care to public health services. The European Journal of Public Health, Vol.23, No.4, pp.529-530. DOI: http://dx.doi.org/10.1093/eurpub/ckt095

Addicott, R. - Ferlie, E. -McGivern, G. (2006): Networks, Organizational Learning and Knowledge Management: NHS Cancer Networks. Public Money and Management, April, pp. 87-94. DOI: http://dx.doi.org/10.1111/j.1467$\underline{9302.2006 .00506 . x}$

Addicott, R. - Ferlie, E. - McGivern, G. (2007): The Distortion of a Managerial Technique? The Case of Clinical Networks in UK Health Care. British Journal of Management, Vol. 18, No. 1, pp. 93-105. DOI: http://dx.doi.org/10.1111/j.14678551.2006.00494.x

Allen, David (2000): Management accountancy in the public sector. Management Accounting: Magazine for Chartered Management Accountants, Vol. 78, Issue 2, February, pp. 44-45.

Anthony, Robert N. - Govindarajan, Vijay (2006): Management Control Systems. 12th edition, McGraw-Hill Higher Education.

Anthony, Robert N. - Young, David (2002): Management Control In Nonprofit Organizations. 7th edition, McGraw-Hill Higher Education.

Agranoff, Robert (2003): Leveraging Networks: A Guide for Public Managers Working across Organizations. IBM Endowment for the Business of Government, Washington, DC.

Agranoff, Robert (2008): Intergovernmental and network administration, accountability, and performance - Symposium introduction. Public Performance \& Management Review, Vol. 31, No. 3, March 2008, pp. 315-319. DOI: http://dx.doi.org/10.2753/PMR1530-9576310300

Agranoff, R. - McGuire, M. (1998): Multinetwork Management: Collaboration and the Hollow State in Local Economic Policy. Journal of Public Administration Research and Theory, Vol. 8, No. 1, pp. 67-91.

Agranoff, R. - McGuire, M. (2001): Big questions in public network management research. Journal of Public Administration Research and Theory. Vol. 11, Issue 3, pp. 295-326. DOI: http://dx.doi.org/10.1093/oxfordjournals.jpart.a003504

Agranoff, R. - McGuire, M. (2003): Collaborative public management: New strategies for local governments. Georgetown University Press, Washington, DC.

Ahgren, B. - Axelsson, R. (2005): Evaluating integrated health care: a model for measurement. International journal of integrated care, Vol.5, Jul-Sep

Arah, O. - Westert, G. - Hurst, J. - Klazinga, N. (2006): A conceptual framework for the OECD Health Care Quality Indicators Project. International Journal for Quality in Health Care, Vol. 18, Issue suppl. 1, pp. 5-13. DOI: http://dx.doi.org/10.1093/intqhc/mzl024 
Aristigueta, Maria P. - van Dooren, Wouter (2007): Toward a performing public sectorThe roles of context, utilization, and networks. Public Performance \& Management Review, Vol. 30, No. 4, June 2007, pp. 463-468. DOI: http://dx.doi.org/10.2753/PMR1530-9576300400

ÁSZ (2011): Jelentés a háziorvosi ellátás működésének és pénzügyi feltételrendszerének ellenőrzéséről. Állami Számvevőszék.

Barabási, Albert-László (2002): Linked: The New Science of Networks. Perseus Books.

Bardach, E. (1994): Can Network Theory Illuminate Interagency Collaboration? Paper prepared for the Workshop on Network Analysis and Innovations in Public Programs, Sept. 29 - Oct. 1, LaFollette Institute of Public Affairs, University of Wisconsin-Madison.

Belicza Éva - Boncz Imre - Horváth Ágnes - Jónásné Katona Katalin (2004, eds): Irányított betegellátási rendszer múködésének értékelése, 1999-2003. Országos Egészségbiztosítási Pénztár, Budapest.

Benson, J.K. (1975): The Inter-Organizational Network as a Political Economy. In: Administrative Science Quarterly, 20, pp. 229-249. DOI: http://dx.doi.org/10.2307/2391696

Benson, J.K. (1982): A Framework for Policy Analysis. In: D.L. Rogers - D.A. Whetton (ed.): Interorganisational Coordination, Ames: lowa State University Press

Berry, F.S. - R.S. Brower - S.O. Choi - W.X. Goa - H.S. Jang - M. Kwon - J. Word (2004): Three Traditions of Network Research: What the Public Management Research Agenda Can Learn from Other Research Communities. In: Public Administration Review, Vol. 64, No. 5, pp. 539-552. DOI: http://dx.doi.org/10.1111/j.1540$\underline{6210.2004 .00402 . x}$

Berry, F.S. - Brower, R.S. (2005): Intergovernmental and intersectoral management: Weaving networking, contracting out, and management roles into third party government. Public Performance and Management Review, 29(1), pp. 7-17.

Bernstein, K. - Bruun-Rasmussen, M. - Vingtoft, S. - Andersen, S.K. - Nøhr, C. (2005): Modelling and implementing electronic health records in Denmark. International Journal of Medical Informatics, Volume 74, Issues 2-4, pp. 213-220. DOI: http://dx.doi.org/10.1016/i.ijmedinf.2004.07.007

Bodnár, Viktória (1999): Controlling, avagy az intézményesített eredménycentrikusság. Doktori értekezés, Budapesti Közgazdaságtudományi Egyetem, Gazdálkodástudományi Kar, Budapest.

Bodnár, Viktória (2005): Teljesítménymenedzsment vagy controlling? In: Gy. Bakacsi, K. Balaton - M. Dobák (eds.): Változás-és-vezetés (pp. 147-153). Aula, Budapest.

Bodnár, Viktória - Drótos, György - Kiss, Norbert - Révész, Éva (2004): From a written strategy to manageable performance: Analysis of motivations to implement performance management systems in public sector organizations. Fourth International Conference on Performance Measurement and Management (PMA 2004), Edinburgh, UK, 28-30 July, 2004 
Bouckaert, G. - W. van Dooren (2003): Performance management in public sector organisations. In: E. Löffler - T. Boivard (ed.): Public Management and Governance, London: Routledge, pp. 127-136

Bouckaert, Geert (2006): The public sector in the 21. century: renewing public sector performance measurement. In: Köz-gazdaság, 1(1), pp. 63-79.

Bouckaert, Geert (2011): Public Sector Performance: An element of economic development and stability. KAPA Conference, Busan, Korea, 29-30 April 2011.

Bouckaert, Geert - Halligan, John (2008): Managing Performance - International Comparisons. Routledge, London.

Bouckaert, Geert - Peters, B. Guy - Verhoest, Koen (2010): The coordination of public sector organisations - Shifting patterns of public management. PalgraveMacmillan.

Brown, K. - Keast, R. (2003): Community-government engagement: Community connections through networked arrangements. Asian Journal of Public Administration, Vol. 25., No. 1., pp. 107-132.

Burns, L. R. - Pauly, M. V. (2002): Integrated delivery networks: a detour on the road to integrated health care? Health affairs, Vol. 21, No.4, pp. 128-143. DOI: http://dx.doi.org/10.1377/hlthaff.21.4.128

Burton, L. C. - Anderson, G. F. - Kues, I. W. (2004): Using Electronic Health Records to Help Coordinate Care. Milbank Quarterly, Vol. 82, Issue 3, pp. 457-481.

Christensen T. - Lægreid P. (2007): The Whole-of-Government Approach to Public Sector Reform. Public Administration Review, Vol.67. No.6., pp. 1059-1066. DOI: http://dx.doi.org/10.1111/i.1540-6210.2007.00797.x

Cochrane, A. (1972): Effectiveness and Efficiency: Random Reflections on Health Services. Nuffield Provincial Hospitals Trust, London.

Cristofoli, Daniela - Mandell, Myrna - Meneguzzo, Marco (2011): "Public networks" say Americans, "public networks" reply Europeans, but are they talking about the same issue? Paper for the Public Management Research Association Conference 2011, Syracuse, NY.

Cristofoli, Daniela - Maccio, Laura - Pedrazzi, Laura (2011b): Networks Funded by the Public Sector Can and Should Be Evaluated - Ok, But how? Paper for the Public Management Research Association Conference 2011, Syracuse, NY.

Dan, S. - Pollitt, C. (2014): NPM Can Work: An optimistic review of the impact of New Public Management reforms in central and eastern Europe. Public Management Review. Ahead-of-print, 1-28. http://repub.eur.nl/pub/51367/NPM-canwork preprint.pdf (downloaded: 1 November, 2014)

Dankó, Dávid - Kiss, Norbert - Molnár, Márk - Révész, Éva (2005): Az IBR alulnézetből egy terepkutatás eredményei. Informatika és Menedzsment az Egészségügyben, Vol.4, No.5., pp. 8-14.

Davis, G.C. - Rhodes, R.A. (2000): From hierarchy to contracts and back again: reforming the Australian public service. In: Keating, M.S. - Wanna, J. - Weller, P.M. (2000, 
eds): Institutions on the Edge: Capacity for Governance. St Leonards: Allen \& Unwin

Dobák Miklós (1996, ed): Vezetés-szervezés. Aula, Budapest.

Donabedian, Avedis (1988): The quality of care: How can it be assessed? JAMA, Vol.260, No.12, pp. 1743-1748. DOI: http://dx.doi.org/10.1001/jama.1988.03410120089033

Dózsa, Csaba (2010): A kórházak stratégiai válaszai a változó környezetre Magyarországon a 2000-es években. Ph.D. értekezés, Budapesti Corvinus Egyetem.

Dózsa, Csaba - Kiss, Norbert - Kuntár, Ágnes - Sinkó, Eszter - Wéber András (2014): Group Practice Pilot Project in Hungary. Poster Display. Barcelona. EFPC conference - Twinning Population Health and Primary Care. Barcelona, 1-2 September, 2014.

Drummond, M.F. - Sculpher, M.J - Torrance, G.W. (2005): Methods for the economic evaluation of health care programmes. Oxford University Press.

Dubnick, Melvin (2005): Accountability and the promise of performance. Public Performance and Management Review, 28(3), pp. 376-417.

EC (2004): e-Health - making healthcare better for European citizens: An action plan for a European e-Health Area. European Commission, COM (2004) 356 final.

EC (2012): eHealth Action Plan 2012-2020 - Innovative healthcare for the 21st century. European Commission, $\operatorname{COM(2012)~} 736$ final.

EGPA (2010): Perspectives for the future (edited by Geert Bouckaert and Win van de Donk). Bruylant, Bruxelles.

Eisenhardt, K.M. (1989): Building theories from case studies research. Academy of Management Review, Vol. 14, No. 4, pp. 532-550. DOI: http://dx.doi.org/10.5465/AMR.1989.4308385

Eris, M. (2012): Improving Health Outcomes and System in Hungary. OECD Economics Department Working Papers, No. 961, OECD Publishing. DOI: http://dx.doi.org/10.1787/5k98rwqj3zmp-en

Evetovits, Tamás - Gaál, Péter (2005): A költséghatékonyság értelmezése az egészségügyben: egészség-gazdaságtani alapok Cochrane-tól Culyerig. In: Gulácsi László (ed): Egészség-gazdaságtan. Medicina, Budapest.

ExAnte (2006): Humánerőforrás-fejlesztési operatív program időközi értékelés 2005 Indikátorok elemzése. Zárótanulmány. Ex Ante Consulting.

Exworthy, M. - Powell, M. - Mohan, J. (1999): Markets, bureaucracy and public management: the NHS: quasi-market, quasi-hierarchy and quasi-network? Public Money and Management, Vol.19, No.4, pp. 15-22. DOI: http://dx.doi.org/10.1111/1467-9302.00184

Fehér, András (2006): HEFOP 4.4 dél-dunántúli projekt, ahogyan mi láttuk. Informatika és Menedzsment az Egészségügyben, Vol. 5, No. 9, pp. 37-39.

Ferlie, Ewan - Mcgivern, Gerry - FitzGerald, Louise (2012): A new mode of organizing in health care? Governmentality and managed networks in cancer services in 
England. Social Science \& Medicine, Vol.74, Issue 3, pp.340-347. DOI: http://dx.doi.org/10.1016/i.socscimed.2011.03.021

Flynn, Norman (2002): Public Sector Management. FT Prentice Hall, London.

Gaál, Péter (2004): Health Care Systems in Transition: Hungary. European Observatory on Health Systems and Policies - WHO, Copenhagen.

Gittel, Jody Hoffer - Weiss, Leigh (2004): Coordination Networks Within and Across Organizations: A Multi-level Framework. Journal of Management Studies, Vol. 41., No. 1., pp. 127-153. DOI: http://dx.doi.org/10.1111/j.1467$\underline{6486.2004 .00424 . x}$

Goldsmith, Stephen - Eggers, William D. (2004): Governing by Network: The New Shape of the Public Sector. Brookings Institution Press, Washington, DC.

Gray, A. - Jenkins, B. (2003): Evaluation and collaborative government: Lessons and challenges. In: A. Gray, B. Jenkins, F. Leeuw, J. Mayne (eds.): Collaboration in public services: The challenge for evaluation, pp. 227-244. Transaction, New Brunswick, NJ.

Hajnal, György (1999): Teljesítmény-orientáció a közigazgatási reformokban. Nemzetközi tapasztalatok a második világháború utáni időszakban. Magyar Közigazgatás, 49(6), pp.289-299.

Hajnal György (2004): Igazgatási reformok és New Public Management reformok egy összehasonlító esettanulmány tükrében. Ph.D. értekezés, Budapesti Közgazdaságtudományi és Államigazgatási Egyetem, Budapest.

HEFOP (2004): Human resources development operational programme, 2004-2006. Ministry of Employment and Labour

Heikkila, Tanya A. - Isett, Kimberley R. (2004): Modeling operational decision making in public organizations: An integration of two institutional theories. American Review of Public Administration, Vol. 34, No. 1, pp. 3-19. DOI: http://dx.doi.org/10.1177/0275074003260911

Herranz, Joaquín, Jr. (2008): The multisectoral trilemma of network management. Journal of Public Administration Research and Theory, Vol. 18., No. 1., pp. 1-31. DOI: http://dx.doi.org/10.1093/jopart/mum004

Herranz, Joaquín, Jr. (2010): Network Performance and Coordination: A Theoretical Review and Framework. Public Performance \& Management Review, Vol. 33, No. 3, pp. 311-341. DOI: http://dx.doi.org/10.2753/PMR1530-9576330301

Hoberecht, S. - Joseph, B. - Spencer, J. - Southern, N. (2011): Inter-Organizational Networks. OD Practitioner, Vol. 43, No.4, pp.23-27.

Holley, J. (2012): Network weaver handbook: A guide to transformational networks. Network Weaver Publishing.

Hood, C. (1991): A public management for all seasons? Public Administration, Vol.69 Spring, pp. 3-19. DOI: http://dx.doi.org/10.1111/i.1467-9299.1991.tb00779.x 
Hood, C. (1995): The new public management in the 1980s: Variations on a theme. Accounting, Organizations and Society, 20(2/3), pp. 93-109. DOI: http://dx.doi.org/10.1016/0361-3682(93)E0001-W

Horváth and Partner (2000): Controlling - Út egy hatékony controlling-rendszerhez. KJKKerszöv, Budapest.

Hudson, B. (2004): Analysing Network Partnerships. In: Public Management Review, Vol. 6, No.1, pp. 75-9. DOI: http://dx.doi.org/10.1080/14719030410001675740

Hurst J. - Jee-Hughes, M. (2001): Performance Measurement and Performance Management in OECD Health Systems. OECD Labour Market and Social Policy Occasional Papers, No. 47, OECD Publishing.

Huxham, C. - Vangen, S. (2013): Managing to collaborate: The theory and practice of collaborative advantage. Routledge.

IRSPM (2011): Predicting the performance of public networks. Panel description. http://www.irspm2012.com/panel/PredictingThePerformanceOfPublicNetwork s.pdf (downloaded: 22 October, 2011)

Isett, Kimberley R. - Mergel, Ines A. - LeRoux, Kelly - Mischen, Pamela A. - Rethemeyer R. Karl (2011): Networks in Public Administration Scholarship: Understanding Where We Are and Where We Need to Go. Journal of Public Administration Research and Theory, Vol. 21, Issue suppl 1, pp. i157-i173 DOI: http://dx.doi.org/10.1093/jopart/muq061

Jann, Werner - Lagreid, Per - Verhoest, Koen (2010): Governance of public sector organisation - Reform waves and the structure of government. In: EGPA (2010), pp. 292-296.

Jaspers, M.W.M. - Smeulers, M. - Vermeulen, H. - Peute, L.W. (2011): Effects of clinical decision-support systems on practitioner performance and patient outcomes: a synthesis of high-quality systematic review findings. Journal of the American Medical Informatics Association, Vol. 18, Issue 3, pp. 327-334. DOI: http://dx.doi.org/10.1136/amiajnl-2011-000094

Jha, A.K. - DesRoches, C.M. - Kralovec, P.D. - Joshi, M.S. (2010): A progress report on electronic health records in US hospitals. Health Affairs, Vol. 29, No. 10, pp. 19511957. DOI: http://dx.doi.org/10.1377/hlthaff.2010.0502

Keast, R. - Mandell, M.P. - Brown, K. - Woolcock, G. (2004): Network structures: Working differently and changing expectations. Public Administration Review, Vol. 64, No.3, pp. 363-371. DOI: http://dx.doi.org/10.1111/i.1540$\underline{6210.2004 .00380 . x}$

Kenis, Patrick - Provan, Keith G. (2009): Towards an exogenous theory of public network performance. Public Administration, Vol. 87, No. 3, pp. 440-456. DOI: http://dx.doi.org/10.1111/j.1467-9299.2009.01775.x

Király, Gyula (2008): Összefoglaló az IME III. Regionális Egészségügyi Konferenciájának A HEFOP 4.4 projekt keretében megvalósult rendszerfejlesztések alul- és felülnézetbôl"kerekasztal vitájáról. Informatika és Menedzsment az Egészségügyben, Vol.7., No.2., p. 55. 
Király, Gyula (2010): Az e-Egészségügy (e-Health) helyzete Magyarországon. Informatika és Menedzsment az Egészségügyben, Vol.9., No.2., pp. 45-48.

Király, Gyula (2011): Az e-Egészségügy (e-Health) magyarországi példákon keresztüli rendszerezése. Informatika és Menedzsment az Egészségügyben, Vol.10., No.4., pp. 29-34.

Király, László György (1999): Teljesítménymérés és -értékelés a közigazgatásban. Vezetéstudomány, 30(7-8), pp.2-18.

Kiss, Norbert - Révész, Éva (2007): Teljesítménymenedzsment a közszektorban. In: G. Kováts (ed.): Közszolgálati szervezetek vezetése (egyetemi jegyzet). Budapesti Corvinus Egyetem, Vezetéstudományi Intézet.

Klijn, Erik-Hans - Teisman, G. R. (1997) Strategies for games in networks. In: W.J.M. Kickert, E.-H. Klijn, J.F.M. Koppenjan (eds): Managing complex networks: Strategies for the public sector. Sage, London, pp. 98-118.

Klijn, E. - J.F.M. Koppenjan (2000): Public Management and Policy Networks. In: Public Management, Vol. 2, No. 2, pp. 135-158. DOI: http://dx.doi.org/10.1080/14719030000000007

Kohler-Koch, Beate - Rittberger, Berthold (2007): Debating the Democratic Legitimacy of the European Union. Rowman and Littlefield.

Krane, D. (2008): Lessons from the adoption of performance-based management by county governments. Public Performance and Management Review, Vol. 31., No. 3., pp. 387-406. DOI: http://dx.doi.org/10.2753/PMR1530-9576310304

Kringos, D. S. - Boerma, W. G. - Bourgueil, Y. - Cartier, T. - Hasvold, T. - Hutchinson, A. - Lember M. - Oleszczyk, M. - Pavlic, D.R. - Svab, I. - Tedeschi, P. - Wilson, A. Windak, A. - Dedeu, T. - Wilm, S. (2010): The European primary care monitor: structure, process and outcome indicators. BMC family practice, 11:81. DOI: http://dx.doi.org/10.1186/1471-2296-11-81

Laumann, Edward O. - Knoke, David (1987): The organizational state. University of Wisconsin Press, Madison, WI.

Lázár, László (2002): Értékek és mértékek. Ph.D. értekezés, Budapesti Közgazdaságtudományi és Államigazgatási Egyetem, Gazdálkodástudományi Kar, Budapest.

Lecy, Jesse D. - Mergel, Ines A. - Schmitz, Hans Peter (2014): Networks in Public Administration: Current scholarship in review. Public Management Review, 16.5, pp. 643-665. DOI: http://dx.doi.org/10.1080/14719037.2012.743577

Lenz, R. - Blaser, R. - Beyer, M. - Heger, O. - Biber, C. -Bäumlein, M. - Schnabel, M. (2007): IT support for clinical pathways-Lessons learned. International Journal of Medical Informatics, Volume 76, Supplement 3, pp. S397-S402. DOI: http://dx.doi.org/10.1016/j.ijmedinf.2007.04.012

Lyngs $\varnothing$, A. M. - Godtfredsen, N. S. - Høst, D. - Frølich, A. (2014): Instruments to assess integrated care: A systematic review. International journal of integrated care, Vol.14, Jul-Sep 
Lukács, András (2007): Beszámoló a HEFOP 4.4 projektről. Informatika és Menedzsment az Egészségügyben, Vol.6., No.5., pp. 50-53.

Mandell, Myrna - Keast, Robin (2007): Evaluating Network Arrangements - Toward Revised Performance Measures. In: Public Performance \& Management Review, Vol. 30, No. 4, June 2007, pp. 574-597. DOI: http://dx.doi.org/10.2753/PMR1530-9576300406

Mandell, Myrna P . - Steelman, Toddi A. (2003): Understanding What Can Be Accomplished through Interorganizational Innovations: The Importance of Typologies, Context, and Management Strategies. Public Management Review, Vol. 5, No. 2, pp. 197-224. DOI: http://dx.doi.org/10.1080/1461667032000066417

Meuleman, L. (2008): Public management and the metagovernance of hierarchies, networks and markets. Heidelberg: Springer.

McClellan, S. R. - Casalino, L. P. - Shortell, S. M. - Rittenhouse, D. R. (2013): When does adoption of health information technology by physician practices lead to use by physicians within the practice?. Journal of the American Medical Informatics Association, 20(e1), e26-e32. DOI: http://dx.doi.org/10.1136/amiajnl-2012$\underline{001271}$

McGuire, Michael (2006): Collaborative Public Management: Assessing What We Know and How We Know It. Public Administration Review, December 2006, Special Issue. DOI: http://dx.doi.org/10.1111/j.1540-6210.2006.00664.x

Megakom (2008): HEFOP időközi értékelés 2007 - Értékelési jelentés, végleges verzió, 2008. július 28.

Meskó, B. - Dubecz, A. (2007): Az orvostudomány és a világháló nyújtotta új lehetőségek. Orvosi Hetilap Vol. 148, No. 44, pp. 2095-2099. DOI: http://dx.doi.org/10.1556/OH.2007.28162

Metcalfe, L. - Richards S. (1990): Improving Public Management. 2nd ed. Sage, London.

Micheli, P. - Mason, S. - Kennerley, M. - Wilcox, M. (2005): Public sector performance: Efficiency or quality? Measuring Business Excellence, Vol. 9, No. 2, pp. 68-73.

Milward, H. Brinton - Provan, Keith G. (2006): A Managers' Guide to Choosing and Using Collaborative Networks. IBM Center for the Business of Government, Washington DC.

Mintzberg, Henry (1996): Managing Government - Governing Management. Harvard Business Review, May-June, 1996, pp. 75-83.

Mintzberg, Henry - Glouberman, Sholom (2001): Managing the Care of Health and the Cure of Disease-Part II: Integration. Health Care Management Review, Winter 2001, pp. 72-86.

Mitchell, R.E. - Florin, P. - Stevenson, P.E. (2002): Supporting Community-Based Prevention and Health Promotion Initiatives: Developing Effective Technical Assistance Systems. Health Education and Behavior, Vol. 29, No. 5, pp. 620-639. DOI: http://dx.doi.org/10.1177/109019802237029

MITSESZ (2003): Magyar információs társadalom stratégia - Egészségügyi és szociális ágazat. ESZCSM-IHM. 
Neely, Andy - Adams, Chris - Kennerly, Mike (2002): The Performance Prism. FT Prentice Hall, London.

NEFMI (2011): Semmelweis Terv az egészségügy megmentésére (Szakmai koncepció). Nemzeti Erőforrás Minisztérium Egészségügyért Felelős Államtitkárság. http://www.kormany.hu/download/3/c4/40000/Semmelweis\%20Terv\%20szak mai\%20koncepci\%C3\%B3\%202011.\%20j\%C3\%BAnius\%2027..pdf (downloaded: 27 November, 2011)

NFÜ (2013): Egészségügyi tárgyú NSRK-fejlesztések értékelése. Értékelési jelentés. Nemzeti Fejlesztési Ügynökség (Hétfa Kutatóintézet, Budapest Intézet, Revita Alapítvány).

NHS (2011): About the NHS: NHS authorities and trusts. http://www.nhs.uk/NHSEngland/thenhs/about/Pages/authoritiesandtrusts.aspx (downloaded on 27 November, 2011)

NICE (2010): Measuring effectiveness and cost effectiveness: the QALY. http://www.nice.org.uk/newsroom/features/measuringeffectivenessandcosteff ectivenesstheqaly.jsp (downloaded: 27 November, 2011)

Nolte, E. - Bain, C. - McKee, M. (2009): Population health. In: Smith et al. (2009, ed), pp. 27-62.

OALI (2013): Operations manual for GPs cluster on public health services in primary health care, version 05, May 31, 2013 (edited by Ádány, Róza). Országos Alapellátási Intézet. http://www.nepegeszseg.hu/swiss/SH.8.1 operations manual version5.pdf (downloaded on 31 October, 2014)

OALI (2014): Az egészségügy forrásainak felhasználásával népegészségügyi fókuszú alapellátás-szervezési modellprogram Virtuális Ellátó Központ támogatásával című program - Félidei értékelés. Kézirat. Országos Alapellátási Intézet.

OALI (2014b): A program bemutatása. Országos Alapellátási Intézet. http://www.oali.hu/svajci-magyar-program (downloaded on 31 October, 2014)

OECD (2004): Public Sector Modernisation: Governing for Performance. In: OECD Observer, October 2004.

OECD (2005): Governance in transition: public management reforms in OECD countries. OECD, Paris.

OECD (2011): Health at a Glance 2011: OECD Indicators, OECD Publishing. DOI: http://dx.doi.org/10.1787/health glance-2011-en

OECD (2012): Health at a Glance: Europe 2012, OECD Publishing. DOI: http://dx.doi.org/10.1787/9789264183896-en

OEP (2014): A háziorvosi szolgálatok indikátor alapú teljesítményértékelése 2014. áprilistól. Országos Egszségbiztosítási Pénztár. http://www.oep.hu/virtualis rovat/altfin virt dok2/Alapellatas/hsz indikator (downloaded: 7 November, 2014)

O'Malley, Ann S. - Grossman, Joy M. - Cohen, Genna R. - Kemper, Nicole M. - Pham, Hoangmai H. (2010): Are Electronic Medical Records Helpful for Care 
Coordination? Experiences of Physician Practices. Journal of general internal medicine, Vol. 25, Np. 3, pp. 177-185. DOI: http://dx.doi.org/10.1007/s11606$\underline{009-1195-2}$

Orosz, Éva (1998): Health Financing in Hungary: Taking Stock. Paper presented to the 2nd International Research Conference on Social Security, International Social Security Association, Jerusalem, 25-28 January, 1998

Orosz, Éva (2013): Az egészségügyi rendszerek kihívásai a gazdasági válság időszakában. Egészségügyi Gazdasági Szemle, Vol. 51., No. 1., pp. 1-11.

Osborne, Stephen P. (2006): The New Public Governance? - Editorial. Public Management Review, Vol. 8, Issue 3, pp. 377-387. DOI: http://dx.doi.org/10.1080/14719030600853022

Osborne, David - Gaebler, Ted (1992): Reinventing the government: How the entrepreneurial spirit is transforming the public sector. Plume, Reading, MA.

O'Toole, L.J. (1997): Treating Networks Seriously: Practical and Research-Based Agendas in Public Administration. In: Public Administration Review, Vol. 57, No. 1, pp. 4552. DOI: http://dx.doi.org/10.2307/976691

O'Toole, L.J. - K.J. Meier (2004): Desperately Seeking Selznick: Cooptation and the Dark Side of Public Management Networks. In: Public Administration Review, Vol. 64, No. 6, pp. 681-693. DOI: http://dx.doi.org/10.1111/i.1540-6210.2004.00415.x

Ouchi, William G. (1979): A conceptual framework for the design of organizational control mechanisms. Management Science, Vol. 25, No. 9., pp. 833-847. DOI: http://dx.doi.org/10.1287/mnsc.25.9.833

PMRA (2011): PRMC 2011 Conference Program. http://www.maxwell.syr.edu/pmrc2011.aspx?id=77309416873 (downloaded: 22 October, 2011)

Pollitt, Christopher (2001): Integrating Financial Management and Performance Management. In: OECD Journal on Budgeting. Vol. 1. No. 2., pp. 7-38.

Pollitt, C. - Bouckaert, G. (2004): Public Management Reform: A Comparative Analysis. 2nd ed. Oxford University Press, Oxford.

Porter, Micheal E. - Teisberg, Elizabeth O. (2006): Redefining Health Care - Creating Value-Based Competition on Results. Harvard Business School Press.

Provan, Keith G. - Kenis, Patrick (2008): Modes of Network Governance: Structure, Management, and Effectiveness. Journal of Public Administration Research and Theory, Vol. 18., Issue 2., pp. 229-252. DOI: http://dx.doi.org/10.1093/jopart/mum015

Provan, Keith G. - Lemaire, Robin H. (2012): Core concepts and key ideas for understanding public sector organizational networks: Using research to inform scholarship and practice. Public Administration Review 72.5, pp. 638-648. DOI: http://dx.doi.org/10.1111/j.1540-6210.2012.02595.x

Provan, K.G. - Milward, B.H. (1995): A Preliminary Theory of Interorganizational Network Effectiveness. Administrative Science Quarterly, Vol. 40., No. 1., pp. 133. DOI: http://dx.doi.org/10.2307/2393698 
Provan, K.G. - Milward, H.B. (2001): Do networks really work? A framework for evaluating public sector organizational networks. Public Administration Review, Vol. 61., No. 4., pp. 414-423. DOI: http://dx.doi.org/10.1111/0033-3352.00045

Provan, K.G. - Sebastian, J.G. (1998): Network Within Networks: Service Link Overlap, Organizational Cliques, and Network Effectiveness. Academy of Management Journal, Vol. 41, No. 4, pp.453-463. DOI: http://dx.doi.org/10.2307/257084

Radin, Beryl A. (1998): The Government Performance and Results Act (GPRA): HydraHeaded Monster or Flexible Management Tool? Public Administration Review, Vol. 58., No. 4., pp. 307-316. DOI: http://dx.doi.org/10.2307/977560

Révész Éva (2010): The content and drivers of performance management tools applications in agency-type organizations of the Hungarian public administration. Ph.D proposal, Corvinus University of Budapest.

Rethemeyer, R. Karl - M. Hatmaker, Deneen (2007): Network Management Reconsidered: An Inquiry into Management of Network Structures in Public Sector Service Provision. Journal of Public Administration Research and Theory, Vol. 18, Issue 4, pp. 617-646. DOI: http://dx.doi.org/10.1093/jopart/mum027

Robinson, Marc (2002): Financial Control in Australian Government Budgeting. Public Budgeting \& Finance, Spring, pp. 80-93. DOI: http://dx.doi.org/10.1111/1540$\underline{5850.00067}$

Rosta, Miklós (2011): What makes a New Public Management reform successful? An institutional analysis: An introductory essay. Paper for the Public Management Research Association Conference 2011, Syracuse, NY.

Rosta, Miklós (2012): Az új közszolgálati menedzsment és a Magyary Zoltán Közigazgatás-fejlesztési Program viszonyáról. Polgári Szemle. Vol.8., No.3-6. http://www.polgariszemle.hu/?view=v article\&ID=503 $\quad$ (downloaded on 1 November, 2014)

Saltman, Richard B. - Bankauskaite, Vaida - Vrangbæk, Karsten (2007, eds.): Decentralization in Health Care: Strategies and outcomes. Open University Press.

Sándor, J. - Kósa, K. - Fürjes, G. - Papp, M. - Csordás, Á. - Rurik, I. - Ádány, R. (2013): Public health services provided in the framework of general practitioners' clusters. The European Journal of Public Health, Vol. 23, No. 4, pp. 530-532. DOI: http://dx.doi.org/10.1093/eurpub/ckt096

Selden, S.C. - Sowa, J.E. - Sandfort, J. (2006): The impact of nonprofit collaboration in early child care and education on management and program outcomes. Public Administration Review, Vol. 66., No. 3., pp. 412-425. DOI: http://dx.doi.org/10.1111/j.1540-6210.2006.00598.x

Shekelle, P.G. (2009): Public performance reporting on quality information. In: Smith, Peter C. - Mossialos, Elias - Papanicolas, Irene - Leatherman, Sheila (2009, szerk.): Performance Measurement for Health System Improvement, Cambridge University Press, pp. 537-551

Simons, Robert (1999): Performance Measurement and Control Systems for Implementing Strategy. Prentice Hall. 
Sinkó, Eszter (2009): Diszfunkcionalitások a magyar egészségügyben. Informatika és Menedzsment az Egészségügyben, Vol. 8., No. 7., pp. 7-10.

Sinkó, Eszter (2013): Beköszöntő: Közös frusztrációnk tele. Informatika és Menedzsment az Egészségügyben, Vol. 12., No. 1., p. 3.

Smith, Peter C. (2005): Performance Measurement in Health Care: History, Challenges and Prospects. Public Money \& Management, Vol. 25, No. 4, pp. 213-220. DOI: http://dx.doi.org/10.1080/09540962.2005.10600096

Smith, Peter C. - Mossialos, Elias - Papanicolas, Irene - Leatherman, Sheila (2009, eds.): Performance Measurement for Health System Improvement. Cambridge University Press.

Strandberg-Larsen, M. - Krasnik, A. (2009): Measurement of integrated healthcare delivery: a systematic review of methods and future research directions. International Journal of Integrated Care, Vol. 9, 4 February

STRAPI (2008): Egészségügyi fejlesztések a Nemzeti Fejlesztési Terv keretében. Strukturális Alapok Programiroda.

Tótth, Árpád (2008): Regionalitás az egészségügyben - helyzetkép. Informatika és Menedzsment az Egészségügyben, Vol. 7., No. 4., pp. 7-10.

Turrini, Alex - Cristofoli, Daniela - Frosini, Francesca - Nasi, Greta (2010): Networking Literature About Determinants Of Network Effectiveness. Public Administration Vol. 88, No. 2, pp. 528-550. DOI: http://dx.doi.org/10.1111/j.14679299.2009.01791.x

Van Dooren, Wouter (2007): Getting the performance through leadership, reform and measurement: A theoretical exploration of some social mechanism, Leading the Future of the Public Sector: The Third Transatlantic Dialogue. University of Delaware, Newark, Delaware, USA, 31 May - 2 June.

Van Dooren, Wouter - Lonti, Zsuzsanna (2011): How to measure performance of governance? Paper for the CAP symposium - ASPA Baltimore - 12/03/2011

Vangen, Siv - Huxham, Chris (2003): Nurturing Collaborative Relations: Building Trust in Interorganizational Collaboration. Journal of Applied Behavioral Science, Vol. 39, No. 1, pp. 5-31 . DOI: http://dx.doi.org/10.1177/0021886303039001001

Wagner, E H - T M Wickizer - A Cheadle - B M Psaty - T D Koepsell - P Diehr - S J Curry - M Von Korff - C Anderman - W L Beery - D C Pearson - E B Perrin (2000): The Kaiser Family Foundation Community Health Promotion Grant Program: Findings from an Outcome Evaluation. Health Services Research, August, 35(3), pp. 561589.

West, D.M. (2005): E-Government and the Transformation of Service Delivery and Citizen Attitudes. Public Administration Review, Vol. 64., No. 1., pp.15-27. DOI: http://dx.doi.org/10.1111/j.1540-6210.2004.00343.x

WHO (2000): The World health report 2000 - Health systems: improving performance. World Health Organization, Geneva.

WHO (2003): Adherence to Long-Term Therapies: Evidence for Action. World Health Organization. 
WHO (2011): The determinants of health - Introduction. World Health Organization. http://www.who.int/hia/evidence/doh/en/ (downloaded: 26 November, 2011)

WHO (2012): National eHealth strategy toolkit. World Health Organization and International Telecommunication Union.

Williams, Paul (2002): The Competent Boundary Spanner. Public Administration Vol. 80, No.1., pp. 103-124. DOI: http://dx.doi.org/10.1111/1467-9299.00296

Williamson, O.E. (1985): The Economic Institutions of Capitalism. New York: The Free Press.

Wimmer, Ágnes (2000): A vállalati teljesítménymérés az értékteremtés szolgálatában. Ph.D. értekezés, Budapesti Közgazdaságtudományi és Államigazgatási Egyetem, Gazdálkodástudományi Kar, Budapest.

Wood, Donna J. - Gray, Barbara (1991): Toward a Comprehensive Theory of Collaboration. Journal of Applied Behavioral Science, 27(2), pp. 139-62. DOI: http://dx.doi.org/10.1177/0021886391272001

Yin, R.K. (2009): Application of Case Study Research. $4^{\text {th }}$ ed. Sage. 